\title{
Mexican Consensus of Multiple Myeloma
}

José A. de la Peña-Celaya', Jocelyn Aguilar-Luevano², Luisa Ma. Alcivar-Cedeño', José L. Álvarez-Vera', Irene Anaya-Cuellar ${ }^{3}$, Erika Añorve-Hernández', Luara L. Arana-Luna', Luis Arteaga-Ortíz ${ }^{5}$,

Pamela E. Báez-Islas 6 , Luisa I. Banda-García', Ramón A. Bates-Martín', Dafne Itzel Campa-Monroy 9 , Mariela Cardiel-Silva10 ${ }^{10}$ Ángel de Jesús Castillo-Salas' ${ }^{1}$ Xóchitl Cota-Rangel${ }^{6}$, Guillermo Díaz-Vargas ${ }^{11}$, M. Eugenia Espitia-Ríos ${ }^{1}$, Patricia Estrada-Domínguez¹, Denisse Fermín-Caminero ${ }^{1}$, Alinka García-Camacho ${ }^{9}$, Carolina García-Castillo ${ }^{12}$, Katheryn B. Garzón-Velásquez ${ }^{13}$, Carlos Gil-Rondero ${ }^{14}$, Lidia V. Guerra-Alarcón ${ }^{15}$, Ana K. Hernández-Colín', Eleazar Hernández-Ruiz ${ }^{16}$, Areli E. Hernández-Alcántara ${ }^{13}$, Silvia A. Hernández-Cervantes ${ }^{1}$, Wilfrido Herrera-Olivares ${ }^{17}$, Gregorio Ignacio-Ibarra ${ }^{18}$, Sergio I. Inclán-Alarcón ${ }^{18}$, Faustino Leyto-Cruz, Juan P. Macías-Flores', Andrea Martínez-de la Vega ${ }^{19}$, Mario Alberto Martínez-Ramírez', Jorge Martínez-Coronel20, Jesús Emanuel Medina-Coraf1, Lizeth Meza-Dávalos ${ }^{1}$, Leire Montoya-Jiménez', Alba Morales-Hernández¹, Elizabeth Morales-López²2, Javier de Jesús Morales-Adrián²3, Maricruz Morales-de Azcué13, Aldo Mújica-Martínez²4, Juan L. Murillo-Cruz ${ }^{1}$, Jéssica Nájera-Martínez ${ }^{13}$, Iris Mabel Narváez-Sarmiento ${ }^{1}$, Lorena Nava-Villegas', Marco A. Nava-Alpide', Juan J. Orellana Garibay'25, Ma. Teresa Palafox-Zaldívar26,

Orlando G. Palma-Moreno', Eugenia P. Paredes-Lozano, Ma. Luisa Pedraza-Colín²7, Juan M. Pérez-Zúñiga', Alejandra B. Pérez-Lizardi ${ }^{9}$, Flavio Rojas-Castillejos ${ }^{28}$, Eduardo Romero-Martínez ${ }^{29}$, Hilda Romero-Rodelo ${ }^{30}$, Josué Ruiz-Contreras' ${ }^{1}$, Azucena Saavedra-González ${ }^{31}$, Erick Saucedo-Montes ${ }^{32}$, Luis G. Silva-Michel', Karina Silva-Vera ${ }^{33}$, Óscar Teomitzi-Sánchez ${ }^{1}$, Fredy Tepepa-Flores', Yanet Ventura-Enríquez²4,

Atenas Villela-Peña ${ }^{1}$, Shendel P. Vilchis-González ${ }^{2}$, Nidia Zapata-Canto ${ }^{13}$, Pedro A. Zárate- Rodríguez ${ }^{34}$, and Martha Alvarado-Ibarra *

'Servicio de Hematología, Centro Médico Nacional 20 de Noviembre, ISSSTE Ciudad de Mexico; ${ }^{2}$ Servicio de Hematología, Hospital General Regional N.o 2, IMSS, Ciudad de Mexico; ${ }^{3}$ Servicio de Hematología, Hospital General Lázaro Cárdenas, ISSSTE, Chihuahua, Chih.; ${ }^{4}$ Servicio de Hematología, Hospital Regional Lic. Adolfo López Mateos, ISSSTE, Ciudad de México; ${ }^{5}$ Servicio de Hematología, Hospital General La Paz, ISSSTE, La Paz, B.C.S.; ${ }^{6}$ Servicio de Hematología, Hospital Ángeles Lomas, Huixquilucan, Edo. Méx.; ${ }^{7}$ Servicio de Hematología, Hospital Regional de Alta Especialidad de Veracruz, Ver.; ${ }^{8}$ Servicio de Hematología, Hospital Regional 1. de Octubre, ISSSTE, Ciudad de Mexico; ${ }^{9}$ Servicio de Hematología, Centro Médico Nacional siglo XXI, IMSS, Ciudad de México; ${ }^{10}$ Servicio de Hematología, Hospital General de Zona 1, IMSS, Ciudad de México; ${ }^{11}$ Servicio de Hematología, Centro Oncológico Estatal ISSEMYM, Toluca, Edo. Méx.; ${ }^{22}$ Servicio de Hematología, Hospital Central Militar, SEDENA, Ciudad de México; ${ }^{13}$ Servicio de Hematología, Instituto Nacional de Cancerología, Ciudad de México; ${ }^{14}$ Servicio de Hematología, Hospital Dr. Fernando Ocaranza, ISSSTE, Hermosillo, Son.; ${ }^{15}$ Centro Regional de Hemato-oncología, Grupo CREHO, Guatemala, Guatemala; ${ }^{16}$ Servicio de Hematología, Hospital Regional Presidente Juárez ISSSTE, Oaxaca de Juárez, Oax.; ${ }^{7}$ Servicio de Hematología, Hospital Regional de Puebla, ISSSTE, Puebla, Pue.; ${ }^{18}$ Servicio de Hematología, Hospital General Regional 1 "Dr. Carlos Mac Gregor Sanchez Navarro" IMSS, Ciudad de México; ${ }^{19}$ Servicio de Hematología Centro Médico ABC, Campos Observatorio, Ciudad de México; ${ }^{20}$ Servicio de Hematología, Hospital Regional "Valentin Gómez Farias" ISSSTE, Guadalajara, Jal.; ${ }^{21}$ Servicio de Hematología, Hospital Civil de Culiacán, Centro de Investigación y Docencia en Ciencias de la Salud (CIDOCS), Culiacan, Sin.; ${ }^{22}$ Servicio de Hematología, Hospital General Regional Orizaba (HGRO), IMSS Orizaba, Ver.; ${ }^{23}$ Servicio de Hematología Hospital Regional "Elvia Carrillo Puerto," ISSSTE, Merida, Yuc.; ${ }^{24}$ Servicio de Hematología, Hospital Naval, Ciudad de México; ${ }^{25}$ Servicio de Hematologia, Hospital Regional de Alta Especialidad "Centenario de la Revolución" ISSSTE, Emiliano Zapata, Mor.; ${ }^{26}$ Servicio de Hematología, Hospital General Saltillo, ISSSTE, Saltillo, Coah.; ${ }^{27}$ Servicio de Hematología, Hospital de alta especialidad de Morelia, ISSSTE, Morelia, Mich.; ${ }^{28}$ Servicio de Hematología, Hospital de Especialidades de Salina Cruz, Salina Cruz, Oax.; ${ }^{29}$ Servicio de Hematología Clínica Hospital 5 de Diciembre, ISSSTE, Mexicali, B.C.; ${ }^{30}$ Servicio de Hematología, Hospital Fray Junipero Serra, ISSSTE, Tijuana, B.C.; ${ }^{31}$ Servicio de Hematología, Hospital Regional tipo B de Alta Especialidad Bicentenario de la Independencia, ISSSTE, Tultitlán, Edo. Méx; ${ }^{32}$ Servicio de Hematología Hospital General de Tampico, ISSSTE, Tampico, Tamps.; ${ }^{33}$ Servicio de Hematología, Hospital General tipo B, ISSSTE, Tultitlán, Edo. Méx.; ${ }^{34}$ Servicio de Hematología, Hospital Central Sur de Alta Especialidad de PEMEX, Ciudad de Mexico. México

\footnotetext{
Correspondence:

*Martha Alvarado-lbarra

E-mail: normoblasto@gmail.com

Gac Med Mex. 2020;156(Suppl 1):S1-S45 Contents available at PubMed www.gacetamedicademexico.com

0016-3813/@ 2020 Academia Nacional de Medicina de México, A.C.. Published by Permanyer. This is an open access article under the CC BY-NC-ND license (http://creativecommons.org/licenses/by-nc-nd/4.0/).

Date of reception: $12-05-2020$

Date of acceptance: 04-06-2020
} 


\begin{abstract}
To identify this increasingly common pathology, known as multiple myeloma ( $M M)$, it is necessary to refer to the specific factors that characterize it; to this end, the classic criteria known as CRAB (hyperkalemia, renal failure, anemia, and lytic lesions) are available, in which renal failure is one of the most frequent complications. Recently, three indisputable biomarkers have been described for the diagnostic support for MM, which are: more than 10\% of clonal plasma cells in bone marrow or, a biopsy that corroborates the presence of a plasmacytoma, light chain ratio $\geq 100 \mathrm{mg} / \mathrm{dL}$ and more than one focal lesion on magnetic resonance imaging. A differential diagnosis for plasma cell leukemia, solitary bone plasmacytoma, and extramedullary plasmacytoma should always be considered. Being this an incurable disease, a lot of research has been done regarding its therapeutic management, whose main objective is the disappearance of plasma cells and the patient clinical improvement. Melphalan was the first drug that showed a benefit in 1958 and afterward, with the addition of a steroid as a second drug, it was possible to improve response rates. Subsequently, different molecules were studied, forming multiple combinations, and achieving better rates of overall survival and progression-free survival. Years later, with the arrival of proteasome inhibitors such as bortezomib, and immunomodulators such as thalidomide and lenalidomide, an important turnaround in the disease has been seen, as deeper responses, more prolonged remissions, and improvement in the quality of life of patients have been achieved. This consensus has the purpose of integrating a group of Mexican specialists and promoting the updating of this pathology.
\end{abstract}

KEY WORDS: Multiple Myeloma. Response. Transplantation. Maintenance. Gammopathy.

\title{
Consenso Mexicano de Mieloma Múltiple
}

\section{Resumen}

Para identificar una patología cada vez más común, conocida como mieloma múltiple, es necesario hacer alusión de los factores específicos que la caracterizan. Para ello existen los clásicos criterios conocidos como CRAB (hipercalcemia, insuficiencia renal, anemia y lesiones líticas), siendo la insuficiencia renal una de sus complicaciones más frecuentes. Recientemente se han descrito tres biomarcadores indiscutibles para el apoyo diagnóstico del mieloma múltiple, que son: más del 10\% de células plasmáticas clonales en medula ósea o biopsia que corrobora la presencia de un plasmocitoma, relación de cadenas ligeras $\geq 100 \mathrm{mg} / \mathrm{dl}$ y más de una lesión focal en resonancia magnética. Se debe tomar siempre en cuenta el diagnóstico diferencial con leucemia de células plasmáticas, plasmocitoma óseo solitario y plasmocitoma extramedular. Al ser una enfermedad incurable, se ha investigado mucho en cuanto al manejo terapéutico, el cual tiene como objetivo principal la desaparición de las células plasmáticas y la mejoría clínica del paciente. El primer fármaco que demostró algún beneficio fue el melfalán en el año 1958 y posteriormente al adicionar un esteroide como segundo fármaco se logró mejorar las tasas de respuesta. Después se fueron estudiando diferentes moléculas, con las que se han realizado múltiples combinaciones, alcanzando mejores tasas de supervivencia global y supervivencia libre de progresión. Años más tarde, con la llegada de los inhibidores de proteosoma como el bortezomib, así como de los agentes inmunomoduladores como la talidomida y la lenalidomida, se presenta un giro importante en la enfermedad, ya que se logran respuestas más profundas, periodo de remisiones más prolongadas y mejoría en la calidad de vida de los pacientes. Este consenso tiene la finalidad de integrar a un grupo de especialistas mexicanos y promover la actualización de esta patología.

PALABRAS CLAVE: Mieloma múltiple. Respuesta. Trasplante. Mantenimiento. Gammapatía. 


\section{Module 1}

\section{Classification of monoclonal gammopathies}

Monoclonal gammopathies are a group of pathologies derived from post-germinal plasma cells which have recovered their replication capacity; these series of conditions are not necessarily sequential. Their clinical spectrum goes from the asymptomatic presence of a monoclonal protein in serum and urine, to disease states with healthy tissue destruction. The symptoms may be the result of the infiltration of clonal plasma cells and the monoclonal protein secreted, or the interaction of the plasma cell with its microenvironment ${ }^{1}$.

Monoclonal gammopathies, their diagnostic criteria and their progression rate are covered in table 1 :

There are other entities related to monoclonal gammopathies, which are mentioned in the following table 2.

\section{Monoclonal gammopathy of uncertain significance (MGUS)}

MGUS is considered the first step before multiple myeloma (MM), it may be present at 8-10 years before the diagnosis. However, up to $25 \%$ of the MM patients never had or were never identified with this alteration ${ }^{3}$.

The incidence increases with age, being estimated from 3 up to $20 \%$ in older than 50 years, and it is higher in men and African-American subjects; it is estimated that the risk of progression to MM is $1 \% /$ year 4 .

The conversion process implies several steps, some of which take place simultaneously. Initially the post-germinal center plasma cell must suffer chromosomic alterations, mainly hyperdiploidy, as well as translocations in the immunoglobin's heavy chain $(\operatorname{lgH})$, this results in the activation of the KRAS oncogene, TP53 inactivation, and genomic instability; at the same time, there is rearrangement of the cellular microenvironment, the plasma cell recovers its proliferative capacity, causing monoclonality ${ }^{5}$.

\section{Prognostic criteria}

Nowadays, there are two risk prediction models developed by the Mayo Clinic and by the PHETEMA group, which consider the following elements.

\section{Quiescent or asymptomatic MM}

Unknown incidence in our country. In the USA, 0.9 cases per 100,000 inhabitants are reported, out of these, $13.7 \%$ evolve to symptomatic MM in subjects older than 67 years $^{6}$ (Table 3).

\section{Diagnostic and prognostic criteria}

Criteria for a patient to be considered as ultra-high risk are as follows:

- Plasma cells in bone marrow (BM) higher than $60 \%{ }^{7}$.

- Relation of free light chains higher than $100^{8}$.

- Presence of at least one bone lesion, determined by body magnetic resonance imaging or low dose full body computed tomography $(\mathrm{CT})^{8}$.

These criteria increase the risk of progression to more than $70 \%$ at 2 years (Table 4 ).

\section{Solitary plasmacytoma}

Solitary plasmacytoma represents $2-5 \%$ of monoclonal gammopathies. It is characterized by the plasma cells extramedullary proliferation in the absence of monoclonality in BM or other signs of target organ damage (CRAB) ${ }^{9}$.

Symptomatology depends on the destruction of the tissue affected by the tumor, a balloon sinuplasty (BSP) presents more frequently in axial skeleton, and an exome sequencing project (ESP) is mostly present in nose and oropharynx. This type of tumor has pathognomonic alterations by imaging; therefore, to integrate a definitive diagnosis, proof of monoclonal CP infiltration by biopsy will be needed ${ }^{10}$.

\section{Prognostic criteria}

a. Location and tumor size: presence of a BSP implies a lower Marfan syndrome than that provided by an ESP $(36.4 \%$ vs. $72.1 \%$ at 10 years). A tumor larger than $5 \mathrm{~cm}$ confers an unfavorable prognosis ${ }^{11}$.

b. Paraprotein and light chains: persistence of monoclonal protein, following radiotherapy, is a risk factor related to MM progression ${ }^{11}$.

\section{Treatment}

At present, radiation is the treatment of choice. The dose to be administered may be 40-50 Gy, but it is variable ${ }^{11}$. The use of surgery and chemotherapy is more controversial than the previous measures. 
Gaceta Médica de México. 2020;156(Suppl 1)

Table 1. Diagnostic criteria an progression rate of monoclonal gammopathy

\begin{tabular}{|c|c|c|}
\hline Pathologies & Diagnostic criteria & Progression \\
\hline Non-IgM MGUS & $\begin{array}{l}\text { - Serum monoclonal protein }<3 \mathrm{~g} / \mathrm{dl} \\
\text { - Clonal plasma cells }<3 \% \\
\text { - Absence of a target organ }\end{array}$ & $1 \% /$ year \\
\hline Smoldering type myeloma & $\begin{array}{l}\text { - Serum monoclonal protein }>3 \mathrm{~g} / \mathrm{dl} \text { or monoclonal protein in urine } \\
>500 \mathrm{mg} / 24 \mathrm{~h} \text { and/or clonal plasma cells } 10-60 \% \\
\text { - Absence of myeloma or amyloidosis defining events }\left(^{* *}\right)\end{array}$ & $10 \% /$ year \\
\hline IgM MGUS & $\begin{array}{l}\text { - IgM Serum monoclonal protein }<3 \mathrm{~g} / \mathrm{dl} \\
\text { - Lymphoplasmacytic infiltration in bone marrow }<10 \% \\
\text { - Absence of target organ damage }\end{array}$ & $1-5 \% /$ year \\
\hline Light chain MGUS & $\begin{array}{l}\text { - Light radio chains }<0.26 \text { or }>1.65 \\
\text { - Increase of involved light chains } \\
\text { (kappa relation }>1.65 \text { and lambda }<0.26 \text { ) } \\
\text { - No heavy chain expression on immunofixation } \\
\text { - Absence of target organ damage } \\
\text { - Clonal plasma cells }<10 \% \\
\text { - Monoclonal proteins in urine }<500 \mathrm{mg} / 24 \mathrm{~h}\end{array}$ & $0-3 \% /$ year \\
\hline Solitary plasmacytoma & $\begin{array}{l}\text { - Bone lesion or soft-tissue biopsy with evidence of clonal plasma cells } \\
\text { - Bone marrow without evidence of plasma cells infiltration } \\
\text { - Normal skeletal findings } \\
\text { - Absence of target organ damage }\end{array}$ & $10 \% / 3$ years \\
\hline $\begin{array}{l}\text { Solitary plasmacytoma with } \\
\text { bone marrow involvement }\end{array}$ & $\begin{array}{l}\text { - Biopsy of a bone lesion or in soft tissue with evidence of clonal plasma } \\
\text { cells } \\
\text { - Bone marrow with }<10 \% \text { plasma cells } \\
\text { - Magnetic resonance or tomography of spine and pelvis without lesions } \\
\text { - Absence of target organ damage }\end{array}$ & $\begin{array}{l}60 \% / 3 \text { years (bone marrow) } \\
20 \% / 3 \text { years (soft tissue) }\end{array}$ \\
\hline
\end{tabular}

Hypercalcemia higher than $11 \mathrm{mg} / \mathrm{dL}$, renal failure creatinine clearance lower than $40 \mathrm{ml} / \mathrm{min}$, serum creatinine higher than $2 \mathrm{mg} / \mathrm{dL}$, anemia lower than $10 \mathrm{~g} / \mathrm{dL}$, lytic lesions detected by X-ray, tomography, or PET-CT.

Table 2. Other conditions related to monoclonal gammopathy

Causes of monoclonal proteins in other diseases

\section{Hematologic}

- Lymphoproliferative syndromes (lymphomas, chronic lymphocytic leukemia, or hairy cell leukemia)

- Myelodysplastic syndromes - myeloproliferative (chronic myeloid leukemia, polycythemia vera, myelofibrosis)

- Paroxysmal nocturnal hemoglobinuria, pure red cell aplasia
Associated
to different
- Systemic erythematous lupus, rheumatoid arthritis
- Scleroderma, polymyositis, thyroiditis
- Solid organ transplantation
pathologies
Dermatologic
Scleroderma, pyoderma gangrenosum, Xanthogranulomatous
Viral
- Hepatitis C and HIV viruses

\section{Endocrinology}
- Hyperparathyroidism

\section{Other}
- Pulmonary hemosiderosis, sarcoidosis, and neoplasms

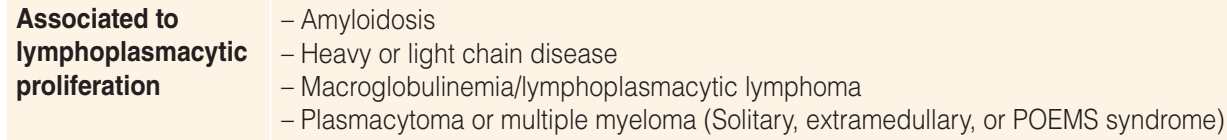

Autoimmune and immunosuppression 
Table 3. A Risk criteria for MGUS

\begin{tabular}{|c|c|c|c|c|}
\hline \multicolumn{4}{|l|}{ MGUS risk criteria } & \multirow[t]{2}{*}{ Follow-up } \\
\hline Risk factors & Risk & $\begin{array}{l}\text { Number of } \\
\text { factors }\end{array}$ & $\begin{array}{l}\text { Risk of progression } \\
\text { at } 20 \text { years }\end{array}$ & \\
\hline \multicolumn{5}{|l|}{ Mayo clinic model } \\
\hline \multirow{4}{*}{$\begin{array}{l}\text { Non-lgG isotype } \\
\text { M Protein > } 1.5 \mathrm{~g} / \mathrm{dL} \\
\text { Altered CL's rel }\end{array}$} & Low & 0 & $5 \%$ & $\begin{array}{l}\text { The above plus bone marrow aspirate, if paraprotein } \\
\text { increases }>25 \% \text { rule out amyloidosis and CRAB }\end{array}$ \\
\hline & \multirow[t]{2}{*}{ Intermediate } & 1 & $21 \%$ & \multirow{3}{*}{$\begin{array}{l}\text { The above plus bone marrow aspirate, if paraprotein } \\
\text { increases }>25 \% \text { rule out amyloidosis and CRAB }\end{array}$} \\
\hline & & 2 & $37 \%$ & \\
\hline & High & 3 & $58 \%$ & \\
\hline \multicolumn{3}{|l|}{ PETHEMA model } & At 5 years & \\
\hline \multicolumn{2}{|l|}{ Abnormal phenotype } & 0 & $2 \%$ & \\
\hline \multirow[t]{2}{*}{ Aneuploidy } & & 1 & $10 \%$ & \\
\hline & & 2 & $46 \%$ & \\
\hline
\end{tabular}

Table 4. Risk criteria for quiescent Myeloma

\begin{tabular}{|c|c|c|c|c|c|}
\hline \multicolumn{5}{|c|}{ Risk criteria for quiescent myeloma } & \multirow[t]{2}{*}{ Follow-up } \\
\hline Risk factors & \multicolumn{2}{|l|}{ Number of factors } & $\begin{array}{c}\text { Risk of progression } \\
\text { at } 5 \text { years }\end{array}$ & $\begin{array}{l}\text { Median } \\
\text { TTP }\end{array}$ & \\
\hline \multicolumn{6}{|l|}{ Mayo clinic model } \\
\hline \multirow{3}{*}{$\begin{array}{l}\text { Rel. CL a normal } \\
P C \text { in } B M>10 \% \\
M \text { protein }>3.0 \mathrm{~g} / \mathrm{dL}\end{array}$} & Low risk & 1 & $25 \%$ & 10 years & Yearly assessment if paraprotein is not $>25 \%$ \\
\hline & Intermediate risk & 2 & $51 \%$ & 5 years & Quarterly assessment during the $1^{\text {st }}$ year ruling out $C R A B$ \\
\hline & High risk & 3 & $76 \%$ & 1.9 years & Bimonthly assessment, consider early treatment \\
\hline PETHEMA model & & & At 5 years & & \\
\hline \multirow{3}{*}{$\begin{array}{l}\text { > 95\% abnormal CP } \\
\text { by flow cytometry/ } \\
\text { CPMO } \\
\text { Immunoparesis }\end{array}$} & 0 & & $4 \%$ & NA & \\
\hline & 1 & & $46 \%$ & 6 years & \\
\hline & 2 & & $72 \%$ & 1.9 years & \\
\hline
\end{tabular}

\section{Module 2}

POEMS (polyneuropathy, organomegaly, endocrinopathy, monoclonal gammopathy) syndrome, Castleman disease and Waldeström Macroglobulinemia (WM)

\section{POEMS syndrome}

POEMS is a para-neoplastic syndrome that presents with plasma cells dyscracia, its name is derived from the acronym coined by Dr. Bardwick in 1980, to describe a patient with polyneuropathy, organomegaly, endocrinopathy, monoclonal gammopathy monoclonal $y$, and skin changes. However, this syndrome is not limited to the disorders conforming the acronym, diagnostic criteria have been modified to get to a wider classification, since they frequently also present: papilledema, extravascular overload, sclerotic bone lesions, and thrombocytosis/erythrocytosis (PEST)'.

Pathophysiology of this entity is scarcely known and vascular endothelial growth factor (VEGF) participation is established; nevertheless, it must be differentiated from gammopathies already described due to variations in 
Table 1. Diagnostic criteria fo POEMS syndrome

Diagnostic criteria for POEMS syndrome

$\begin{array}{ll}\begin{array}{ll}\text { Mandatory } \\ \text { major criteria }\end{array} & \text { 1. Demyelinating polyneuropathy } \\ & \text { 2. Monoclonal plasma cell dyscrasia } \\ \begin{array}{l}\text { Other major } \\ \text { criteria }\end{array} & \text { 3. Castleman disease } \\ \end{array}$

$\begin{array}{ll} & \text { 4. Sclerotic bone lesions } \\ & \text { 5. VEGF serum increase } \\ \text { Minor criteria } & \text { 6. Organomegaly } \\ \text { 7. Extravascular hydric overload } & \text { 8. Endocrinopathy } \\ \text { 9. Skin changes (hyperpigmentation, } \\ \text { hypertrichosis, plethora) } \\ \text { 10. Papilledema } \\ \text { 11. Thrombocytosis/polycythemia }\end{array}$

Other symptoms 12. Weight loss, hyperhidrosis, pulmonary hypertension, diarrhea

Modified from Dispenzieri, 2017

their management and prognosis. There are established criteria to differentiate it from other blood dyscracias ${ }^{2}$ (Table 1). Its epidemiology is not well determined due to the scarce number of cases presented even in reference sites; it is estimated that, in Japan, one of the countries with a higher number of reported cases, there are 0.3 cases $/ 100,000$ inhabitants $^{3}$.

The diagnosis requires a large number of tests to determine the damage or grade of involvement in each organ or system known to be probably affected by the syndrome. A complete clinical history, including a thorough physical and neurological examination with emphasis in menstrual disorders in women, or other disorders of probable endocrine origin is very important. On the other hand, imaging and clinical tests must be performed guided by clinical findings and questioning, in such a way to allow us to determine which criteria are met with the smaller amount of used resources.

From the total signs and symptoms that may occur, the most frequent are: neuropathy, in up to $100 \%$ of the cases; peripheral edema, skin hyperpigmentation, thrombocytosis, and plasma cells dyscracias, these in up to $88 \%$ of the cases. There are no other specific predictive models for this entity, but it has been shown that its survival, both as progression free and as overall, is better than that of other gammopathies (overall survival [OS] at 10 years of up to $79 \%)^{4}$.

POEMS syndrome treatment will be determined based on the degree of plasma cells infiltration into the $\mathrm{BM}$. In those cases, where the infiltration is scarce or almost null, radiotherapy is considered the standard treatment, with response rates from 50 to $70 \%$, and a noticeable symptomatology improvement ${ }^{5}$. On the other hand, when there is an important plasma cell dyscrasia component, the treatment of choice should be based on those used in this group of diseases. There is no standard treatment and inconclusive results have been reported with different treatment schemes, based on the use of proteasome inhibitors $(\mathrm{PI})$ in combination with an ImiD, such as thalidomide and lenalidomide, with good response rates $^{6}$. However, hematopoietic stem cells (HSC) transplantation still reports response rates of up to $100 \%$ with a disease-free survival (DFS) of $72 \%$ at 6 years in a Mayo Clinic series ${ }^{4}$.

The follow-up and response assessment are done based on initially involved organs and the treatment administered; hence, in case of a PI plus IMiD is used, the response assessment points should be at 4 months initially, to be re-evaluated at 6 months (Table 2).

\section{Castleman disease and POEMS syndrome}

Castleman disease was initially described in the 50 's, specifically in the case of patient with mediastinum nodes, fever and weight loss in those with suspicion of diverse pathologies, such as tuberculosis, which were discarded after the description of plasmocytic infiltration found in such nodes, corresponding to what we know as unicentric Castleman disease ${ }^{6}$.

This disease may be related to several pathologies, both, infectious (human immunodeficiency virus [HIV], and human herpesvirus 8) and autoimmune, and in this case, hematologic. Although it is considered a benign disease, it confers an increase in the risk of lymphoma and other neoplasms.

Regarding its pathophysiology, this will depend on the type of disease, we are facing. In both cases, there is an interleukin (IL)-6 increase, with lymphocytic proliferation resulting in the increase of VEGF stimulating factor, and a hyaline-vascular disease, the difference lies in the relation of the formerly mentioned viruses for the multicentric and almost exclusive IL- 6 activity for the unicentric presentation. A Castleman variant may be found, in which there are proliferation and infiltration of plasmacytic cells with IgG or IgA overexpression and restriction of the lambda chains, and this 
Table 2. Response criteria for POEMS syndrome

\begin{tabular}{l|l|l|l}
\hline \multicolumn{2}{l}{} & \multicolumn{2}{c}{ Response criteria } \\
\hline Parameter & CR & Improvement & Progression \\
\hline Plasma VEGF & Normal & $50 \%$ decrease from baseline & $50 \%$ increase from baseline \\
\hline Hematologic & $\begin{array}{l}\text { Negative immunofixation in } \\
\text { serum and urine }\end{array}$ & $\begin{array}{l}50 \% \text { decrease from monoclonal } \\
\text { peak }\end{array}$ & $25 \%$ increase from baseline \\
\hline Ascites/edema & Absent & 1 point improvement in CTCAE & 1 point worsening in CTCAE \\
\hline Ventricular systolic pressure. By Eco TT & Normal & Below 40 mmHg & NA \\
\hline Papilledema & Absent & Absent & Present
\end{tabular}

VEGF: vascular endothelial growth factor; CTCAE: Common Terminology Criteria for Adverse Events.

Modified from Dispenzieri, 2017.

variant should be considered at the moment of making a differential diagnosis between POEMS and WM. This plasmocytic form has been reported in up to $44 \%$ of the multicentric Castleman cases?.

Diagnosis should consider both approaches the histopathological and the exclusion one. The approach in patients with Castleman or POEMS should basically include the same tests described for the previous syndrome. Furthermore, autoimmune diseases which may be related to the disease should be ruled out. In the specific case of correlation between Castleman and POEMS, the definition is based on the histopathologic report of the first one, with clinical characteristics of the second; this is the point in which several Castleman disease cases with "singular" characteristics really correspond to a Castleman in the POEMS frame. Neuropathy present in Castleman tends to be milder than that in POEMS and remits partially. There is a lambda chain restriction observed in the lab, but with normal IgM levels, tending more toward to an IgG and IgA polyclonal elevation, which helps to the differentiation between $\mathrm{WM}$ and $\mathrm{MM}^{1}$.

Treatment of Castleman disease is varied, there is no standard treatment and most of the regimes used are off-label. In a meta-analysis published in 2016 steroids-based schemes were found, reporting a 2-year survival of up to $88 \%$; other based on chemotherapy, such as cyclophosphamide, with a 2 year survival of $90 \%$, and schemes with rituximab with survival of up to $100 \%$ at 2 years. However, bortezomib, immunomodulators (IMiD), and other chemotherapies have been described and used with similar response rates to those reported with more traditional treatments. IL- 6 has become the target of some novel treatments, specifically for the multicentric HIV negative type, with variable response rates?
In the case of a documented relationship between POEMS and Castleman, treatment must be oriented to the resolution of the plasmacytic proliferation, with the use of PIs o IMiD, it is known that this relation, observed in $15-25 \%$ of the cases, has a favorable response to those treatments ${ }^{8}$.

The response assessment and follow-up do not vary in comparison with those described for the POEMS syndrome; the second-line treatment will depend on the resources available and on the response to the first-line treatment.

\section{WM}

\section{Definition}

According to the last WHO review in 2016, WM belongs to the group of mature $B$ cells neoplasms, in the subgroup of lymphoplasmacytic lymphomas. WM is a clinical-pathological entity defined by: BM infiltration, lymphoplasmacytic lymphoma, and the presence of a monoclonal IgM component in serum ${ }^{9}$.

\section{Epidemiology and classification}

WM has a global incidence of $3 /$ million person-year and represents, approximately $1-2 \%$ of non-Hodgkin lymphomas ${ }^{10,11}$. Age adjusted incidence is $3.4-7.3 / \mathrm{mi}-$ llion in men, and 1.7-4.2/million in women, in the population of United States of America and Europe, respectively ${ }^{11,12}$. Opposite to MM incidence, WM prevalence is higher in Caucasian population than in African-Americans ${ }^{13}$. Mean age at presentation is 63-75 years ${ }^{13}$. There is a strong family predisposition, reporting a risk of up to 20 times higher of developing WM in first-degree family members who are WM 
Table 3. Diagnostic evaluation for WM

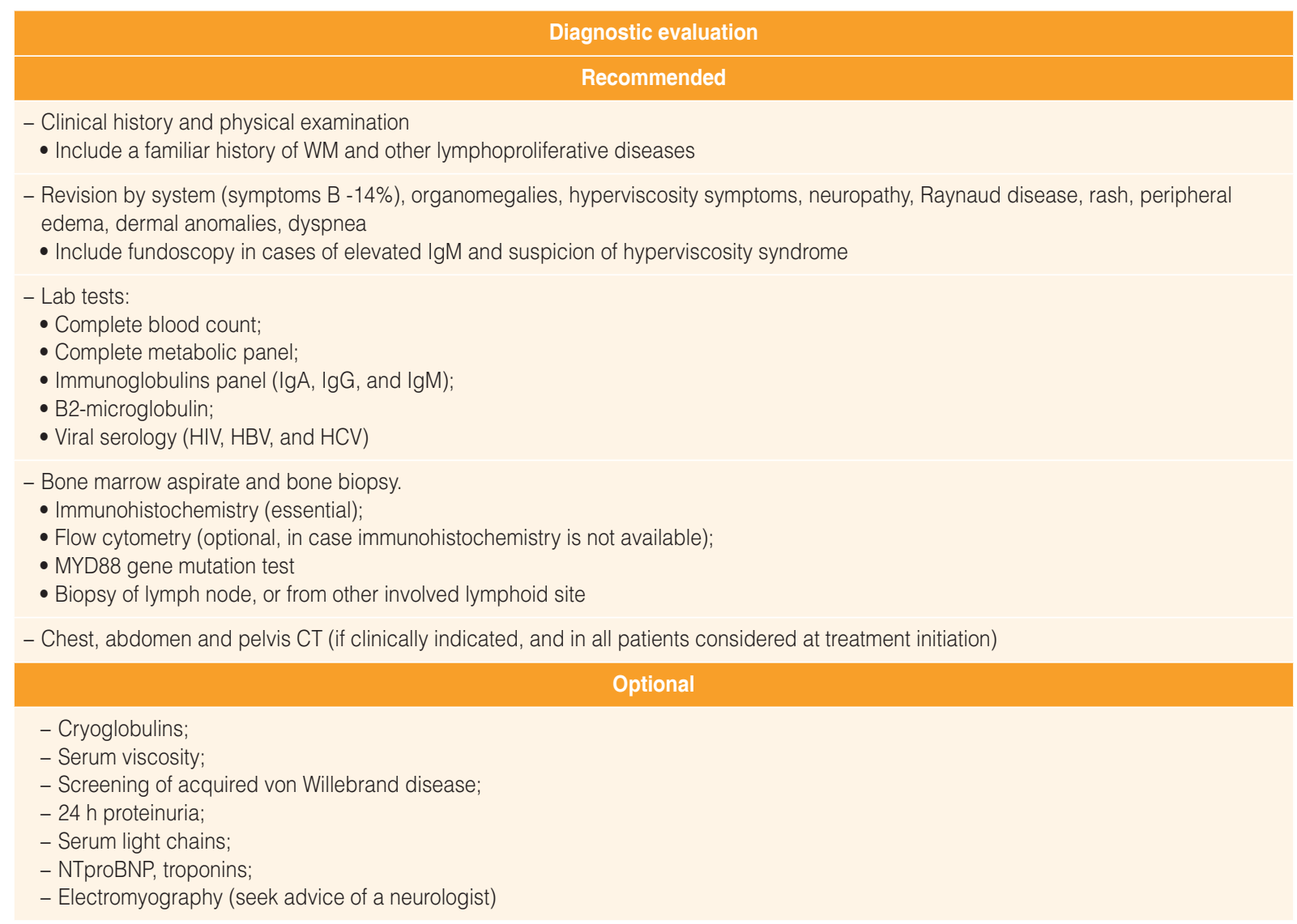

carriers ${ }^{14}$. In Mexico, there is a reported incidence of $0.18 \%$ of all the hematologic diseases, being 11 times less frequent than in the Caucasian population ${ }^{15}$.

Although it is considered an incurable disease, the median DFS has improved from 6 years in the 90's- 8 years as from $2000^{16}$.

It is important to differentiate it from the MGUS IgM type, MM, mantle lymphoma (ML), chronic lymphocytic leukemia (CLL), and marginal zone lymphoma (MZL). Infections such as hepatitis, HIV, and several rheumatic diseases also elevate IgM levels. The presence of the MYD88 L265P mutation differentiates WM from other $B$ cell chronic lymphoproliferative diseases ${ }^{17}$.

\section{Pathogenesis}

There are several abnormalities and genetic mutations, the most common include: del(6q) (50\%), immunoglobulin heavy variable somatic hypermutation, $\mathrm{t}(9 ; 14)$ (p13;q32) (50\%), and trisomy 4 (20\%). In WM oncogenesis, somatic mutations in genes MYD88
(> 90\%) and chemokine type 4 receptor (CXCR4) $(30-35 \%)$ play a key role ${ }^{18}$.

The gene product of the myeloid differentiation primary response (MYD88) is an adaptative protein (connects extracellular and intracellular signals) of the 4 toII-like receptor and the IL-1R and 2 (IL-2R) receptors. It may be activated directly by these receptors or by interaction of the TIR domain adaptative protein and Bruton Tyrosine Kinase, promoting the activation of the NF-kB pathway. There are several somatic variants, being MYD88 L265P (substitution of leucine by proline in position 265) the most frequent, resulting in a gain of function $^{19}$. This mutation is rare or is not present in MGUS$\operatorname{lgM}(10-60 \%)$, MZL (7\%), CLL (3\%), and MM $(0 \%)^{20}$.

The CXCR4 is a G-protein coupled receptor, which plays an important role in cytokine release and chemotaxis. Mutations in this protein result in permanent activation by stromal-derived factor 1-alpha. Suppression of CXCR4 results in the inhibition of migration and adhesion of WM cells. Somatic mutations of this receptor are found in $27 \%$ of patients with MW' ${ }^{21}$; CXCR4 S338 mutation has shown inferior responses to ibrutinib22. 
Table 4. Diagnostic Criteria for Waldestrom macroglobulinemia Diagnostic criteria for Waldenström macroglobulinemia

IgM monoclonal gammopathy (regardless of the concentration); Bone marrow infiltration by lymphoplasmoblasts: Immunophenotype of M.O: CD5-, CD10-, CD19+, CD20+, CD23-; Rule out other mature lymphocyte pathologies

Modified from Mayo Clin Proc. 2010 Sep; 85(9).

\section{Diagnosis}

WM diagnosis is based on the histopathological confirmation of BM infiltration by a lymphoplasmacytic lymphoma (presence of small lymphocytes with plasma cells and lymphoplasmocytes) and the detection of an IgM monoclonal component in serum, which must always be confirmed by immunofixation ${ }^{10}$. Dutcher's bodies (IgM-containing intranuclear vacuoles) are frequently observed. The lymphoplasmacytic monoclonal population in BM, must express CD19, CD20, CD22, and CD79a in lymphocytes by immunophenotype or immunohistochemistry; CD38 for the plasmacytic component; in addition to the accumulation of $B$ cells with phenotype CD22 (+ dim), CD25 +, CD27 +, and IgM +, which differentiates it from other lymphomas by its negative expression of CD5, CD10, CD11c, or CD10323. The rest of the diagnostic evaluation is summarized in table 3 .

Once recommended tests for a WM diagnose are performed, the disease stage must be classified based on the following criteria (Table 4).

\section{Clinical manifestations}

Manifestations may be divided into two large groups: target organ involvement, and IgM paraprotein related symptoms. Target organ involvement include: B symptoms (fever, weight loss, fatigue, and nocturnal diaphoresis), Iymphadenopathy, hepatomegaly, and/or BM infiltration. Related symptoms to IgM paraprotein include: systemic amyloidosis, cryoglobulinemia, peripheral neuropathy (20-25\% of cases), and symptoms related to hyperviscosity (visual changes, neurologi$\mathrm{cal}$, and cardiovascular compromise, normally occurring when levels are above 30-40 g/dL) ${ }^{24}$.

\section{Risk stratification and prognostic factors}

A multivariate analysis performed on 1511 patients registered in the RFS from January 2000 to December
Table 5. Risk stratification according to IPSSWM 2019

\begin{tabular}{|l|c|c|c|}
\hline \multicolumn{4}{|c|}{ Risk stratification according to IPSSMW 2009} \\
\hline Risk group & Low & Intermediate & High \\
\hline Risk factors ${ }^{\mathrm{a}}$ & $0-1$ (except for age) & Age or 2 & $\geq 3$ \\
\hline OS at 5 years & $87 \%$ & $68 \%$ & $36 \%$ \\
\hline
\end{tabular}

aRisk factors: age $\geq 65$ years, $\mathrm{Hb} \leq 11.5 \mathrm{~g} / \mathrm{dL}$, platelets $\leq 100 \times 10^{\%} \mathrm{~L}, \mathrm{~B} 2 \mathrm{M}>3 \mathrm{mg} / \mathrm{dL}$ and $\lg M>70 \mathrm{~g} / \mathrm{L}$.

2014 showed that age, symptoms B, elevated DHL, and hemoglobin $(\mathrm{Hb})$ levels $<11.5 \mathrm{~g} / \mathrm{dl}$ were factors of poor prognosis. The serum immunoglobulin $\mathrm{M}$ level had no prognostic significance; likewise, the sex of the individual did not present prognostic significance.

International Prognostic Scoring System (IPSS) described for $\mathrm{WM}^{10}$, includes five variables impacting negatively in the prognosis: anemia, thrombocytopenia, beta-2-microglobulin levels, IgM serum concentration, and age (Table 5).

IPSS did not include the HDL serum level and low levels of albumin which have adverse prognostic relevance.

\section{Treatment}

\section{Asymptomatic patients (watch-and-wait)}

There is not a standardized treatment for the asymptomatic disease. In WMA patients a follow-up with a 3-4 months frequency are recommended, in case of stable disease, the follow up may be extended up to every 6 months. Within the evaluation the following points should be considered: careful physical examination, including fundoscopy (preferably assessed by an ophthalmologist) to assess retinal vein congestion, bleeding or exudates, and papilledema.

\section{Criteria for treatment initiation}

Treatment must be initiated in those patients with IgM levels $>60 \mathrm{~g} / \mathrm{L}$, constitutive symptoms, symptomatic hepatosplenomegaly or lymphadenopathies, either symptomatic or bulky (>5 cm), hyperviscosity syndrome, severe neuropathy, systemic amyloidosis or symptomatic cryoglobulinemia ${ }^{25}, \mathrm{Hb} \leq 10 \mathrm{mg} / \mathrm{dL}$, and platelets $<100 \times 10^{925}$. 


\section{Symptomatic patients}

In WM, there is not a standard treatment, the lack of randomized trials between regimes make it difficult to provide recommendations with a evidence level. Treatment options are largely based on the long-term experience and the experts' opinion. Multiagent immunochemotherapy should be preferred over rituximab as monotherapy, since it has shown PR rates of $80 \%$ versus rituximab, where response rates are $<50 \%$.

Hyperviscosity is an infrequent manifestation of WM; the most common presentation is nose or gums bleeding. The level of viscosity should always be measured in patients with suspicion of hyperviscosity syndrome, and the therapy of choice is the plasma exchange. A single plasma exchange may normalize viscosity and allow chemotherapy to successfully reduce the tumor mass. An inconvenience of rituximab monotherapy is the slow response time and the transient IgM increase or "flare," which takes place within the $1^{\text {st }}$ and $4^{\text {th }}$ months of treatment in $10-15 \%$ of the cases, with a risk of exacerbating neuropathy and the symptomatology associated to hyperviscosity. Besides, caution is required to differentiate an IgM flare from a lack of response ${ }^{26}$.

Regimes of combined treatment with rituximab have shown a fast reduction of the IgM levels, being used in patients with hepatosplenomegaly or BM significant infiltration and requiring a fast cytoreduction.

The combination of rituximab with cyclophosphamide and dexamethasone showed efficacy in a prospective trial of 72 naive patients, resulting in an ORR of $83 \%$; the progression-free survival (PFS) and OS at 2 years of 67 and $81 \%$, respectively ${ }^{27}$. In the trial update, the mean time to relapse was 35 months; in relation with the risk groups, the OS at 8 years was 100, 55, and $27 \%$ for the groups of low, intermediate, and high risk, respectively ${ }^{28}$.

In a randomized trial of 64 patients, the use of CHOP versus $\mathrm{R}-\mathrm{CHOP}$ was compared, where the latter resulted in a higher OR ( $91 \%$ vs. $60 \%)$ and PFS at 2 years $(78 \%$ vs. $47 \%)$. Fludarabine has shown a significant response in combination with rituximab (FR), as well as in combination with the latter and cyclophosphamide (Fludarabine, cyclophosphamide, and rituximab [FCR]). FR showed an overall response rat (ORR) and PFS at 2 years of 96.3 and $67 \%$, respectively ${ }^{29,30}$. FCR reached an ORR and OS at 3 years of 76 and $96 \%$, respectively ${ }^{31}$. The regimes associated to fludarabine are recommended in relapsed/refractory patients due to prolonged cytopenia and the risk of second neoplasms (10-15\%). The combined use of rituximab and bendamustine (BR) showed better results versus $\mathrm{R}-\mathrm{CHOP}$ in a Phase III clinical trial ${ }^{32}$, reaching a higher PFS (69.5 months vs. 28.1 months; $p<0.001)$ with a better safety profile.

The use of $\mathrm{PI}$, as in $\mathrm{MM}$, has shown a significant response in patients with WM. In a Phase II trial ${ }^{33}$ with 26 patients, the combined use of bortezomib and rituximab reached a minor or better response in $88 \%$, with an IgM decrease in $100 \%$ of the patients; the median PFS was not reached, with an estimated OS of $96 \%$ at 1 year. The scheme with rituximab and dexamethasone (BRD) has proven efficacy in two studies, reaching an ORR of $90-96 \%$, PFS $40-80 \%$, and an OS of $80-100 \%$. However, the most frequent toxicity was neuropathy, requiring the withdrawal of bortezomib in $8-61 \%$ of the patients ${ }^{34,35}$.

In a Phase III trial in previously treated patients, the use of carfilzomib resulted in an $87.1 \%$ ORR, with a lower frequency of neuropathy $(3.2 \%)$ and to be $\geq$ Grade III. Carfilzomib, as from $20 \mathrm{mg} / \mathrm{m}^{2}$ and a scale of $36 \mathrm{mg} / \mathrm{m}^{2}$, was received on days $1,2,8$, and 9 of each cycle; rituximab and dexamethasone on days 2 and 9 of each cycle, and a maintenance treatment every 8 weeks for eight cycles. As overall response, the rate in 31 patients was $87 \% ; 36 \%$ reached $\geq$ very good partial response (VGPR) with a mean response time of 2.1 months without peripheral neuropathy $>$ Grade 1. This combination has also been used to treat the relapsed disease ${ }^{36}$ (Figure 1).

\section{Relapse of refractory disease}

The use of rituximab has shown efficacy in relapsed or refractory patients. In a Phase II trial ${ }^{23} 72$ patients were included (34 previously treated), reaching a similar response on treated and untreated patients (51.4 years $52.9 \%$, respectively). The combination of rituximab plus fludarabine or brentuximab has shown better responses with an ORR of 83.3 and $93.8 \%$, respectively ${ }^{39}$. In a retrospective study ${ }^{30}$, the scheme FCR showed an ORR and OS at 3 years of 77.2 and $89 \%$, respectively.

PIs have proven efficacy in different trials, initially in studies with bortezomib as monotherapy. In a small study of 10 patients ${ }^{31}$, where they reached an overall response and a major response of 80 and $60 \%$, respectively. In two other studies with a larger population ${ }^{39}$, bortezomib as monotherapy resulted in overall responses and major responses of $78-85$ and $44-48 \%$, respectively. In both studies, the time to reach a response 


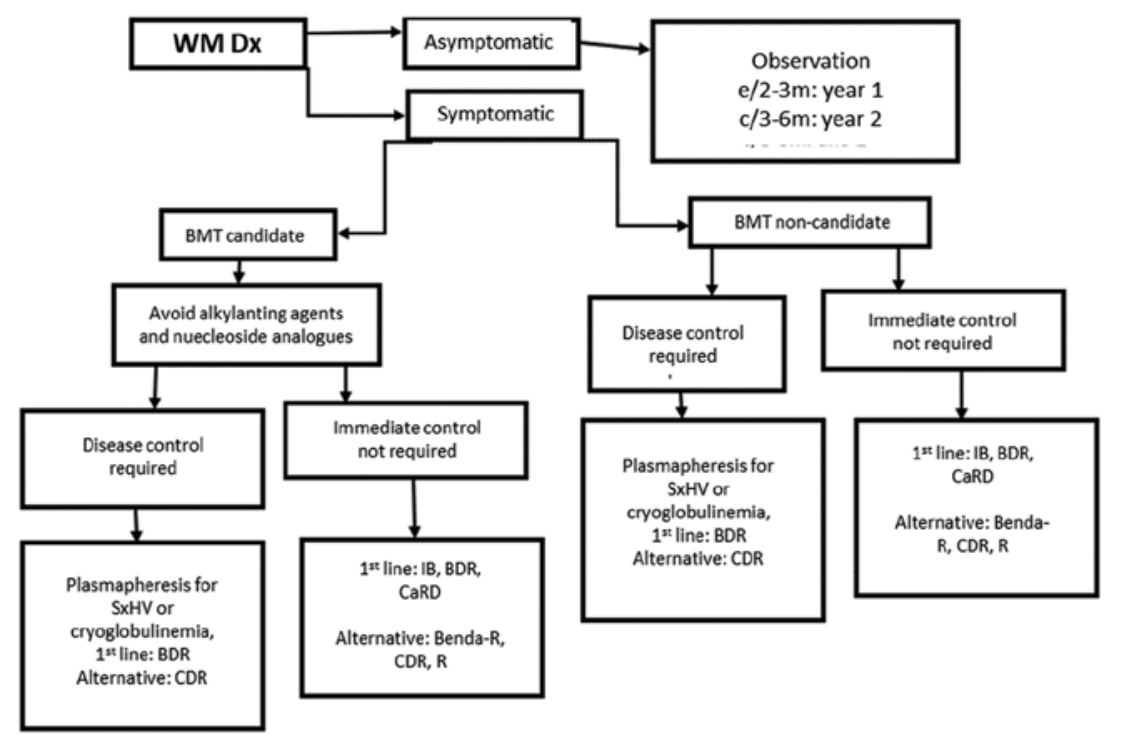

Figure 1. Dx: diagnosis; WM: waldenström's macroglobulinemia; BMT: bone marrow transplant; HVS: hyperviscosity syndrome; benda-R: bendamustine + rituximab; BDR: bortezomib + dexamethasone + rituximab; CaRD: carfilzomob-lenalidomide-dexamethasone; CDR: carfilzomib-daratumumab-lenalidomide; $R$ : rituximab.

Adapted from Gertz MA.201826

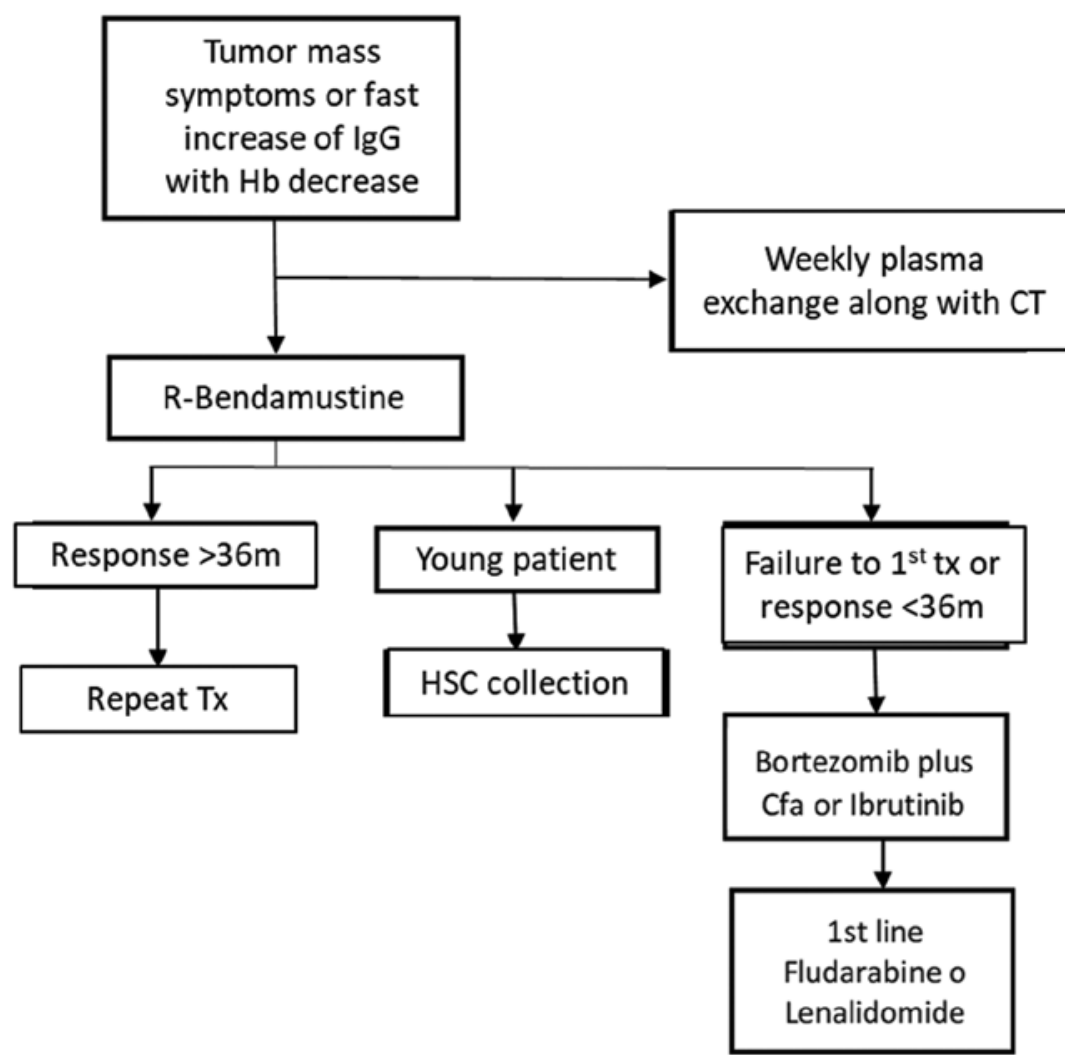

Figure 2. IgG: immunoglobin G; Hb: hemoglobin; tto: treatment; $\mathrm{CPH}$ : hematopoietic progenitor cells; Cfa: cyclophosphamide. Adapted from Gertz MA.2018. ${ }^{26}$ 
was fast (1.4 and 1.5 months) and variable duration of response, with a mean progression of 6.6 months in one study ${ }^{39}$ and PFS of 16 months in the other ${ }^{33}$. In a more recent, Phase II trial ${ }^{22}$ bortezomib was evaluated as monotherapy, and in those cases with the lack of response dexamethasone were added to the scheme (20 $\mathrm{mg} /$ day for 2 days); the ORR was $43.2 \%$, OS at 2 years $84 \%$ and a median PFS of 15.3 months, without differences between the groups in which dexamethasone was or not added.

The combined use of bortezomib with other treatment schemes has improved the depth of the response and PFS. In a prospective study ${ }^{35}$, BDR showed efficacy, with an ORR and major response of 96 and $83 \%$, respectively; the time to reach a response was fast (1.4 months). In the follow-up of this study ${ }^{40}$, the OR and the major response were 96 and $91 \%$, respectively, with a mean progression of 52 months. However, the most relevant toxicity was bortezomib related neuropathy, requiring the suspension in up to $60 \%$ of the patients. Regarding a way to improve neurotoxicity, Ghobrial et al., administered different dose schemes in two similar trials, reaching and ORR and a major response of $81-88$ and $51-65 \%$, respectively; peripheral neuropathy was present in $41 \%$ grades $1-2$ and only $5 \%$ grade $\geq 3^{37}$.

The use of carfilzomib with a low risk of peripheral neuropathy, but a higher risk of cardiotoxicity, has been evaluated in a series of cases $(p=7)$ in combination with dexamethasone in relapsed patients, reaching an overall response and a major response of 100 and $86 \%$, respectively.

The mTOR inhibitor, everolimus, has been used to treat WM in a trial with 60 patients who were treated in relapse or refractory with an ORR of $50 \%$ and a clinical benefit rate of $73 \%$. The median response time for patients reaching a PR was 2 months. Median PFS was $21 \%$. Unfortunately, toxicities grade $\geq$ 3 were observed in $67 \%$ of the patients. Everolimus has also been combined with bortezomib and rituximab in a Phase 1-2 trial where six cycles were administered, followed by maintenance with everolimus; $57 \%$ of the patients had previous use of bortezomib and $98 \%$ of rituximab; however, the OS at 1 year was $89 \%$, the PR rate was $53 \%$, and the median PFS was 21 months $^{38}$ (Figure 2).

\section{Maintenance}

Castillo et al. recruited 182 patients with three treatment schemes: Benda-R, Borte Dexa R, Ciclo, and
Table 6. Response criteria fron the International workshop on WM

\begin{tabular}{l|l|l|}
\multicolumn{2}{|c|}{ Response criteria form the international workshop on WM } \\
\hline $\begin{array}{l}\text { Response } \\
\text { Complete } \\
\text { response }\end{array}$ & Ableviation & Criteria \\
\hline $\begin{array}{l}\text { Very good } \\
\text { partial } \\
\text { response }\end{array}$ & VGPR & $\begin{array}{l}\text { Normal IgM, disappearance of } \\
\text { abnormal protein by immunofixation, } \\
\text { adeno and visceromegaly } \\
\text { resolution, asymptomatic }\end{array}$ \\
$\begin{array}{l}\text { Partial } \\
\text { response }\end{array}$ & PR & $\begin{array}{l}\text { Serum IgM decrease }>90 \% \text { or } \\
\text { size of adeno and visceromegaly } \\
\text { reduction. Without new symptoms }\end{array}$ \\
$\begin{array}{l}\text { Minor } \\
\text { response }\end{array}$ & MR & $\begin{array}{l}\text { Serum IgM reduction }>50 \% \\
\text { or adeno and visceromegaly } \\
\text { reduction. Without new symptoms }\end{array}$ \\
$\begin{array}{l}\text { Stable } \\
\text { disease }\end{array}$ & SD & $\begin{array}{l}\text { Serum IgM reduction of } \geq 25 \% \text { but } \\
<50 \% \text {. Without new symptoms }\end{array}$ \\
$\begin{array}{l}\text { Disease } \\
\text { progression }\end{array}$ & PD & $\begin{array}{l}\text { IgM }<25 \% \text { reduction and }<25 \% \\
\text { increase or adenomegaly }\end{array}$ \\
\hline $\begin{array}{l}\text { IgM increase of } \geq 25 \% \text { or } \\
\text { symptomatology or complication } \\
\text { caused by MW }\end{array}$
\end{tabular}

Modified from Blood, 2015.

Dexa-R, followed or not by maintenance with rituximab for symptomatic patients. Patients achieving a longer disease-free survival were those treated with BDR, followed by maintenance with rituximab for $p<0.001$.

After the treatment administration, the grade of response achieved with the treatment must be assessed, based on criteria described in the following table 6 .

\section{Module 3}

\section{Myeloma overview}

\section{Clinical manifestations}

Clinical manifestations of MM may be divided in two: Those which are secondary to the disease activity and part of the CRAB acronym, and those that are a consequence of a high tumor load, as those related to hyperviscosity or plasmacytomas.

Most patients with a MM final diagnosis arrive to the hematologist after a long way through many different specialties, and after the study of complications such as pathologic fractures, renal failure, and anemia related symptoms. The early reference of these patients to our offices depends on the experience and knowledge of the first contact physician, who must bear in mind the clinical manifestations of the disease to suspect this. 
Most frequent data are: anemia (73\%), bone pain $(52 \%)$, fatigue $(32 \%)$, creatinine increase $(48 \%)$, hypercalcemia (28\%), and weight loss (24\%), fever was only present in $0.7 \%$ of the cases ${ }^{1}$.

\section{Diagnostic criteria}

Diagnostic criteria for MGUS, asymptomatic MM, and other gammopathies will be covered specifically in the corresponding section; here, we will only focus on the criteria for MM.

Gammopathies are diseases of complex biology that requires a series of studies to integrate the different diagnoses. The initial diagnostic approach for myeloma should be done based on a clinical suspicion and supported on the following lab and clinical tests.

Clinical component: anemic syndrome, bone pain, lethargy, headache, or any other sign of hyperviscosity syndrome.

- Biochemical component: complete blood count, glucose, creatinine, blood urea nitrogen, globulins, albumin, total proteins, lactic dehydrogenase, alanine aminotransferase, aspartate aminotransferase, uric acid, beta-2 microglobulin, serum calcium; $24 \mathrm{~h}$ urine creatinine clearance.

- Assessment of serum immunoglobulins levels.

- Detection and assessment of the monoclonal component by electrophoresis in serum and/or urine.

- Immunofixation to determine restrictions of light chains restrictions.

- Morphological component: BM aspirate and biopsy.

- Imaging component: metastatic bone series, CAT, and IMR.

Once all the tests are done there would be the possibility to integrate any of the gammopathies diagnoses, specifically for MM, according to the IMWG 2014 review (Table 1).

\section{Staging and prognosis}

The first step to stage a disease is to differentiate prognostic from predictive factors. The former refer to factors which provide information about how the disease will evolve; while the latter provide guidance on how feasible is that the disease respond to a given therapeutic intervention ${ }^{2}$. Having clarified this, the clinical and biological factors must be differentiated.

Conventionally, MM had been staged based on the Durie-Salmon classification, which considers clinical
Table 1. International Myeloma Working Group Criteria

\section{Both criteria must be met}

Clonal plasma cells $>10 \%$ or bone biopsy with involvement or extramedullary plasmacytoma.

- One or more of the following defining events:

- Evidence of target organ damage which may be attributed to a proliferative disorder of plasma cells, specifically:

- Hypercalcemia: serum calcium >0.25 mmol/L (> $1 \mathrm{mg} / \mathrm{dL})$

higher than the upper limit of normal or $>2.75 \mathrm{mmol} / \mathrm{L}$

(>11 mg/dL);

- Renal failure: creatinine clearance $<40 \mathrm{~mL} / \mathrm{min}$ or serum creatinine > 177 umg/dL);

- Anemia: hemoglobin decreases of $>2 \mathrm{~g} / \mathrm{dL}$ below the lower

limit of normal, or hemoglobin < $10 \mathrm{~g} / \mathrm{dL}$;

- Bone lesions: one or more osteolytic lesions by X-ray, CT, PET-CT;

- Clonal plasma cells in bone marrow $>60 \%$;

- Alteration in the FLC ratio > 100;

- $>1$ lytic lesion by IRM (5 mm at least).

Based on the monoclonal component found, the frequency order is: $\lg G 52 \%, \lg A 21 \%$, light chains $16 \%$, IgD $2 \%$, biclonal $2 \%$, IgM $0.5 \%$, non-secreting $6.5 \%$

Modified from Kyle et al.

\section{Table 2. International Prognostic Index}

\begin{tabular}{|l|l|l|}
\hline \multicolumn{3}{|c|}{ International prognostic index } \\
\hline Stage & Criteria & Overall survival \\
\hline I & $\begin{array}{l}\text { Beta-2 microglobulin }<3.5 \text { and serum } \\
\text { albumin }>3.5 \mathrm{~g} / \mathrm{dL}\end{array}$ & 62 months \\
\hline II & None I or III & 44 months \\
III & Beta-2 microglobulin $>5.5$ & 29 months \\
\hline
\end{tabular}

Adapted from Moreau et al., 2017.

and biochemical factors, segmenting the disease into three categories (low, intermediate, and high risk) based on the presence of lytic lesions, monoclonal component, $\mathrm{Hb}$, and serum calcium (table to be defined); besides, subdividing the patients into two groups according to their renal function. This system is no longer used due to its low utility and applicability with new imaging techniques ${ }^{3}$.

Nowadays, the most used is the International System (ISS), which requires two easily accessible biochemical markers and stages de disease in three categories based on beta-2 microglobulin and albumin ${ }^{4}$ (Table 2).

The use of biochemical, molecular, and genetic prognostic factors has changed radically our understanding of myeloma, and therefore, also the way we approach it from diverse points of view.

The reviewed ISS is a system that considers the ISS traditional factors and adds cytogenetic factors ${ }^{5}$. 
Table 3. Cytogenetic abnormalities and clinicla course

\begin{tabular}{|c|c|}
\hline \multirow{2}{*}{$\begin{array}{l}\text { Cytogenetic } \\
\text { abnormality }\end{array}$} & Determination of the clinical stage \\
\hline & Multiple myeloma \\
\hline Trisomies & Good prognosis, standard risk, OS 7-10 years \\
\hline$t(11: 14)(q 13 ; q 32)$ & Good prognosis, standard risk, OS 7-10 years \\
\hline t(6:14)(p21;q32) & Good prognosis, standard risk, OS 7-10 years \\
\hline t(4:14)(p16;q32) & Intermediate risk, OS 5 years \\
\hline$t(14: 16)(q 32 ; q 23)$ & $\begin{array}{l}\text { High risk, OS } 3 \text { years, relates to a high degree } \\
\text { of free light chains and initial renal failure }\end{array}$ \\
\hline$t(14: 20)(q 32 ; q 11)$ & High risk, OS 3 years \\
\hline Gain (1q21) & Intermediate risk, OS 5 years \\
\hline $\operatorname{Del}(17 p)$ & High risk, OS 3 years \\
\hline Normal & Good prognosis, OS 7-10 years \\
\hline
\end{tabular}

Modified from Rajkumar, 2016

Table 4. International Staging System (ISS)

\begin{tabular}{|c|c|c|}
\hline Stage & $\begin{array}{c}\text { Overall survival at } 5 \\
\text { years }\end{array}$ & $\begin{array}{c}\text { Progression-free survival } \\
\text { at } 5 \text { years }\end{array}$ \\
\hline ISS-R I & $82 \%$ & $55 \%$ \\
\hline ISS-R II & $62 \%$ & $36 \%$ \\
ISS-R III & $40 \%$ & $24 \%$ \\
\hline & Revised international staging system \\
\hline \multicolumn{2}{|c}{ Stage } \\
\hline \multicolumn{2}{|c}{} \\
\hline
\end{tabular}

Stage I

All the following criteria:

- Serum albumin $\geq 3.5 \mathrm{mg} / \mathrm{dL}$

- Serum beta-2 microglobulin < $3.5 \mathrm{mg} / \mathrm{dL}$;

- No high-risk cytogenetic alterations;

- Normal serum lactate dehydrogenase

Stage II

- Does not meet criteria for Stages I or III

\section{Stage III}

Both criteria:

- Serum beta-2 microglobulin $>5.5 \mathrm{mg} / \mathrm{dL}$

- High-risk cytogenetic alterations [t (4:14) or Del17p] or elevated LDH

Modified from Rajkumar, 2016

\section{Cytogenetic risk}

With the arrival of new technologies, cytogenetic alterations became more relevant in the determination of a prognosis of this disease, those techniques have already proven their usefulness for other hemopathies; hence, it
Table 5. Revised International Staging system

\begin{tabular}{|c|c|}
\hline \multicolumn{2}{|c|}{ Cytogenetic risk stratification of the mayo clinic } \\
\hline Risk group & $\%$ of de novo patients with the alteration \\
\hline Standard risk & $75 \%$ \\
\hline Trisomies & \\
\hline$t(11 ; 14)$ & \\
\hline$t(6: 14)$ & \\
\hline Intermediate risk & $10 \%$ \\
\hline$t(4: 14)$ & \\
\hline Gain (1q) & \\
\hline High risk & $15 \%$ \\
\hline$t(14: 16)$ & \\
\hline$t(14 ; 20)$ & \\
\hline $\operatorname{Del}(17 p)$ & \\
\hline
\end{tabular}

was only a matter of time to prove their use for myeloma. Initially, karyotype was the tool used for this purpose and was followed by in situ hybridization (fluorescence in situ hybridization). The panel of alterations must contain, at least, those contained in table 3.

Translocations related to chromosome 14 [t (4:14), $t$ (11:14), $t(6: 14), t(14: 16)$, and $t(14: 20)]$ result in fusion products related the immunoglobulin heavy chain, which in turn stimulate a series of oncogenes that increase the proliferative capacity of the altered clone. The deletion of the short arm of chromosome 17 (Del17p) is related to the loss of the TP53 suppressor gene ${ }^{3}$.

As mentioned before, a combination of clinical, biochemical, and cytogenetic factors increases the predictive capacity and overall prognosis of these factors, giving place to the ISS revised scheme (Table 4), which is independent from the patient's age and the therapy received previously, providing a better prognostic information with respect to the ISS. The Mayo Clinic has also developed a cytogenetic staging scale that guides us on the prognosis of the newly diagnosed patients (Table 5).

\section{Module 4}

\section{Treatment}

MM treatment has radically changed in the past 10 years. The inclusion of new agents and combinations has allowed physicians to design treatments according 
to each patient's characteristics and needs; however, the large amount of generated information requires a precise and objective analysis to make decisions in each case. There are several international guidelines which have been developed and updated during the last decade, containing very valuable information, since they provide objective guidance for clinicians in their daily work for a MM patient.

Objectively, we have divided the different therapeutic options by grouping the patients based on: age, physical status, cytogenetic risk, and treatment lines received, to facilitate the making of decisions.

\section{First-line treatment for patients younger than 65 years, good physical performance (fit) and/or candidates for HSC transplantation, standard risk}

This group of patients represents a large proportion in medical centers where the diagnostic approach protocol is carried out, while there is a low percentage in reference centers. First-line treatment for these patients must be directed to reach the best possible response before the hematopoietic stem cell transplant (HSCT), this is done through the combination of agents with different mechanisms of action to ensure the coverage of diverse pathological points of the disease, to generate a deep response.

Several studies have shown that a combination of three drugs with different mechanisms of action reaches this goal. In a meta-analysis published by the Brazilian group, in which the treatments available in the scientific literature were stratified, from 2006 to 2016, grouping them into those based in anthracyclines, PI, and IMiD, it was found that those with better response rates were those including IMiD and PIs, and in the last place, those based on anthracyclines. Safety profiles by chosen combination may guide each treatment according to each patient's comorbidities'.

European and American guidelines reproduce the indication of combining three drugs for this specific group, including regimes with $\mathrm{PI}, \mathrm{IMiD}$, and chemotherapy combinations, issuing special considerations for specific groups which will be discussed in other sections. Based on these recommendations, the following guidelines are determined:

- In patients younger than 65, good performance status, and candidates to HSCT, treatment should be initiated with three-drug schemes, including at least one $\mathrm{PI} / \mathrm{IMiD}$, possible combinations are summarized in figure 1 and 2.
- After four cycles the disease response should be determined, following the criteria mentioned in the "Response criteria" section.

- Follow guidelines presented in section "HSC autologous transplantation" to request its inclusion in the waiting list for the transplantation program.

- Residual minimal disease has an added value for clinicians in the decision-making regarding the number of cycles de patient must receive.

Follow-up in these patients will be done according to guidelines presented in the "Response criteria and follow-up" section.

At present, there are studies that have analyzed the efficacy of thalidomide containing schemes versus those with cyclophosphamide, showing higher complete response (CR) and strict $\mathrm{CR}$ ( $\mathrm{SCR}$ ) rates for the schemes including thalidomide. However, the high incidence of neurologic and thrombotic adverse events when compared to cyclophosphamide, must be considered before indicating it ${ }^{2}$. Special regimes should also be considered for this group of patients, such as those with PI contraindications, in which schemes such as lenalidomide-dexamethasone may be used with good response rates compared to traditionally used schemes, such as melphalan or thalidomide. Schemes used by international consensus for patients requiring intensive chemotherapy (plasma cells leukemia or extramedullary disease) recommend VTD-PACE as an option (bortezomib, dexamethasone, thalidomide, cisplatin, doxorubicin, cyclophosphamide, and etoposide), however, and due to the high toxicity related to treatment with this scheme, the case of the patient should be discussed and assessed thoroughly before deciding in favor of this therapeutic option ${ }^{3}$.

\section{Patients over 65 years or in poor physical condition, not candidates for HSCT}

Frailty scales have made it possible to unify criteria for the selection of patients who are not transplant candidates. The use of new agents and combinations should be considered in this group of patients, since they have shown an increase in survival, with deeper responses and a better quality of life.

For this reason, in patients who are not HSCT candidates, because of their age or a bad performance status, the following should be considered:

- Use combinations including a PI and an IMiD for at least eight cycles of the selected scheme, the possible combinations are summarized in figure 3 .

- Perform disease assessments following guidelines in section "Response criteria." 


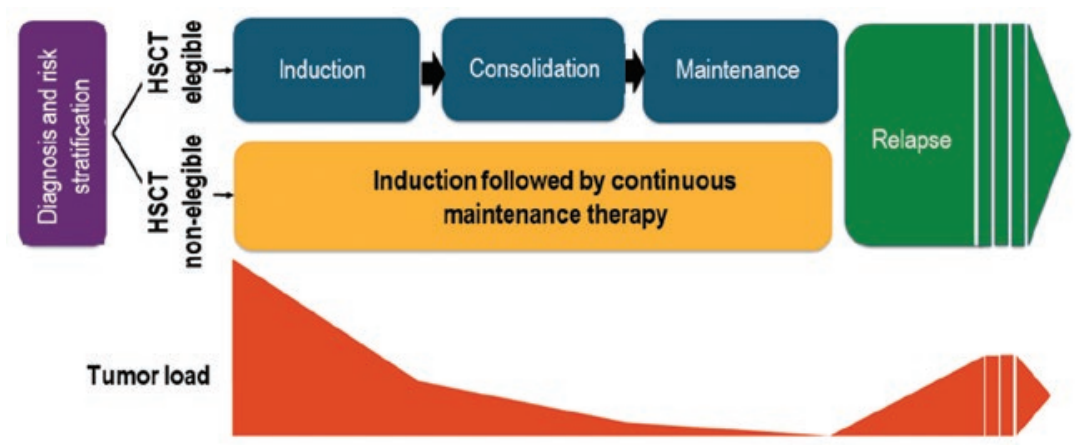

Figure 1. Modified from Shaji Kumar. Ideal treatment scheme for multiple myeloma patients, according to the transplantation eligibility.

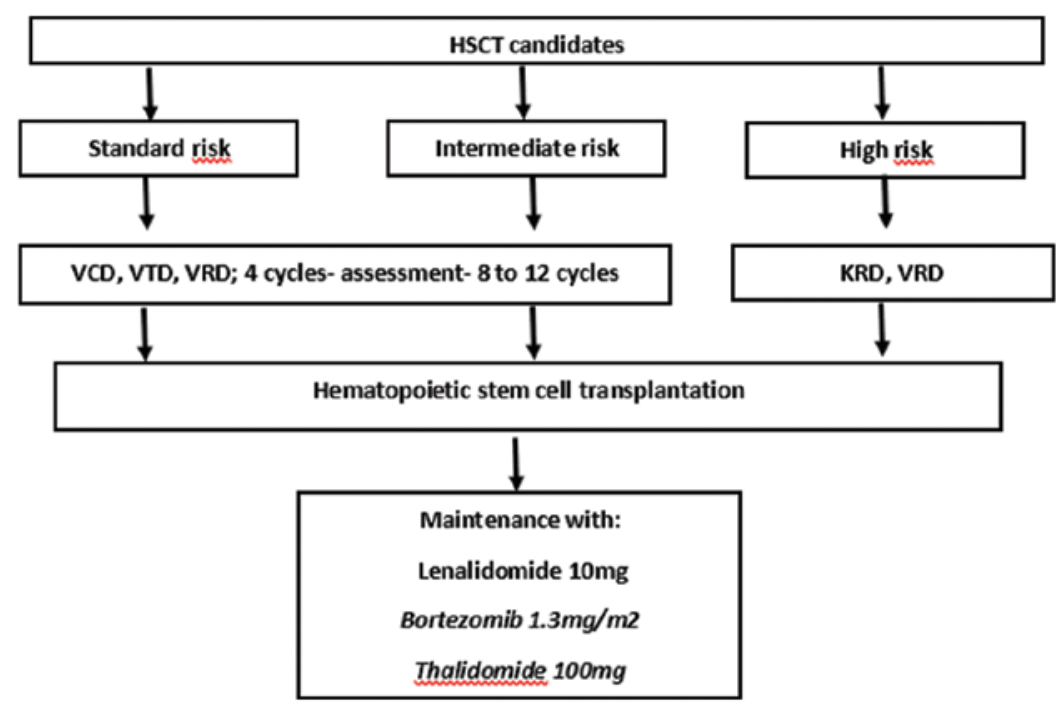

Figure 2. Treatment algorithm for tansplant elegible patients. Adapted from Dingli, et al., $2017^{4}$.

- After finishing the minimum cycles according to the chosen scheme, continue with the maintenance.

In the same way, as in those candidates for HSCT, the use of alternative schemes can be considered in special cases, such as intolerance to IMiDs or PIs, previous neuropathy, or contraindication by any of the other consultation support services (e.g., heart disease, severe kidney disease, and dementia). In these cases, the use of two-drug regimens will be considered, according to the profile of each patient (Table 1 and 2).

\section{Second-line treatment and progression in candidates and non-candidates to HSCT}

Managing relapses in these patients involve a deeper analysis of the disease, the patient, and the response to previous treatment or treatments. This is the section where factors related to poor prognosis take on greater importance, since they will determine, to a certain extent, which therapy we should choose for our patient. It is worth mentioning that a basic goal of the relapse treatment is to achieve the best possible response, whether or not the patient is a transplant candidate.

Choosing a treatment regimen for a relapse is complicated, since many factors must be assessed, such as: time to relapse, response and depth of response reached with the previous therapy, relapseaggressiveness, and physical performance. For this reason, the selection of a rescue scheme in relapsed patients is crucial since it will impact on the progression-free period, considering that the duration of the responses in subsequent remissions will be less than the first response achieved ${ }^{4}$.

Progression should be treated as soon as identified; table 3 shows the criteria requiring treatment for the patient. 


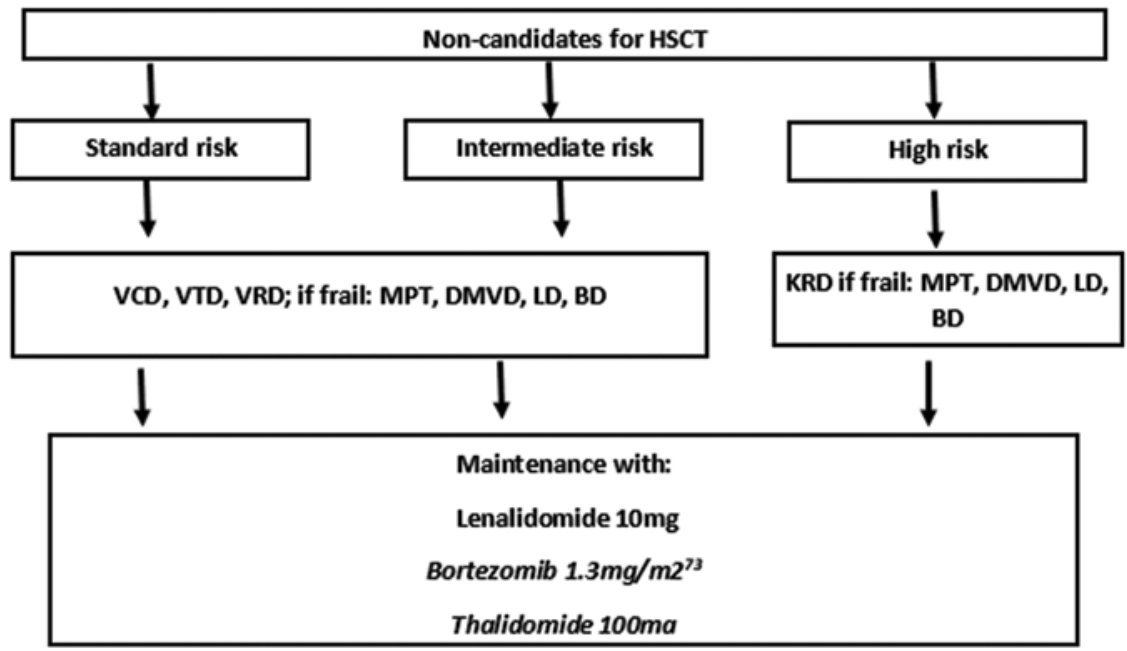

Figure 3. Treatment algorithm for non-elegible tansplant patients.

Adapted from Dingli, et al., $2017^{4}$.

Table 1. Routes of administration, dosage, adverse events, and special considerations for proteasome inhibitors

\begin{tabular}{|c|c|c|c|}
\hline & Bortezomib & Carfilzomib & Ixazomib \\
\hline Route of administration & SC & IV & PO \\
\hline Doses and schemes & $\begin{array}{l}1.3 \mathrm{mg} / \mathrm{m}^{2} \text { on days } 1,4,8, \\
\text { and } 11 \\
28 \text { days cycles }\end{array}$ & $\begin{array}{l}20 / 27 \mathrm{mg} / \mathrm{m}^{2} \text { on days } 1,2,8,9,15,16 \text {, or } \\
20 / 70 \mathrm{mg} / \mathrm{m}^{2} \text { weekly for } 3 \text { weeks } \\
28 \text { days cycles }\end{array}$ & $\begin{array}{l}4 \mathrm{mg} \text { on days } 1,8 \text {, and } 15 \\
28 \text { days cycles }\end{array}$ \\
\hline $\begin{array}{l}\text { Adverse events to be } \\
\text { followed }\end{array}$ & $\begin{array}{l}\text { - Peripheral neuropathy } \\
\text { - Hypotension } \\
\text { - Cardiotoxicity } \\
\text { - Lung toxicity } \\
\text { - Gl toxicity } \\
\text { - Thrombocytopenia } \\
\text { - Neutropenia }\end{array}$ & $\begin{array}{l}\text { - Cardiac failure } \\
\text { - Renal failure } \\
\text { - Lung toxicity and dyspnea } \\
\text { - Hypertension } \\
\text { - Venous thrombosis } \\
\text { - Bleeding } \\
\text { - Thrombocytopenia } \\
\text { - Liver toxicity }\end{array}$ & $\begin{array}{l}\text { - Thrombocytopenia } \\
\text { - Gl toxicity } \\
\text { - Peripheral neuropathy } \\
\text { - Rash } \\
\text { - Liver toxicity }\end{array}$ \\
\hline $\begin{array}{l}\text { Management } \\
\text { considerations }\end{array}$ & $\begin{array}{l}\text { Monitor platelet count, safe } \\
\text { in } \mathrm{Rl}\end{array}$ & Watch cardiac and renal function & $\begin{array}{l}\text { Reduce dose in case of renal } \\
\text { failure }\end{array}$ \\
\hline
\end{tabular}

Table 2. Routes of administration, doses, adverse events, and special considerations of IMiD

\begin{tabular}{|c|c|c|c|}
\hline & Lenalidomide & Pomalidomide & Thalidomide \\
\hline Route of administration & $\mathrm{PO}$ & PO & $\mathrm{PO}$ \\
\hline Doses and schemes & $\begin{array}{l}25 \mathrm{mg} / \text { day for } 21 \text { days and } 1 \text { week off } \\
\text { (induction) } \\
10 \mathrm{mg} / \text { day for maintenance }\end{array}$ & $4 \mathrm{mg} /$ day 21 days and 1 week off & 200 mg daily \\
\hline $\begin{array}{l}\text { Adverse events to be } \\
\text { followed }\end{array}$ & $\begin{array}{l}\text { - Venous thromboembolism } \\
\text { - Thrombocytopenia } \\
\text { - Neutropenia } \\
\text { - Fatigue } \\
\text { - Rash } \\
\text { - Poor HSC mobilization } \\
\text { - Second neoplasms }\end{array}$ & $\begin{array}{l}\text { - Venous thromboembolism } \\
\text { - Neutropenia } \\
\text { - Fatigue } \\
\text { - Liver toxicity } \\
\text { - Rash }\end{array}$ & $\begin{array}{l}\text { - Venous thromboembolism } \\
\text { - Constipation } \\
\text { - Peripheral neuropathy } \\
\text { - Orthostatic hypotension } \\
\text { - Rash } \\
\text { - Bradycardia } \\
\text { - Somnolence }\end{array}$ \\
\hline $\begin{array}{l}\text { Management } \\
\text { considerations }\end{array}$ & \multicolumn{3}{|c|}{$\begin{array}{l}\text { Watch the renal function (dose adjustment in treatment with lenalidomide). } \\
\text { Prophylaxis for thrombosis according to individual risk factors or myeloma related factors. } \\
\text { ASA (81-325 mg/day) or LMWH (enoxaparin } 40 \text { mg/day) o warfarin (INR: 2-3). }\end{array}$} \\
\hline
\end{tabular}


Table 3. IMGW criteria for MM progression

\begin{tabular}{|c|c|c|}
\hline \multicolumn{3}{|c|}{ IMWG criteria for MM progression } \\
\hline \multicolumn{2}{|c|}{ Non-aggressive relapse } & Aggressive relapse \\
\hline Biochemical & Clinical & Adverse cytogenetic abnormalities: $t(4: 14)$, del (17p) \\
\hline M protein increase & Mild symptoms and mild $\mathrm{M}$ protein increase & $\begin{array}{l}\text { B2MG elevation or albumin decrease, extramedullary disease, LDH } \\
\text { increase }\end{array}$ \\
\hline \multirow[t]{4}{*}{ Asymptomatic } & Relevant organic involvement & Short duration of achieved response \\
\hline & & Aggressive clinical presentation \\
\hline & & Circulating PCs \\
\hline & & Change of the immunoglobulin clone or isotype or light chain \\
\hline
\end{tabular}

Modified from Sonneveld et al. 2017.

Table 4. Clinical trials with schemes based on lenalidomide for patients with relapsed/refractory MM

\begin{tabular}{|c|c|c|c|c|}
\hline Treatment & $\begin{array}{c}\text { Response } \\
\text { rates \% }\end{array}$ & $\begin{array}{l}\mathrm{RC} \\
\%\end{array}$ & $\begin{array}{c}\text { PFS } \\
\text { meses }\end{array}$ & $\begin{array}{c}\text { SG } \\
\text { meses }\end{array}$ \\
\hline $\begin{array}{l}\text { ENDEAVOR } \\
\text { Kd vs. Vd } \\
\text { Dimopoulos, et } \\
\text { al., } 2016^{7}\end{array}$ & 77 vs. 63 & 13 vs. 6 & $\begin{array}{l}18.7 \text { vs. } 9.4 \\
\text { HR: } 0.53\end{array}$ & $\begin{array}{l}\text { NA vs. } 24.3 \\
\text { HR: } 0.79\end{array}$ \\
\hline $\begin{array}{l}\text { CASTOR } \\
\text { DVd vs. Vd } \\
\text { Palumbo, et al., } \\
2016^{9}\end{array}$ & 84 vs. 63 & 29 vs. 10 & $\begin{array}{l}16.7 \text { vs. } 7.1 \\
\text { HR: } 0.31\end{array}$ & $\begin{array}{l}\text { NA } \\
\text { HR: } 0.63\end{array}$ \\
\hline
\end{tabular}

Table 5. Clinical trials with schemes based on lenalidomide for patients with relapsed/refractory MM

\begin{tabular}{|c|c|c|c|}
\hline Treatment & $\begin{array}{c}\text { Response } \\
\text { rates \% }\end{array}$ & $\begin{array}{c}\text { PFS } \\
\text { months }\end{array}$ & $\begin{array}{c}\text { SG } \\
\text { months }\end{array}$ \\
\hline $\begin{array}{l}\text { Pom/Dex } \\
(n=302) \\
\text { Richardson, et al., } 2014^{10}\end{array}$ & 31 vs. 10 & 4.0 vs. 1.9 & 12.7 vs. 8.1 \\
\hline $\begin{array}{l}\text { Bortezomib + Pom/Dex } \\
(n=559) \\
\text { Richardson, et al., } 2019^{11}\end{array}$ & 82 vs. 50 & 11 vs. 7 & NA \\
\hline $\begin{array}{l}\text { Carfilzomib + Pom/Dex } \\
(n=57) \\
\text { Shah, et al., } 2015^{12}\end{array}$ & 62 & 10.3 & $\begin{array}{l}\text { NA (1 año: } \\
67 \%)\end{array}$ \\
\hline $\begin{array}{l}\text { Daratumumab + Pom/Dex } \\
(n=103) \\
\text { Chari, et al., } 2017^{13}\end{array}$ & 60 & 8.8 & 17.5 \\
\hline $\begin{array}{l}\text { Ixazomib + Pom/Dex } \\
(n=32) \\
\text { Krishnan, et al., } 2018^{14}\end{array}$ & $48-58$ & & \\
\hline $\begin{array}{l}\text { PFS: progression-free survival; SG: gl } \\
\text { Dexametasona. } \\
\text { Modified from Richardson PG et al. }{ }^{11} \\
2018^{15}\end{array}$ & $\begin{array}{l}\text { al survival; NA:; } \\
\text { Shah JJ. et al. }{ }^{13} \text {, }\end{array}$ & Pom/Dex: Poma & $\begin{array}{l}\text { domida/ } \\
\text { rishnan, et al. }\end{array}$ \\
\hline
\end{tabular}

It is adequate to consider the following to start a treatment:

1. Characteristics of the patient in relapse: the physical performance of the patient must be taken into account, as well as his eligibility for a HSCT. In frail and elderly patients, the schemes will target not only the best possible response but also the least possible toxicity (ref relapse blood). The usable combinations for this group of patients can be those that include PI, IMiD, and alkylating agents, such as melphalan. The IWMG suggests that schemes with known toxicity are to be used with less possible impact (ref IWMG relapse). In patients in good condition their wishes and needs in other areas of life should be taken into account, that is, if the patient is able to go to receive their established intravenous therapy or he/she prefers or needs an oral scheme, always bearing in mind the achievement of the deepest response.

2. Disease characteristics: known risk factors for relapse and poor response to treatment are relevant. Alterations such as del17p could have been absent at the time of diagnosis and could be identified in the evaluation of progression, in the same way; there are patients with standard risk at diagnosis who relapse with high-risk characteristics. (Ref 17 IWMG relapse) It was until recently that value was given to these factors for decision-making; in this way, the use of more aggressive schemes is currently preferred, for those who tolerate it, when one of these data is present; the combination of three drugs, including second generation Pls and second generation IMiDs, is preferred over retreatment with the previous scheme based on the observation of 


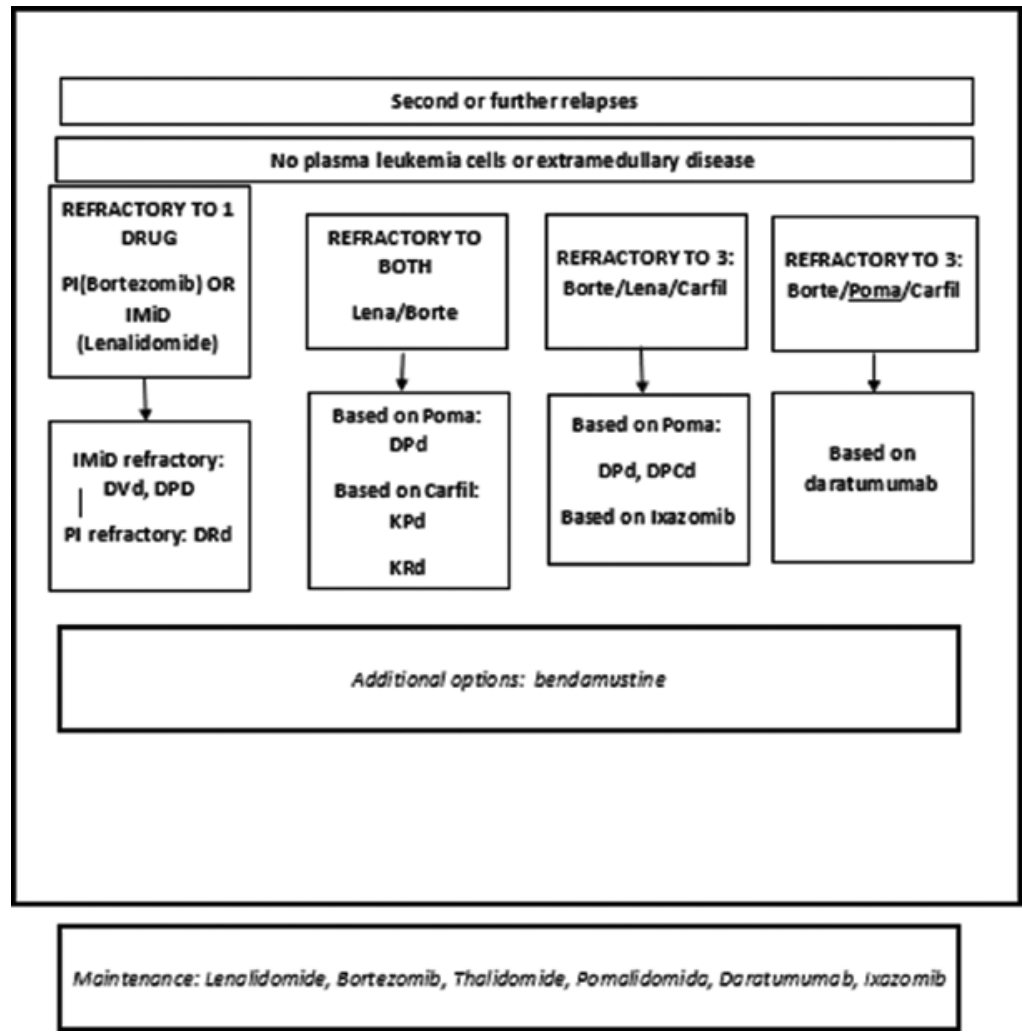

Figure 4. Schemes recommended for relapsed/refractory patients.

Modified from Stewart AK. ${ }^{7}$, Palumbo A et al. ${ }^{9}$

several phase two studies, in which regimens based on carfilzomib, lenalidomide, or other novel agents were administered to patients with these characteristics.

3. Characteristics of the previous response: retreatment with the previous scheme can be considered as long as the previous response had been a partial response with a duration of at least 18 months, or a free treatment interval of 6-9 months, taking into consideration adverse effects and toxicities secondary to treatment. If the progression occurred during treatment or with duration of $<6$ months, the patient should be considered as a high-risk patient and treated according to such group. (ref IWMG relapse) In those cases, where a deep response is not achieved during retreatment, one of the agents used can be titrated before deciding on a complete combination change.

4. Transplant eligibility: those patients who have not undergone HSCT should be treated in seek of a deep response to be brought to this procedure, based on a combination of three drugs. In general, a second treatment scheme and a second transplant are considered in those who have previously undergone one, and who have had a progression-free survival (PFS) of 18-24 months or more. If patients have not received a consolidation scheme after the first transplantation, it should be considered after the second transplant $^{5}$.

\section{Third and further lines}

As treatment lines increase, the chances of response decrease by an average of $5 \%$ for each scheme.

Schemes for the third line or later should take into account the same characteristics that were taken in the previous relapse, considering the physical performance of the patient at the second- or third-line of treatment, since they may have had significant deterioration and probably need the support from other areas such as geriatrics, pain management, and palliative care.

Most patients in these circumstances are receiving maintenance therapy at the time of relapse, either based on PIs or IMiDs; therefore, the recommendation for them is the initiation of combinations that include at least one drug that has not been previously used. 
Table 1. Response evaluation tests at the induction ${ }^{1}$

\begin{tabular}{|c|c|c|c|}
\hline Test & Monthly & Quarterly & Biannual \\
\hline Complete blood count & + & + & + \\
\hline Biochemistry, including calcium, creatinine, total proteins: albumin, globulin & + & + & + \\
\hline Lactate dehydrogenase & + & + & + \\
\hline Serum proteins electrophoresis & & + & + \\
\hline $24 \mathrm{~h}$ urine collection for protein electrophoresis & & + & + \\
\hline Immunoglobulins quantification (Nephelometry) & & + & + \\
\hline Serum and urine immunofixation & & + & + \\
\hline Serum light chains measurement & & + & + \\
\hline Bone radiologic study including spine, pelvis, and skull & & & + \\
\hline Bone marrow aspirate and/or biopsy; morphology and immunophenotype & & & + \\
\hline \multicolumn{4}{|c|}{$\begin{array}{l}\text { Cytogenetic of bone marrow plasma cells (metaphase karyotype and fluorescence in situ hybridization) } \\
\text { * biannual * }\end{array}$} \\
\hline $\begin{array}{l}\text { Bone scan, CAT, or magnetic resonance if clinically indicated, as in the case of } \\
\text { plasmacytoma at diagnosis. }\end{array}$ & & & + \\
\hline
\end{tabular}

FISH: fluorescent in situ hybridization; CT: computed tomography; MRI: magnetic resonance; PET-CT: positron emission tomography-computed tomography. Adapted from Rajkumar, et al., $2014^{1}$

Second-generation PI Carfilzomib has shown a good safety and efficacy profile, in a Phase II trial, in patients relapsed or refractory to bortezomib and/ or lenalidomide, with ORRs of $50 \%$ and OS at 12 months of $60 \%$, with an acceptable safety profiles, at least for patients with a good performance status ${ }^{6}$ (Table 4).

Daratumumab, a monoclonal antibody, was initially used in relapsed patients with multiple prior treatment lines in combination with dexamethasone, with ORRs of up to $26 \%$. After that, it has shown improvement of such response rates when combined with bortezomib or lenalidomide plus dexamethasone, with ORRs of up to $93 \%$. The safety profile of this drug is acceptable, despite the high rate of infusion related reactions, of reactions related to the infusion, which are manageable; it is considered a good option in cases of $\mathrm{OI}$ or IMiD refractoriness (ref castor and pollux $)^{8,9}$.

Pomalidomide, a third-generation IMiD, indicated in lenalidomide refractory patients, has shown to be effective, both in patients with a good performance status, and in frail patients ${ }^{10}$. The dosage turns this into a good option for patients who may not or do not want to be submitted to the administration of intravenous or subcutaneous drugs (Table 5$)^{10}$.
In Figure 4 are summarized therapeutic schemes for relapse/refractory patients.

\begin{tabular}{lllll|}
\hline Treatment & Response rates $\%$ & $\begin{array}{l}\text { CR } \\
\%\end{array}$ & $\begin{array}{l}\text { PFS } \\
\text { Months }\end{array}$ & $\begin{array}{l}\text { OS } \\
\text { Months }\end{array}$ \\
\hline $\begin{array}{l}\text { ASPIRE } \\
\text { KRd vs Rd }\end{array}$ & 87 vs 67 & 32 vs 9 & $\begin{array}{l}26.3 \text { vs } 16.6 \\
\text { HR: } 0.69\end{array}$ & $\begin{array}{l}48.3 \text { vs } 40.4 \\
\text { HR: } 0.79\end{array}$ \\
$\begin{array}{l}\text { TOURMALINE } \\
\text { lxaRd vs Rd }\end{array}$ & 78 vs 72 & 14 vs 7 & $\begin{array}{l}20.6 \text { vs } 14.7 \\
\text { HR: } 0.74\end{array}$ & NA \\
$\begin{array}{l}\text { POLLUX } \\
\text { DRd vs Rd:0 }\end{array}$ & 93 vs 76 & & $\begin{array}{l}44.5 \text { vs } 17.5 \\
\text { HR: } 0.44\end{array}$ & $\begin{array}{l}\text { NA vs NA } \\
\text { HR } 0.63\end{array}$ \\
\hline
\end{tabular}

\section{Module 5}

\section{Response criteria in MM}

Disease evaluation is key at the time of establishing the diagnosis, at the third cycle, and at the end of the protocol, with evidence of the prognostic value shown by the PETHEMA-GEM group. Ideally, for such evaluation, the studies included in the following table 1 should be performed, comparatively with the Baseline.

Table 2 summarized International IMWG criteria for response.

It is worth mentioning that any response must be maintained by 6 months at least. A monthly disease follow-up during therapy is suggested, along with the performance of a complete blood count, calcium, and total proteins. The quantification of monoclonal proteins in serum and urine must be performed 


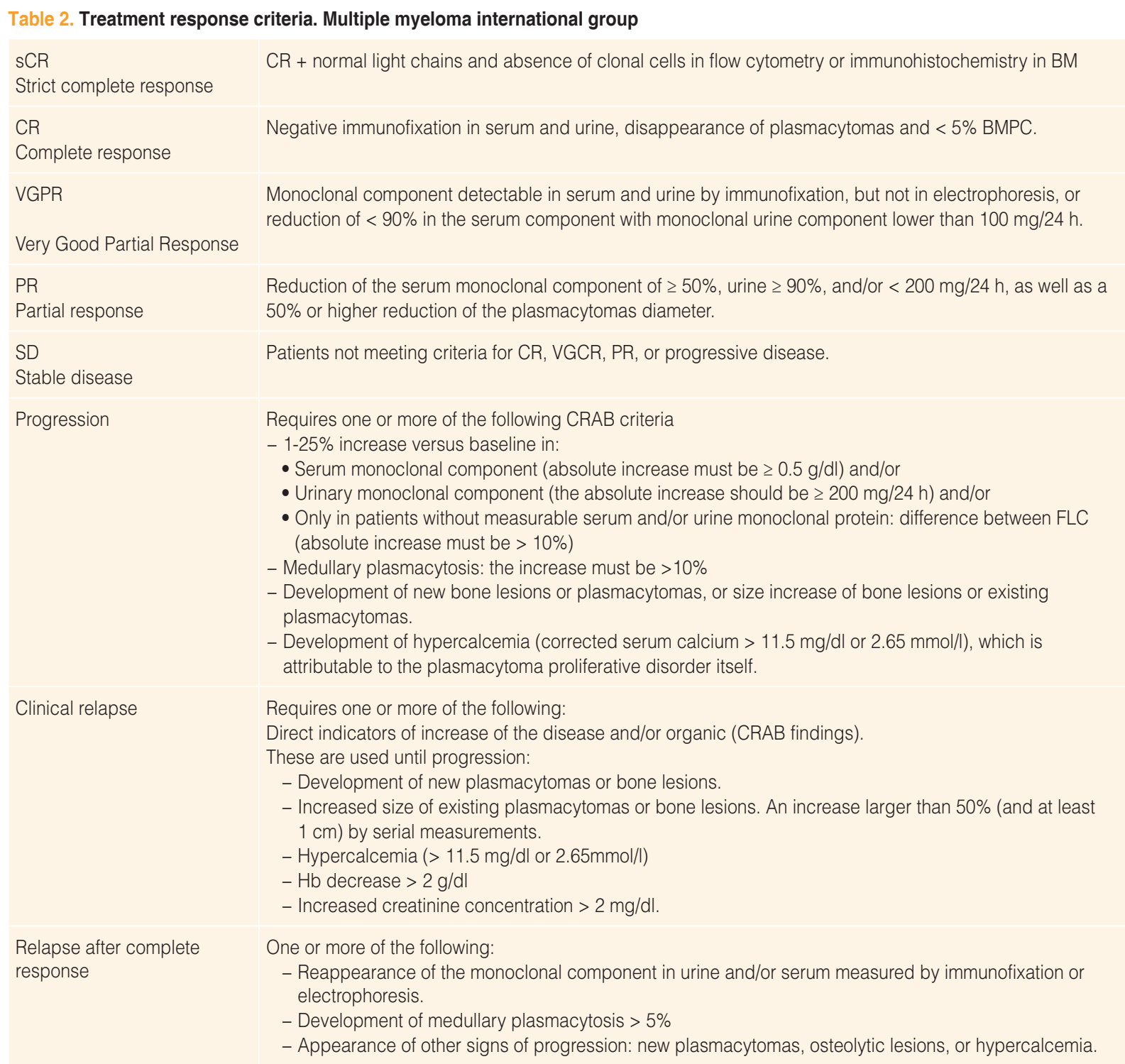

systematically every 3 months. In patients with heavy chains myeloma the follow-up will be done by electrophoresis in urine and/or serum².

It is possible to issue recommendations for specific myeloma forms. In patients with heavy chains of IgA isotype with an M spike in serum, electrophoretic migration in the beta region, other serum proteins may confound the precise evaluation of the monoclonal component. In those cases, a total IgA by nephelometry has been a useful tool for the quantitative follow-up. Appearance of specific antibodies against IgA-kappa and IgA-lambda may also be used to distinguish between monoclonal and polyclonal $\lg \mathrm{A}$, which allows a more precise assessment. When a patient only has a monoclonal light chain with serum monoclonal protein, but the IFE is negative for $\operatorname{Ig} G, \lg A$ or $\operatorname{Ig} M$, the possibility of a monoclonal IgD must be considered. IgD serum quantification and electrophoresis in $24 \mathrm{~h}$ urine in patients with $\operatorname{lgD}$ myeloma are required. In cases of oligosecretory myeloma, the serum $\mathrm{M}$ component below $10 \mathrm{~g} / \mathrm{l}$ and a urine component below 200 $\mathrm{mg} / 24 \mathrm{~h}$ have been established as diagnostic criteria $^{3,4}$.

In patients with suspicion of relapse treatment should be initiated, only if there are certain clinical or biochemical criteria for relapse. 
Table 1. Common phenotype of normal plasma cells

\begin{tabular}{l|c|}
\hline Marker & Expression \\
CD38 & ++ \\
CD138 & + \\
CD19 & + \\
CD45 & + \\
CD56 & - \\
cylgk/cylgh & Polyclonal \\
$\beta 2$ microglobulin & + \\
CD81 & + \\
CD117 & - \\
CD27 & + \\
CD28 & + \\
\hline
\end{tabular}

+: positive expression, ++: intense positive expression, -: negative expression

\section{Module 6}

\section{Usefulness of the flow cytometry in the MM diagnosis}

Due to the subjectivity of the morphology and its impossibility to demonstrate clonality, the evolution of flow cytometry has positioned itself in the comprehensive clinical management of $\mathrm{MM}$ and other plasma cells alterations both, in a sensitive and specific way, with the aim of characterizing plasma cells, differentiating normal phenotypes (Table 1) from aberrant ones through antibodies panels that have been standardized, allowing the comparison among different diagnostic centers, unifying the information given to

Table 2. EuroFlow panel for plasma cells diagnosis ${ }^{2}$

\begin{tabular}{l|c|c|c|c|c|c|c|c|}
\hline \multirow{2}{*}{ Tubes } & \multicolumn{7}{c|}{ Markers and fluorochromes } \\
\cline { 2 - 11 } & PacB & Pac0 & FITC & PE & PerCP Cy 5.5 & PECy7 & APC & APC-H7 \\
\hline Tube 1 Diagnosis and clonality & CD45 & CD138 & CD38 & CD56 & $\beta 2$ micro & CD19 & cylgk & cylgk \\
\hline Tube 2 Prognosis & CD45 & CD138 & CD38 & CD28 & CD27 & CD19 & CD117 & CD81
\end{tabular}

PacO: pacific orange, PacO: pacific blue, PE: phycoerythrin, PECy7: phycoerythrin cyanin 7, PerCPCy5.5: peridinin chlorophyll-protein-cyanin5.5, APC: allophycocyanin,

FITC: fluorescein isothiocyanate; APC-H7: allophycocyanin H7.

Table 3. EuroFlow panel for MRD monitoring ${ }^{3}$

\begin{tabular}{|l|l|l|l|l|l|l|l|l|}
\hline \multirow{2}{*}{ Tubes } & \multicolumn{7}{|c|}{ Markers and fluorochromes } \\
\cline { 2 - 10 } & BV421 & BV510 & FITC & PE & PerCP Cy 5.5 & PECy7 & APC & APC-H7 \\
\hline Tube 1 & CD138 & CD27 & CD38* & CD56 & CD45 & CD19 & CD117 & CD81 \\
\hline Tube 2 & CD138 & CD27 & CD38* & CD56 & CD45 & CD19 & cylgk & cylgк \\
\hline
\end{tabular}

BV421: brilliant violet 421, BV510: brilliant violet 510, PE: phycoerythrin, PECy7, phycocyanin cyanin 7, PerCPCy5.5, peridinin chlorophyll-protein-cyanin5.5, APC, allophycocyanin, FITC, fluorescein isothiocyanate, APC-H7, allophycocyanin $\mathrm{H7}$. ${ }^{*}$ Optional change to CD38-multiepitope in patients with anti-CD38 therapy.

Table 4. Usefulness of plasma cells' markers²

\begin{tabular}{|c|c|c|c|c|}
\hline TUBE & Antigen & Plasma cells identification & Aberrant markers & Clonality identification \\
\hline Common markers & $\begin{array}{l}\text { CD38 } \\
\text { CD138 } \\
\text { CD19 } \\
\text { CD45 }\end{array}$ & $\begin{array}{l}X \\
X \\
X \\
X\end{array}$ & $\begin{array}{l}C \\
C \\
C\end{array}$ & \\
\hline Tube 1 & $\begin{array}{l}\text { cylgh } \\
\text { cylgк } \\
\text { CD56 } \\
\beta 2 \text { Micro }\end{array}$ & & $\begin{array}{l}C \\
P \\
P\end{array}$ & $\begin{array}{l}X \\
X\end{array}$ \\
\hline Tube 2 & $\begin{array}{l}\text { CD27 } \\
\text { CD28 } \\
\text { CD117 } \\
\text { CD81 }\end{array}$ & & $\begin{array}{l}P \\
P \\
P \\
P\end{array}$ & \\
\hline
\end{tabular}


the treating physician 1 . The only standardized strategy is that designed by the EuroFlow consortium, which published the panels for diagnosis and prognosis (Table 2), and the monitoring of the minimal residual disease (MRD) (Table 3).

To differentiate the phenotypic alterations in aberrant plasma cells, it is essential to know the antigenic use it defines, which is described in table 4.

Specifications recommended by the NCCN of 2019 to perform a new generation cytometry (NGF) in the MRD monitoring, are the following:

1) Sensitivity: 1 in 100,000 events $\left(10^{-5}\right)$, acquisition of 10 million cells $\left(10^{7}\right)$ at least.

2) The use of operating procedures standardized by EuroFlow for MRD in $\mathrm{MM}^{3,4}$.

Regarding the monitoring specifications for the MRD in MM, according to the experts meeting in 2018, it is recommended to perform this in all patients reaching a CR or a VGPR, according to the International Workgroup of Myeloma (IWGM) criteria ${ }^{5}$.

\section{Module 7}

\section{Hematopoietic stem cell transplantation in MM}

MM is an incurable disease that makes up $10-13 \%$ of hematological neoplasms, the median age at diagnosis is $65-70$ years. Thirty years after the work of Powles, Barlogie, and McElwain, it led to the beginning of the concept of high-dose therapy (HDT), followed by an autologous HSC transplantation (AHSCT). Transplantation remains the standard for the treatment of newly diagnosed MM (NDMM) in young and elderly patients with an adequate performance. The superiority of the procedure was initially approved by the Intergroupe Francophone du Myelome (IFM) and then confirmed by the UK Medical Research Council. Despite its significant and confirmed impact on event-free survival (EFS), several trials failed to show a significant impact on OS. Although it is considered a standard therapy, the procedure is still challenged by inevitable relapses that threaten prolonged remissions. ${ }^{1}$.

Early AHSCT has been shown to be superior to the latter option (in terms of relapse), even in the era of new agents. A meta-analysis, where 3829 patients with de novo MM who received high doses of chemotherapy with an early AHSCT compared to standard chemotherapy or late transplantation were analyzed, the results were favorable for early transplantation regarding progression-free survival with hazard ratio (HR) 0.73 (95\% 0.56-0.94), although this difference was not observed in OS with an HR 0.86 (95\% confidence intervals [Cl] 0.70-1.04)'.

Transplant-related mortality (TRM) with AHSCT is very low (1-2\%), median PFS is $50-56$ months and the expected median SG is 8-10 years. Through a multivariate analysis it was observed that the SCR is an independent predictor for better survivals, HR 0.44 (95\% $0.25-0.80)^{2}$.

\section{AHSCT indications in MM}

AHSCT in MM remains the consolidation treatment of choice in eligible patients. Since the 90's, better ORRs have been shown, further deepening the RC rate by $15-20 \%$. In addition, better rates of OS and PFS have been achieved in patients undergoing HSCT. In subsequent studies, the greatest benefit of transplantation has been observed in terms of PFS, being more inconsistent in demonstrating this same benefit in terms of SG (Figure 1).

This benefit had been demonstrated with induction schemes based on cytotoxic chemotherapy; however, there was not a clear benefit in the era of novel therapies (IMiDs, Pls, etc.) with which the best global outcomes were achieved'. Phase III CT results have been published recently, which assessed the benefit of a HSCT in the current therapy scenario (RVD vs. RVD-HSCT), demonstrating a PFS benefit in patients undergoing a HSCT (50 vs. 36 months; $p<0.001$ ) in all patient subgroups. Likewise, a better CR was observed (59\% vs. $48 \% ; p=0.03)$ and MRD negativization (79\% vs. $65 \%$, $\mathrm{p}<0.001$ ), with no impact on 4-year OS or TRM ${ }^{3}$.

\section{Eligibility}

There is no consensus on an age limit beyond which a HSCT treatment is questionable, and, as such, this practice varies by institution and country.

Advanced age is no longer an exclusion criterion for determining transplant eligibility. In a Phase II trial, there was no difference in TRM in patients of 60-65 years versus 65-70 years, with a low TRM rate in the two cohorts $(<1 \%)^{4}$.

A previous study, in which the median age of the patients was 72 years, concluded that elderly MM patients should not be excluded from transplantation, showing good results with melphalan $140 \mathrm{mg} / \mathrm{m}^{2}$.

In a consensus made by the Mayo Clinic, they recommended that, in contrast to strict chronological age limits for eligibility for HSCT, the functional status and comorbidities should be considered for eligibility 


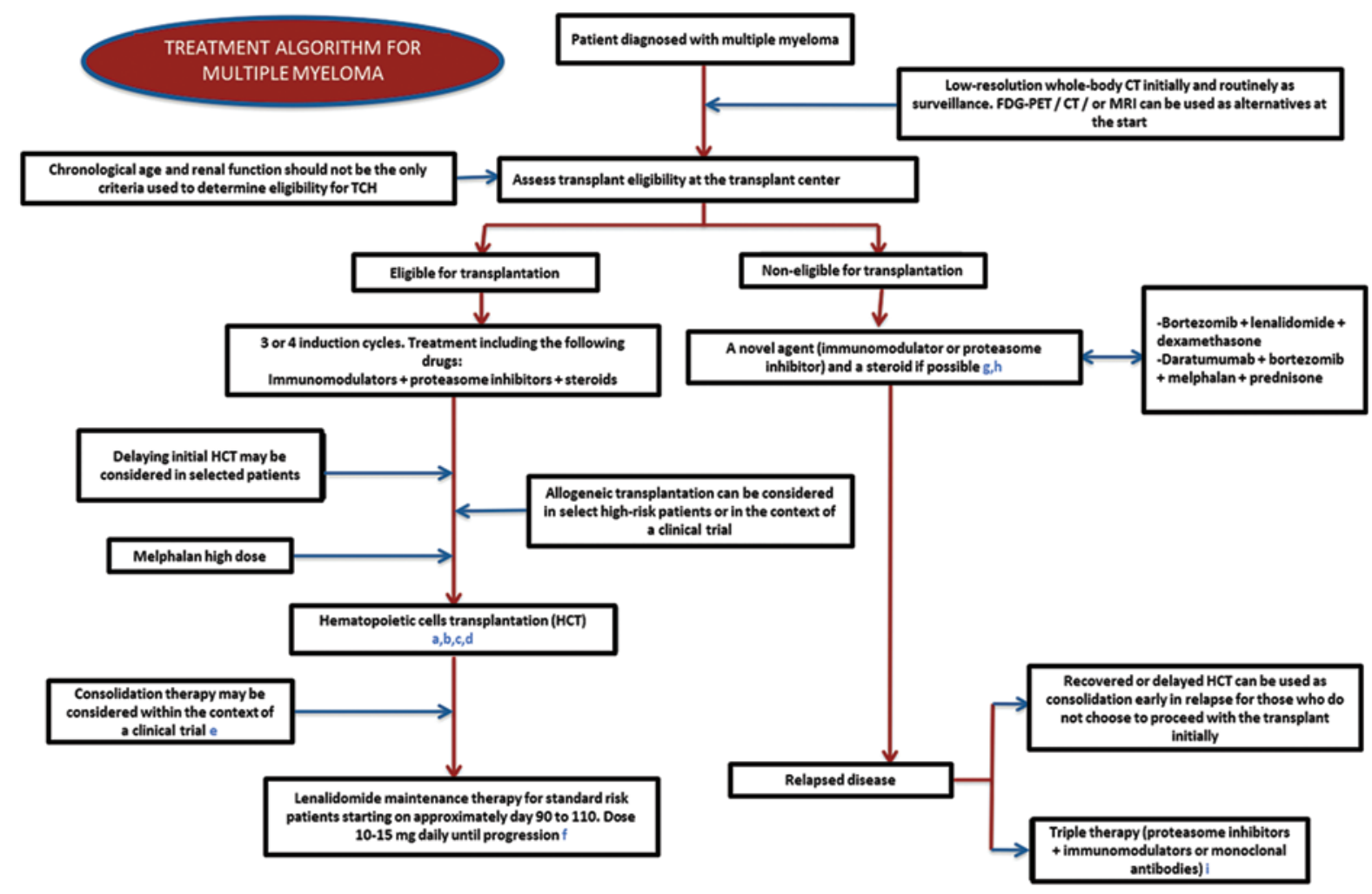

Figure 1. Multiple myeloma treatment algorithm.

HSCT: hematopoietic stem cell transplantation; CT: computed tomography; FDG-PET / CT: positron emission tomography / tomography 18F-fluorodeoxyglucose computerized; MRI: magnetic resonance.

for HSCT. They further recommend that the depth of the induction chemotherapy should not dictate transplant eligibility. Both recommendations with a level of evidence III, grade of recommendation $\mathrm{B}^{5}$.

The indication of an AHSCT in de novo MM or in $1^{\text {st }}$ relapse should be extended to any patient with partial or better response, regardless of the degree of depth reached during induction. It is not necessary to routinely evaluate the MRD; however, it is recommended to evaluate it on any patient who is in SCR before the transplantation to document the depth of the response, as the pre-transplant response has been shown to be a determinant for PFS in these patients ${ }^{5}$.

\section{Comorbidity scales}

Some authors recommend using comorbidity scales to assess a patient's eligibility for HSCT. The three most used scales are the HCT Comorbidity Index (HCT-Cl), Charlson Comorbidity Index (CCl) and the Pretransplant Assessment of Mortality score; being the last the most used for allogeneic transplantation ${ }^{6}$ (Table 1).

Although there are no defined criteria for the indication of transplantation in the MM patient, there are increasing studies that reflect that a complete remission should be an important goal for the patient when thinking about a transplant. The depth of response (ideally the spinal and extramedullary negative MRD) correlates with increased PFS and OS in all patient subgroups, including those with high cytogenetic risk.

In a consensus made by IMWG in 2016, it was recommended to initiate intensive chemotherapy (HDT) with a HSCT as the standard therapy for patients eligible for transplantation with NDMM. It contributes to improving the outcome in all prognostic groups. Dual HDT/HSCT combined with bortezomib may improve PFS in patients with $t(4 ; 14)$ or del $(17 p)$, and in those with both abnormalities. Although the results of stratified randomized trials are not yet available, HDT plus double ASCT is recommended for patients with high-risk cytogenetics ${ }^{6}$.

Performing an early transplantation versus a late option has been analyzed in several studies. In times of conventional chemotherapy, the French Group reported, since 1998, the results of both arm, and they were comparable in terms of OS, however, early transplantation was superior in terms of quality of life by reducing the treatment associated toxicity, and 
Table 1. Comparison of Charlson Comorbidity Index and Specific comorbidity index for hematopoietic cell transplantation

\begin{tabular}{|c|c|c|c|c|}
\hline Comorbidity & Definition & $\begin{array}{l}\text { CCI } \\
\text { score }\end{array}$ & HCT-Cl definitions & $\begin{array}{l}\text { HCT-Cl } \\
\text { score }\end{array}$ \\
\hline $\begin{array}{l}\text { Lung disease } \\
\text { Mild } \\
\text { Moderate } \\
\text { Serious }\end{array}$ & $\begin{array}{l}\text { Dyspnea in moderate activity } \\
\text { Dyspnea in light activity } \\
\text { Dyspnea at rest with oxygen }\end{array}$ & $\begin{array}{l}1 \\
1\end{array}$ & $\begin{array}{l}\text { Dyspnea in moderate activity or DLco and/or FEV1 } \\
81-90 \% \\
\text { Dyspnea in light activity DLco and/or FEV1 } 66-88 \% \\
\text { Dyspnea at rest or requires oxygen or DLco and/or } \\
\text { FEV1 } \leq 65 \%\end{array}$ & $\begin{array}{l}2 \\
3\end{array}$ \\
\hline $\begin{array}{l}\text { Cardiac disease } \\
\text { General } \\
\text { Arrhythmia } \\
\text { Valvular disease }\end{array}$ & $\begin{array}{l}\text { Congestive heart failure } \\
\text { N/A } \\
\text { Except mitral valve prolapse }\end{array}$ & $\begin{array}{l}1-2 \\
0 \\
0\end{array}$ & $\begin{array}{l}\text { Coronary disease, congestive heart failure, IAM LVEF } \\
<50 \% \\
\text { Atrial fibrillation or flutter, sick sinus, ventricular } \\
\text { arrhythmias } \\
\text { Except mitral valve prolapse }\end{array}$ & $\begin{array}{l}1 \\
3\end{array}$ \\
\hline $\begin{array}{l}\text { Liver disease } \\
\text { Mild } \\
\text { Moderate to severe }\end{array}$ & $\begin{array}{l}\text { Chronic hepatitis or cirrhosis } \\
\text { Portal hypertension, esophageal } \\
\text { varicose veins }\end{array}$ & $\begin{array}{l}1 \\
3\end{array}$ & $\begin{array}{l}\text { Chronic hepatitis, bilirubin }>1.5 \text { times or AST/ALT } \\
>2.5 \text { times } \\
\text { Cirrhosis or fibrosis or bilirubin }>1.5 \text { times or AST/ALT } \\
>2.5 \text { times }\end{array}$ & 1 \\
\hline $\begin{array}{l}\text { Renal disease } \\
\text { Mild } \\
\text { Moderate to Severe }\end{array}$ & $\begin{array}{l}\text { Creatinine } 2-3 \mathrm{mg} / \mathrm{dl} \\
\text { Creatinine }>3 \text {, dialysis, kidney } \\
\text { transplant }\end{array}$ & $\begin{array}{l}0 \\
2\end{array}$ & $\begin{array}{l}\text { Creatinine } 1.2-2 \mathrm{mg} / \mathrm{dl} \\
\mathrm{Cr}>2 \mathrm{mg} / \mathrm{dl} \text {, dialysis or kidney transplant }\end{array}$ & 0 \\
\hline $\begin{array}{l}\text { Other neoplasms } \\
\text { Solid tumor } \\
\text { Metastatic cancer }\end{array}$ & $\begin{array}{l}\text { Treated in the last } 5 \text { years } \\
\text { Present }\end{array}$ & $\begin{array}{l}2 \\
6\end{array}$ & $\begin{array}{l}\text { Treated at any time in the patient's medical history } \\
\text { Not included }\end{array}$ & $\begin{array}{l}1 \\
\mathrm{~N} / \mathrm{A}\end{array}$ \\
\hline $\begin{array}{l}\text { Other comorbidities } \\
\text { Diabetes }\end{array}$ & Treatment with insulin and/or oral & 1 & Treatment with insulin and/or oral hypoglycemics & 1 \\
\hline $\begin{array}{l}\text { Cerebrovascular } \\
\text { disease } \\
\text { Rheumatologic } \\
\text { Peptic ulcer }\end{array}$ & $\begin{array}{l}\text { Vascular event, transient ischemic } \\
\text { attack } \\
\text { SLE, RA, polymyositis, mixed } \\
\text { connective tissue disease. } \\
\text { Requires treatment }\end{array}$ & $\begin{array}{l}1 \\
1 \\
1\end{array}$ & $\begin{array}{l}\text { Vascular event, transient ischemic attack } \\
\text { SLE, RA, polymyositis, mixed connective tissue } \\
\text { disease } \\
\text { Requires treatment }\end{array}$ & $\begin{array}{l}1 \\
2 \\
2\end{array}$ \\
\hline
\end{tabular}

increasing the time without symptoms and/or treatment. In more recent trials, transplantation benefit is evident due to the treatment response depth and an increase in PFS (79). Based on these data, it is safe to conclude that an A-HSCT significantly improves overall outcomes, both in first line, and in the rescue scenario; hence, it should continue to be part of the consolidation scheme in patients eligible for transplantation with NDMM $\left(1^{\text {st }} \text { line }\right)^{7}$.

In the era of conventional chemotherapy, tandem HSCT was a therapeutic option that improved global outcomes in terms of PFS and OS, even in patients who did not achieve pre-transplant $\mathrm{CR}^{1}$. In the age of immunotherapy, the role of tandem transplantation needs to be reassessed. The results of the EMN02/ HO95 (RVD) study have recently been published where significant beneficial impact was shown in terms of CR, OS, and PFS in the tandem transplant arm, including in the subgroup of high cytogenetic risk. On the other hand, the StaMINA trial did not identify this same benefit ${ }^{1}$.

Allogeneic HSCT in MM is controversial. Early studies failed to demonstrate a clinical benefit due to an increase in TRM. Subsequently, still in the era of induction schemes based on cytotoxic chemotherapy, tandem transplantation was proposed (autoHSCT followed by reduced intensity aloHSCT), achieving discordant results in the different studies, probably due to heterogeneity in the conditioning schemes, prophylaxis for GVHD and design of clinical trials. In the age of novel therapies, the role of allogeneic transplantation takes place in the scenario of the patient 
with post-autoHSCT relapse and within the clinical trial scenario, especially due to the modest activity of grafting against tumor (GvT) in MM (JCO) .

\section{Mobilization}

Autologous transplantation in MM faces the problem of reaching an adequate cell dose during the harvest period, since this is one of the diseases considered to be a poor mobilizer; the problem increases when there is the intention to harvest for tandem transplantation. The minimum number of peripheral blood stem cells (PBSC) required for an AHSCT is $2-10^{6} \mathrm{CD} 34+/ \mathrm{kg}$ cells; harvests of $<1 \times 10^{6} / \mathrm{kg}$ associate to a late graft with high transfusion requirements and even permanent graft loss, while $3-5 \times 10^{6} \mathrm{CD} 34+/ \mathrm{kg}$ cells are ideal ${ }^{8}$.

There are two different strategies for mobilizing HSC from MO to SP, these are: (1) colony-stimulating factors (CSF), and (2) a sequence of chemotherapy followed by CSF.

\section{Colony stimulants}

For granulocyte CSF (G-CSF) mobilization, the only products approved are filgrastim and lenograstim. The recommended dose for filgrastim is $10 \mu \mathrm{g} / \mathrm{kg} /$ day SC for 5-7 consecutive days and lenograstim $10 \mu \mathrm{g} / \mathrm{kg} /$ day SC for 4-6 consecutive days. The use of biosimilar G-CSF has equivalent efficacy ${ }^{9}$. The use of pegfilgrastim of 6 and $12 \mathrm{mg} \mathrm{SC}$, single dose, also has favorable evidence in harvest for auto-transplantation, in a meta-analysis pegfilgrastim versus filgrastim were compared, showing increased harvest of CD34 and an earlier harvest day for patients with pegfilgrastim. No difference was found for the number of apheresis performed or on the day of transplant grafting.

It is expected to achieve the ideal number of CD34+ in the first mobilization with the lowest toxicity, so the CD34 number in SP is monitored to select the $1^{\text {st }}$ day of apheresis, being earlier with the use of pegfilgrastim, between days 3-5, and days 5-7 for filgrastim, and between days 10-13 post-chemotherapy for CT+ G-CSF. The ideal day to start the harvest is when it is expected to have $>10 \mathrm{CD} 34+$ cells $/ \mathrm{mcl}^{10}$.

If the number of cells collected is inadequate, mobilization with G-CSF can continue for 1-2 days. However, if the collection target is not reached after the third leukapheresis, successful mobilization is unlikely.

The main advantages of CSF mobilization are: relatively low toxicity, predictable leukapheresis time, outpatient administration, and reduced costs compared to chemo-mobilization. The main disadvantages are variable mobilization failure rates and lower CD34+ cell yields compared to chemo-mobilization. G-CSF mobilization can only be used in patients without additional chemotherapy, for example, in patients with stable remission of the underlying disease. It is estimated that around $20 \%$ of MM patients will not be able to achieve an adequate harvest under the G-CSF scheme ${ }^{11}$.

\section{Mobilization with chemotherapy}

The use of chemotherapy in combination with G-CSF is the preferred form of mobilization for all patients who will need a greater decrease in tumor load and/or those with the need to collect a large number of HSC.

The most commonly used dose is cyclophosphamide (CY) 2-4 $\mathrm{g} / \mathrm{m}^{2}$ also called chemo-mobilization, which has been shown to provide higher number of CD34+ for harvesting. Higher doses of cyclophosphamide have been associated with prolonged neutropenia, antibiotic use, and transfusions.

Another scheme that has proven effectiveness is intermediate doses of cytarabine (ID-AraC) with doses of $1.6 \mathrm{~g} / \mathrm{m}^{2}+\mathrm{G}-\mathrm{CSF}$ as a first- or second-line mobilization scheme, which in a retrospective study proved to be more efficient than CY + G-CSF or G-CSF alone, with a median 1-day apheresis compared to two with G-CSF alone, with a median harvest of 20.2 (2.9$59.4) \times 10^{6} \mathrm{CD} 34+/ \mathrm{kg}$ with ARA-C versus $5.9(0-11)$ $\times 10^{6} \mathrm{CD} 34+\mathrm{kg}(\mathrm{p}<0.00001)$. Toxicity was higher in the group receiving CT with Grade 3/4 neutropenia in $34 \%$ and Grade $3 / 4$ thrombocytopenia in $75 \%{ }^{11}$.

Furthermore, there is high mobilization effectiveness with plerixafor, a CXC-4 antagonist, in combination with G-CSF, which has been shown to be able to harvest $>2 \times 10^{6} \mathrm{CD} 34 / \mathrm{kg}$ in the first collection (OR $\times 4.05,95 \%$ $\mathrm{Cl}, 1.19-13.83, \mathrm{p}=0.03)$ and $5 \times 106 / \mathrm{kg} \mathrm{CD} 34+$ in total harvest. $(\mathrm{OR}=3.09,95 \% \mathrm{Cl}, 1.04-9.23, \mathrm{p}=0.04)^{12}$.

\section{Predictors of suboptimal mobilization}

The failure of mobilization is generally defined as the inability to obtain $2 \times 10^{6} \mathrm{CD} 34+$ cells $/ \mathrm{kg}$ in four apheresis sessions. Despite recent advances in PBSC collection strategies, the inability to obtain an adequate cellular dose continues to delay and exclude auto-HCT in suitable transplant candidates. Factors associated with inadequate HSC mobilization in MM patients include: thrombocytopenia, age $>60$ years, 


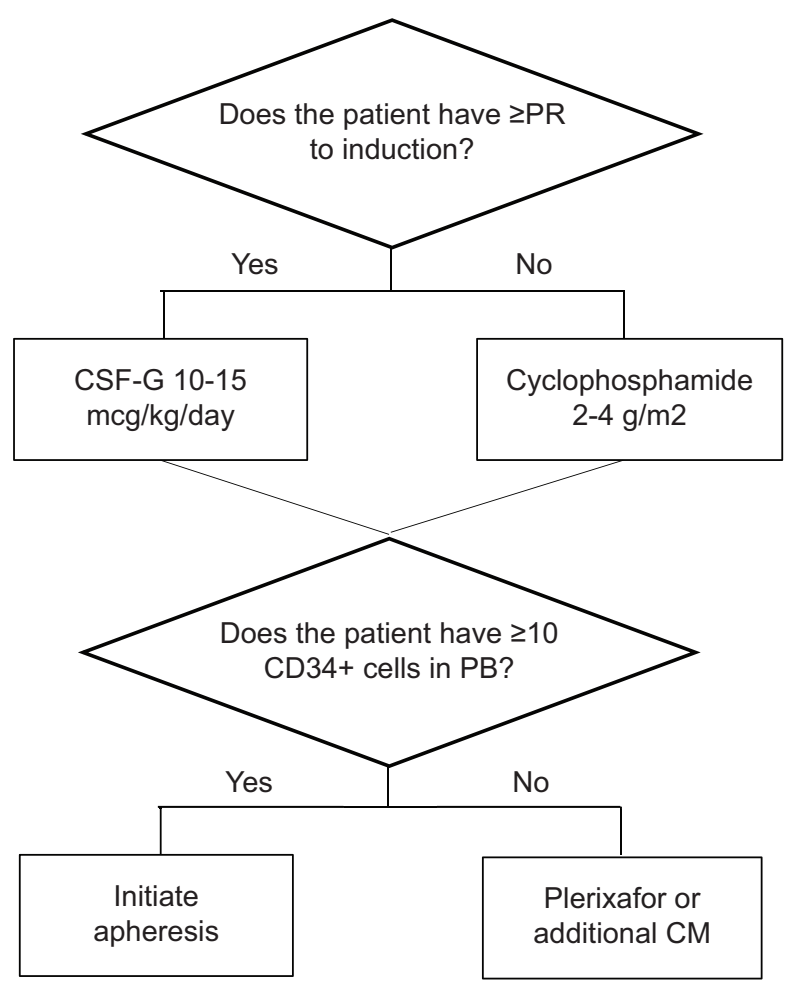

Figure 2. Movilization Prognostic factors. Modified from Wallis et al. CSF-G: Colony stimulating factor; PB: Peripheral blood; CM: Chemomobilization.

extensive treatment course, prior radiation therapy, prior exposure to alkylating agents, and prolonged use of lenalidomide ${ }^{13}$ (Figure 2).

\section{Conditioning}

\section{Conditioning scheme}

In MM patients undergoing an AHSCT, the standard conditioning is melphalan $200 \mathrm{mg} / \mathrm{m}^{2}$. Several studies have been conducted with the aim of finding the best conditioning scheme.

The IFM Group performed a Phase III, open, randomized study, in 2017 to compare melphalan $200 \mathrm{mg} / \mathrm{m}^{2}$ versus bortezomib $1 \mathrm{mg} / \mathrm{m}^{2}$ for 4 days + melphalan 200 for 1 day; no difference was found in responses, OS, or adverse events; however, the scheme has not been evaluated regarding MRD ${ }^{14}$.

In a Phase II study comparing busulfan $130 \mathrm{mg} / \mathrm{m}^{2} / \mathrm{day}$ for 4 days + melphalan $70 \mathrm{mg} / \mathrm{m}^{2}$ for 2 days, an increase in PFS was observed, but with no difference in response rates ${ }^{15}$. In 2019, Bashir et al. compared busulfan $32 \mathrm{mg}$ for 4 days + melphalan $140 \mathrm{mg} / \mathrm{m}^{2}$ versus melphalan $200 \mathrm{mg} / \mathrm{mm}^{2}$ in a Phase II study with
202 patients, in which an EFS of 64.7 versus 43.5 months, respectively ( $\mathrm{HR} 0.53,95 \% \mathrm{Cl} 0.30$ $0.91, p=0.022)$. More non-hematological adverse events Grades 3 and 4 were reported, mainly diarrhea and mucositis, but lower incidence of hepatic veno-occlusive disease ${ }^{15}$.

Another scheme evaluated the use of bortezomib (1.3 $\mathrm{mg} / \mathrm{m}^{2}$ added to BUMEL) in a Phase II study. It showed a $75 \%$ VGPR or better, $55 \%$ CR at 3 months post-ASCT; however, it will be necessary to perform Phase III studies to be able to compare between V-BuMel and BuMel versus MEL20016.

The addition of bendamustine $200 \mathrm{~m}^{2}$ for 2 days + melphalan $100 \mathrm{mg} / \mathrm{m}^{2}$ for 2 days is being explored with promising results in response rates and PFS in the second transplant with unfavorable cytogenetics ${ }^{17}$ (Figure 3 ).

\section{Special cases}

In the case of extramedullary disease, the use of BEAM as conditioning scheme (dexamethasone with carmustine, etoposide, cytarabine, and melphalan) has been evaluated in retrospective studies, which is typically used as conditioning in patients with lymphoma and may be effective ${ }^{18}$.

In patients with renal disease at diagnosis (GFR $<30 \mathrm{ml} / \mathrm{min}$ or $\mathrm{Cr}>2 \mathrm{mg} / \mathrm{dL}$ ), a retrospective study with melphalan $140 \mathrm{mg} / \mathrm{m}^{2}$ versus Melphalan $200 \mathrm{mg} / \mathrm{m}^{2}$ was less toxic with no difference in transplant associated mortality, PFS, OS 87 Badros. Patients over 70 years of age in good condition should not be excluded, because conditioning with melphalan $140 \mathrm{mg} / \mathrm{m}^{2}$ is less toxic and equally effective as melphalan $200 \mathrm{mg} / \mathrm{m}^{2} 19$.

So far, the Mayo Stratification of Myeloma and Risk-Adapted Therapy (mSMART) consensus confirmed that melphalan $200 \mathrm{mg} / \mathrm{m}^{2}$ remains the standard conditioning therapy used outside a clinical trial. Participation in clinical trials with new agents such as conditioning schemes is suggested to continue the search for the best conditioning scheme. Evidence Level I, grade of recommendation $A^{5}$.

\section{Post-transplant maintenance}

The aim should be to extend the duration of remission without impacting on the quality of life. Thalidomide produces $7-19 \%$ grade $3-4$ PPN which leads to the drug suspension hence it is NOT an ideal medicine. 


\section{Newly diagnosed Multiple Myeloma}

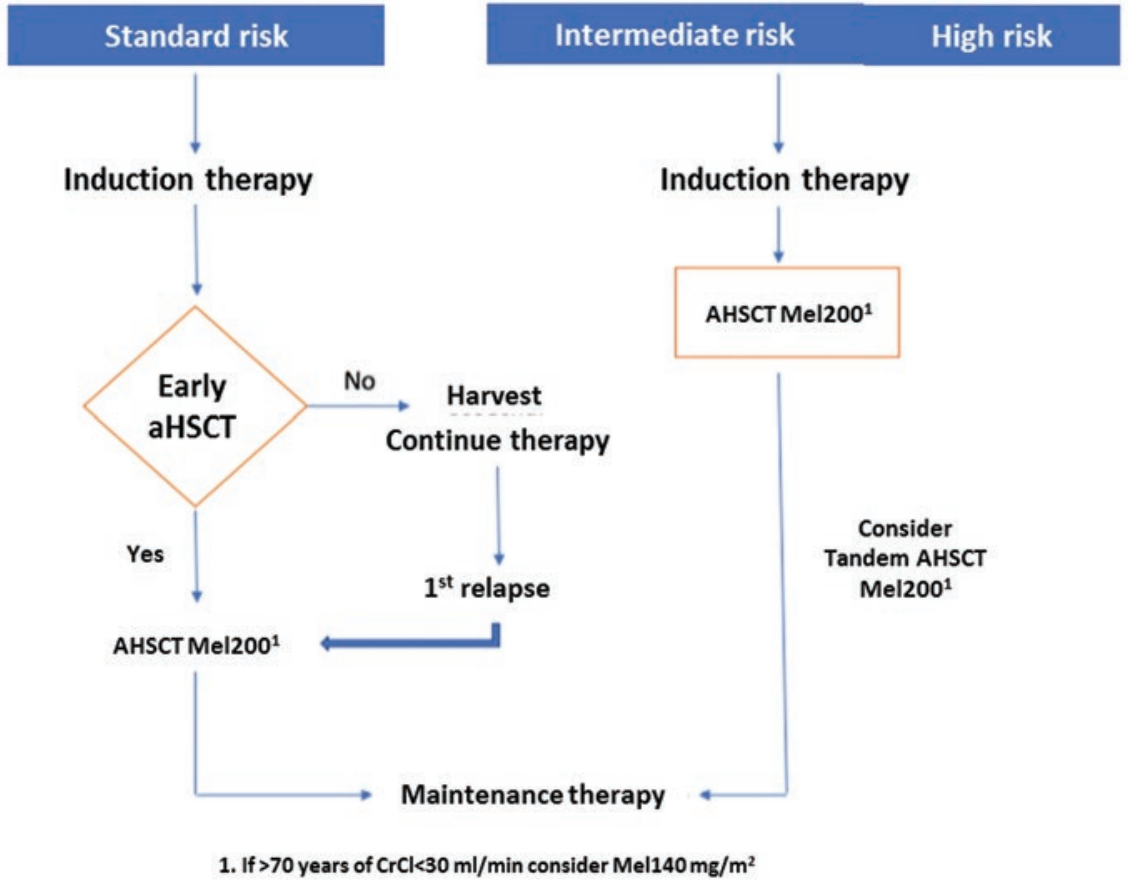

Figure 3. Induction therapy scheme. * $/ f>70$ years or $\mathrm{CrCl}<30 \mathrm{ml} / \mathrm{min}$, consider Mel $140 \mathrm{mg} / \mathrm{m} 2$. aHSCT: autologous hematopoietic progenitor cell transplantation; Mel: melphalan; CrCl: creatinine clearance.

Adapted from Gonsalves et al., $2019^{5}$

\section{Table 2. Post-transplant maintenance schemes}

\begin{tabular}{|c|c|c|}
\hline Maintenance & \multicolumn{2}{|l|}{ Treatment of Choice } \\
\hline \multirow[t]{3}{*}{$\begin{array}{l}\text { Lenalidomide (IA) } \\
\text { Thalidomide (AI) } \\
\text { Bortezomib (IB) }\end{array}$} & $\begin{array}{l}\text { - Lenalidomide has a better toxicity profile than } \\
\text { thalidomide, which favors its long-term use. } \\
\text { - Bortezomib is safer and more effective than } \\
\text { thalidomide. } \\
\text { - IMIDs alone could be suboptimal in high-risk patients } \\
\text { and in patients with renal failure, who may benefit } \\
\text { from bortezomib. } \\
\text { - Ixazomib reduces the risk of progression or death } \\
\text { compared to placebo. } \\
\text { - Carfilzomib is safe and effective. }\end{array}$ & $\begin{array}{l}\text { - The treatment of choice should consider the } \\
\text { characteristics of the patient and the expected } \\
\text { toxicity. }\end{array}$ \\
\hline & \multicolumn{2}{|c|}{ Duration of therapy } \\
\hline & $\begin{array}{l}\text { - Lenalidomide: at least } 2 \text { years or until tolerated. } \\
\text { - Thalidomide: until tolerated. } \\
\text { - Bortezomib: } 2 \text { years. } \\
\text { - Ixazomib: weekly for } 2 \text { years. } \\
\text { - Carfilzomib: weekly for } 1 \text { year. }\end{array}$ & $\begin{array}{l}\text { - There are no randomized studies comparing } \\
\text { lenalidomide for } 2 \text { years with lenalidomide until } \\
\text { progression. } \\
\text { - The use of long-term thalidomide is limited due to } \\
\text { poor tolerance. } \\
\text { - Bortezomib has been administered in clinical trials } \\
\text { for up to } 2 \text { years. }\end{array}$ \\
\hline
\end{tabular}

Modified from Gay et al.

Bortezomib (HOVON-65/GMMG-HD4 study) significantly reduces the risk of progression $(p=0.04)$ and death $(p=0.05)$ compared to thalidomide, but with similar PPN rate ( $5 \%$ vs. $8 \%)$. It is suggested that pre-transplant induction and maintenance with bortezomib significantly reduces SV in patients with del (17p) and FRC.

Lenalidomide is less neurotoxic (four studies demonstrated benefit in maintenance PFS with lenalidomide vs. not giving it) (HR 0.46-0.5) and randomized 
studies report an increase in OS (OS at 7 years $62 \%$ vs. $50 \%$, HR $0.75 p=0.001$ ), except in patients with high cytogenetic risk, and improvement in PFS. The main toxicity Grade $3-4$ is neutropenia (23 vs. $51 \%$ ) and infections (6-13\%), although the second neoplas$\mathrm{ms}$ are higher (hematological $6.1 \%$ vs. $2.8 \%$ and solid tumors 7.3 vs. $4.2 \%)^{20}$.

In the TOURMALINE-MM3 study, post-transplant maintenance with ixazomib against placebo was evaluated, a $28 \%$ reduction in the risk of progression or death was observed, PFS 26.5 months $(95 \% \mathrm{Cl} 23.7$ 33.8) versus 21.3 months (18-24.7); HR $0.72,95 \% \mathrm{Cl}$ 0.58-0.8921; $\mathrm{P}$ post-transplant maintenance.

Carfilzomib is safe as 1-year maintenance in NDMM (including patients over 75 years) and leads to a deeper response $(50 \% \mathrm{CR}$ at the end of maintenance, with PFS at 28.1 months and estimated OS at $36 \mathrm{~m}$ of approximately $70 \%=0.0023$ ). There was no increase of second neoplasms with ixazomib: $12(3 \%)$ patients, against $8(3 \%)$ placebo patients; $108(27 \%)$ out of 394 patients in the ixazomib group; and 51 (20\%) out of 259 patients in the placebo group experienced adverse events. During treatment, one patient died in the ixazomib group and none in the placebo group ${ }^{21}$.

A summary of the characteristics of both schemes of conditioning is presented in Table 2.

\section{Module 8}

\section{Pain and supportive treatments}

$\mathrm{MM}$ is a disease which from the very early stages manifests with symptoms interfering with the quality of life.

It is important to mention that a MM patient will be affected on the physical, social, emotional, and spiritual spheres, so they require a transdisciplinary approach.

Usually, chemotherapy and radiotherapy may control some of the complications; however, additional treatments must be implemented to improve comfort and quality of life.

Among the main symptoms presented by patients, there is bone pain, neuropathy, anxiety, fatigue, and insomnia, among others ${ }^{1}$.

\section{Bone complications}

Myeloma-related bone disease is a frequent complication that presents in different grades, from mild osteopenia; it is estimated to be present in $85 \%$ of cases and may go to severe bone lesions which result in pathological fractures and their specific complications. This disease is due to the loss of balance of the osteoclasts-mediated bone resorption and bone formation that is the osteoblasts responsibility. It is known that myeloma cells stimulate osteoclasts due an increased release of ILs, macrophages-colonies stimulating factor, tumor necrosis factor (TNF)-alpha and beta, as well as other molecules, which in turn, stimulate osteoclasts to release several molecules which stimulate the replication of MM cells, closing thereby the vicious circle? .

Finally, a lot of importance has been given to a signaling pathway that has proven to be involved in the bone disease of diverse neoplasm pathologies, including myeloma: the RANK-RANKL-OPG pathway. Osteoclasts are derived from hematopoietic precursors, RANKL, a TNF family protein of cytokines which regulates the replication, mobilization, and functioning of these cells, its opposite ligand, osteoprotegerin (OPG) secreted by stromal cells regulates RANKL in turn. An unbalance of the RANKL/OPG relation results in the inappropriate functioning of osteoclasts and altered bone resorption².

Bone disease lesions myeloma related are lytic, may be present in any bone, and are related to a high tumor activity. Conventionally, the diagnosis and determination of these lesions have been made with metastatic bone series, which, despite of being the less costly and available in most of the medical centers, have a big drawback, it is only sensitive to very advanced lesions, considering that among 30 and $50 \%$ of the bone may suffer destruction before being detected by this technique ${ }^{3}$. Low dose computerized tomography is, presently, one of the most widely used tests, its sensitivity and specificity, as well as the relative availability of the equipment needed to perform it, turn this test into one of the better diagnostic options for this complication ${ }^{4}$. Magnetic resonance and PET-CT are highly useful tests for the early detection of lytic lesions, with a high sensitivity, however, they are not available in most medical centers, and require a more complex preparation from the patient to be performed.

\section{Treatment of MM-related bone disease}

Treatment of MBD has been determined after the approval of agents used for bone complications in other neoplasms. The management cornerstone is bisphosphonates: pyrophosphate analogs which in 
turn inhibit pyrophosphate synthase, inhibiting the proliferation and maturation of osteoclasts, inducing their apoptosis and preventing their fixation to bone. Clodronate, pamidronate, and zoledronic acid are the approved bisphosphonates currently approved for use in MM. Multiple Phase III trials have been carried out comparing activity and benefit of these drugs one-toone. One of the most recent and large is the one performed by the Medical Research Council of the United Kingdom, called Myeloma IX trial, comparing the use of clodronate versus zoledronic acid, where the latter showed to be more efficacious in decreasing the number of fractures related to lytic lesions, as well as an improvement in the quality of life and even in the OS. Zoledronic acid dosing varies according the group consulted; however, the most commonly used is $4 \mathrm{mg}$ IV every 4 weeks for 2 years 5 .

Bisphosphonates safety profile is acceptable, but there are two very relevant events to be considered primarily:

1. Osteonecrosis of the jaw (ONJ) may occur between $2 \%$ and $10 \%$ of patients with the use of bisphosphonates. This complication is characterized by the exposure of bone tissue in the oral cavity. Among the risk factors for developing ONJ are dental injuries before the use of the drug, poor dental hygiene, advanced age, and late evolution of myeloma. When this complication occurs, stomatology experts should be consulted, and before this, the patient should be guided to carry out adequate dental hygiene, avoid unnecessary dental procedures, and monitor the oral cavity; if an urgent surgical dental intervention is required, the use of the chosen bisphosphonate should be suspended for up to 90 days before the procedure. If the complication is already established, broad-spectrum antibiotic treatment should be initiated, and the experts should be consulted 6 .

2. Acute renal failure: It can be seen in up to $12 \%$ of patients with myeloma and the use of zoledronic acid, since it is eliminated in up to $40 \%$ through the kidneys. There are no studies of the use of this drug in patients with severe kidney failure; however, the recommendation is to decrease and adjust the dose of the drug in case of kidney failure.

The recently describe RANKL-OPG guidelines brought a ne set of opportunities to find new therapeutical targets. One of the first developments focused on this area was denosumab, a human monoclonal antibody that binds and inhibits RANKL irreversibly. Its efficacy was proven first in bone metastatic disease in solid tumors, to be directed to EORM later on, where it showed the non-inferiority versus zoledronic acid in the event free survival, defined as a pathological fracture or the need of palliative radiotherapy (EFS 22 vs. 23 months), as well as similar OS. Regarding safety, there was a slight increase in the frequency of osteonecrosis of the jaw in the denosumab group versus zoledronic acid, without statistical significance. The dosage of this monoclonal antibody is administered subcutaneously, with load doses on days 8 and 15 in the first cycle, followed by $120 \mathrm{mg}$ every month, conferring it a good practical and safety profile ${ }^{2}$. Some of the advantages of denosumab are: ${ }^{2}$

1. Monthly subcutaneous administration.

2. No accumulation in bone.

3. Half-life 26 days.

4. It is cleared by the reticuloendothelial system (it is not necessary to adjust the dose based on the renal function).

Disadvantages:

1. Hypocalcemia.

2. Necrosis of the jaw.

Table 1 summarized dose adjustment of zolendronic acid.

Radiotherapy is still an important tool, in special for the relief of the secondary symptomatology from pathological fractures. It is estimated that $38 \%$ of $\mathrm{MM}$ patients will receive palliative radiotherapy during their disease. Indications for this therapeutic option are: prevention and treatment of fractures that may not be corrected by surgical means, intense pain, vital organ involvement, extramedullary disease, and palliation of other symptomatology fracture-related. Fractioned doses between 10 and 30 Gy are used, with response rates of up to $76 \%$, at least for pain palliation ${ }^{6}$.

Regardless of the option available in each site, it is important to consider the management of this complication due to its huge impact on the quality of life and the overall experience of the patient with the treatment provided for his neoplastic pathology.

\section{Pain management}

Cancer pain may be due to tumor progression (lymphatic and vascular obstruction, distention, edema, inflammation, and necrosis). Tumor bone infiltration is the most frequent cause of pain in the hematological patient. The mechanisms causing bone pain are explained by the production of prostaglandin E 2 (PGE2) 


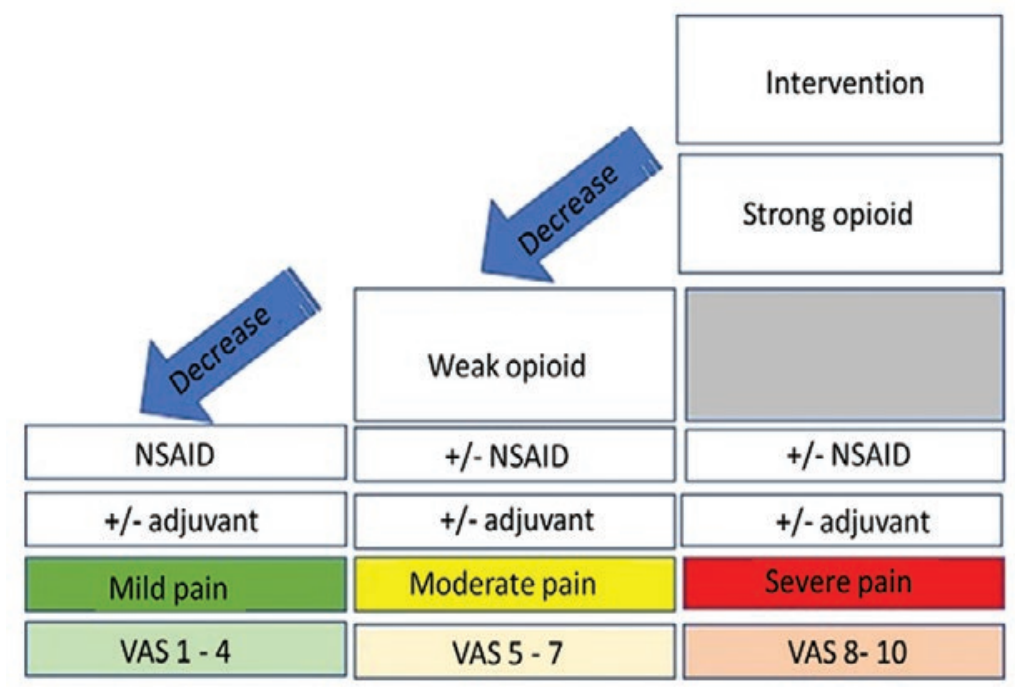

Figure 1. WHO analgesic scheme.

NSAID: Nonsteroideal anti-inflammatory drugs; VAS: Visual analogical scale.

\section{Table 1. Zoledronic acid dose}

- Standard dose $4 \mathrm{mg}$.

- Not recommended if $\mathrm{ClCr}<30 \mathrm{ml} /$ minute.

- Patients with mild to moderate RF (CICr 30-60 ml/minute) recommended dose:

- $\mathrm{ClCr}>60 \mathrm{ml} / \mathrm{min} \rightarrow 4 \mathrm{mg}$

- $\mathrm{ClCr} 50-60 \mathrm{ml} / \mathrm{min} \rightarrow 3.5 \mathrm{mg}$

- $\mathrm{ClCr} 40-49 \mathrm{ml} / \mathrm{min} \rightarrow 3.3 \mathrm{mg}$

- $\mathrm{ClCr} 30-39 \mathrm{ml} / \mathrm{min} \rightarrow 3.0 \mathrm{mg}$
Table 2. Classification of analgesics

\begin{tabular}{l|l}
\hline Weak & Strong \\
\hline Nalbuphine & Sufentanil \\
\hline Tapentadol & Fentanyl \\
\hline Tramadol & Buprenorphine \\
\hline Codein & Hydromorphone \\
\hline D - propoxyphene & Oxycodone
\end{tabular}

that sensitizes nociceptors. Bone destruction leads to pathological fractures and perineural invasion. Among hematological diseases, MM has the highest incidence of bone pain, affecting up to $75 \%$ of patients ${ }^{2}$.

To reduce bone pain, the most effective way is to control the underlying disease, but sometimes it is necessary to resort to the use of conventional analgesics such as nonsteroidal anti-inflammatory drugs (NSAIDs), opioids, and adjuvant drugs (paracetamol, local anesthetics, steroids, antidepressants, neuromodulators, alpha 2 agonists, and among others). The treatment of pain can be systematized according to what is proposed in the analgesic ladder of the World Health Organization $(\mathrm{WHO})^{3}$.

To understand pain treatment, it is important to know the classification.

According to its pathophysiology, it is classified as nociceptive (somatic) and neuropathic. Nociceptive pain is caused by the stimulation of $\mathrm{Ad}$ and $\mathrm{C}$ fibers by a harmful stimulus on the body tissues; it is a physiological response to aggression. Somatic pain originates from injuries to the skin, muscle, bone, and joint capsules, it is usually well localized. Bone pain falls into this category. Neuropathic pain originates as a direct consequence of injury or disease affecting the central or peripheral nervous system ${ }^{4}$.

With the above, it is also important to mention the analgesia scheme proposed by the WHO (Figure 1).

To evaluate pain intensity there are different scales; however, the easiest is the verbal analogue scale (VAS) or any other unidimensional analog scale to assess pain.

The use of NSAIDs is limited to patients whose kidney function is $>60 \mathrm{ml} / \mathrm{min}$ and the recommendation is to use it in a maximum period of 7 consecutive days. For this reason, it is important to mention that the pharmacological management of bone pain in patients with MM is based on opioids. 
Gaceta Médica de México. 2020;156(Suppl 1)

Table 3. Analgesics used in Renal Failure and adjustment according to GF

\begin{tabular}{|c|c|c|c|c|c|}
\hline \multirow[t]{2}{*}{ Group and drugs } & \multicolumn{4}{|c|}{ Glomerular filtration (GF) (ml/min/1.73 $\left.\mathrm{m}^{2}\right)$} & \multirow[t]{2}{*}{ Hemodialysis } \\
\hline & Mild $(>60)$ & \multicolumn{2}{|c|}{ Moderate $(30-60)$} & Severe $(<30)$ & \\
\hline Fentanyl & \multicolumn{4}{|l|}{$\begin{array}{l}\text { FENTANILO }^{\circledR} \\
\text { EFFENTORA }^{\circledR} \\
\text { ACTIQ }^{\circledR} \\
\text { ABSTRAL }^{\circledR} \\
\text { PECFENT }^{\circledR} \\
\text { INSTANYL }^{\circledR}\end{array}$} & $\begin{array}{l}\text { Safe with dose reduction } \\
\text { Scarcely dialyzable } \\
\text { Caution }\end{array}$ \\
\hline Buprenorphine & \multicolumn{4}{|l|}{ TRANSTEC ${ }^{\otimes}$} & \\
\hline Tramadol & & & & $\begin{array}{l}10-30 \mathrm{ml} / \mathrm{min}: 200 \mathrm{mg} / 24 \mathrm{~h} \\
>10 \mathrm{mi} / \mathrm{min}: 50 \mathrm{mg} / 24 \mathrm{~h}\end{array}$ & $\begin{array}{l}\text { Eliminates minimal } \\
\text { amounts of tramadol }\end{array}$ \\
\hline $\begin{array}{l}\text { Prolonged } \\
\text { released tramadol }\end{array}$ & & & & & $\begin{array}{l}\text { Eliminates minimal } \\
\text { amounts of tramadol }\end{array}$ \\
\hline Morphine & & & $\begin{array}{l}25 \% \text { in GF } 30-59 \\
\mathrm{ml} / \mathrm{min}\end{array}$ & $\begin{array}{l}50 \% \text { GF } 115-29 \mathrm{ml} / \mathrm{min} \text { and } \\
75 \% \text { GF }>15 \mathrm{ml} / \mathrm{min}\end{array}$ & $\begin{array}{l}\text { Caution and dose } \\
\text { adjustment } \\
\text { Dialyzable }\end{array}$ \\
\hline \multicolumn{6}{|l|}{$\begin{array}{l}\text { Prolonged released } \\
\text { morphine }\end{array}$} \\
\hline $\begin{array}{l}\text { Oxicodone } \\
\text { oxicodone/naloxone }\end{array}$ & $\begin{array}{l}\text { OXYCONTIN }{ }^{\circledR} \\
\text { TARGIN }^{\circledR}\end{array}$ & & \multicolumn{2}{|c|}{$\begin{array}{l}\text { Need to adjust dose in RF } \\
\text { Initiate with half (50\%) the usual dose and titrate } \\
\text { accordingly } \\
\text { In case of sever RF, a strict medical surveillance is } \\
\text { particularly necessary }\end{array}$} & \\
\hline Hydromorphone & JURNISTA ${ }^{\circledR}$ & & \multicolumn{2}{|c|}{$\begin{array}{l}\text { Need to adjust dose in moderate RF } \\
\text { Initiate with a third to a half of the usual dose and } \\
\text { adjust as necessary }\end{array}$} & $\begin{array}{l}\text { Turns into a less active } \\
\text { metabolite, which is } \\
\text { easily eliminated by } \\
\text { hemodialysis }\end{array}$ \\
\hline Tapentadol retard & \multirow[t]{2}{*}{$\begin{array}{l}\text { YANTIL }{ }^{\circledR} \\
\text { PALEXIA }^{\circledR}\end{array}$} & & & $\begin{array}{l}\text { Not recommended in severe } \\
\text { renal failure (GF }<30 \mathrm{ml} / \mathrm{min} \text { ) }\end{array}$ & \\
\hline Codeine & & & $\begin{array}{l}\text { Need to adjust dose } \\
\text { in moderate RF } \\
\text { Initiate with } 75 \% \text { of } \\
\text { the usual dose and } \\
\text { adjust as needed }\end{array}$ & $\begin{array}{l}\text { Not recommended in severe } \\
\text { renal failure (GF }<30 \mathrm{ml} / \mathrm{min})\end{array}$ & \\
\hline Gabapentin & & $\begin{array}{l}50-79 \mathrm{ml} / \mathrm{min}: \\
600 \mathrm{mg} / 8 \mathrm{~h}\end{array}$ & $\begin{array}{l}30-49 \mathrm{ml} / \mathrm{min}: 300 \\
\mathrm{mg} / 8 \mathrm{~h}\end{array}$ & $\begin{array}{l}15-29 \mathrm{ml} / \mathrm{min}: 300 \mathrm{mg} / 12 \mathrm{~h} \\
<15 \mathrm{ml} / \mathrm{min}: 300 \mathrm{mg} / 24 \mathrm{~h}\end{array}$ & With caution \\
\hline Pregabalin & & $\begin{array}{l}>60 \mathrm{ml} / \mathrm{min}: \\
300 \mathrm{mg} / 12 \mathrm{~h}\end{array}$ & $\begin{array}{l}>30-59 \mathrm{ml} / \mathrm{min}: \\
150 \mathrm{mg} / 12 \mathrm{~h}\end{array}$ & $\begin{array}{l}15-30 \mathrm{ml} / \mathrm{min}: 150 \mathrm{mg} / 24 \mathrm{~h} \\
<15 \mathrm{ml} / \mathrm{min}: 75 \mathrm{mg} / 24 \mathrm{mg}\end{array}$ & With caution \\
\hline Paracetamol & & & & $\begin{array}{l}<10 \mathrm{ml} / \mathrm{min} \text { stagger dose } \\
\text { every } 8 \mathrm{~h}\end{array}$ & \\
\hline \multirow[t]{2}{*}{ NSAID } & & & \multicolumn{2}{|c|}{ Avoid unnecessary use in RF } & \\
\hline & Allowed & & Caution & & Contraindicated \\
\hline
\end{tabular}

Allowed Caution Contraindicated

This group of drugs may be classified according to their potency as follows as shown in table 2.

Morphine is considered the gold standard of opioids and their potency is determined according to it ${ }^{7}$.
It is suggested to initiate pain management with weak opioids and to adjust the dose, however, is pain is very intense treatment could start with a strong opioid to control pain and adjust the dose as necessary. 


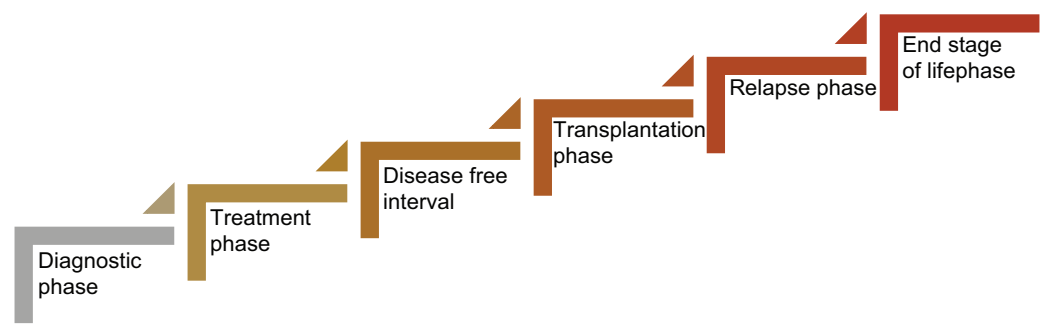

Figure 2. Objective of the psychological interventions according to the different phases of the disease.

Recommended initial doses for pain management are the following:

Nalbuphine: $10-20 \mathrm{mg}$ every 3-6 h. Maximum dose $160 \mathrm{mg} / 24 \mathrm{~h}^{8}$.

Tapentadol: $50-100 \mathrm{mg}$ every $6 \mathrm{~h}$. Maximum dose $500-600 \mathrm{mg} / 24 \mathrm{~h}^{9}$.

Tramadol: $1-3 \mathrm{mg} / \mathrm{kg}$. Initial dose $25 \mathrm{mg}$. Maintenance dose 50-100 mg every $6 \mathrm{~h}$. Maximum dose $600 \mathrm{mg} / 24 \mathrm{~h}$. Adjusted dose based on renal function: $200 \mathrm{mg} / 24 \mathrm{~h}$ maximum ${ }^{8}$.

Morphine: $10-15 \mathrm{mg} / 12 \mathrm{~h}$ (opioid naive patients) and 20-30 mg/12 h (patients previously exposed to opioids). Initial dose $5 \mathrm{mg} / 4 \mathrm{~h}$. In patients with mild-to-moderate renal failure it is necessary to adjust the dose to $25-50 \%$ of the baseline dose ${ }^{10}$.

Oxycodone: $5 \mathrm{mg} / 4 \mathrm{~h}$. (1 $\mathrm{mg}$ oxycodone= $2 \mathrm{mg}$ morphine). It is safer to use in patients with renal failure ${ }^{11}$.

Buprenorphine: 0.3-0.6 mg/6-8 h. Maximum dose $140 \mathrm{mcg} / \mathrm{h}(3,360 \mathrm{mcg} / 24 \mathrm{~h})$.

Fentanyl: $0.04 \mathrm{mcg} / \mathrm{kg}$ as initial dose and 0.5-1 $\mathrm{mcg} / \mathrm{kg} / \mathrm{h}$ for maintenance ${ }^{9}$.

It is important to point out the dual action of opioids such as tramadol and tapentadol ${ }^{9}$.

Table 3 shows the dose adjustments for analgesics based on the renal function for a safe use in MM patients.

Once pharmacological pain management has begun, or if there is no favorable response or inadequate pharmacological resources, it is suggested to refer the patient to a palliative care clinic for transdisciplinary symptom management.

\section{Neuropathic pain: origin, clinical manifestations, and treatment}

MM is a disease with a very high symptom load and may condition the patient to present neuropathy and neuropathic pain, which presents different characteristics in the perception and reference by the patient versus bone pain.
Table 4. Mucositis according to WHO classification

\section{Grade Mucositis according to WHO}

$0 \quad$ No lesion

$1 \quad$ Painless pink mucosa with abundant saliva

2 Erythema, small ulcers, swallowing are maintained

3 Extensive ulcers, edematous gums, thick saliva, swallowing of liquids, pain, and difficulty speaking

$4 \quad$ Very extensive ulcers, bleeding gums, infections, no production of saliva makes swallowing impossible, very severe pain

Characteristics of neuropathic pain include: paresthesia, dysesthesias, burning pain, impaired sensitivity to touch, muscle contraction, and skin disorders such as hyperesthesia, hypoesthesia, and paresthesia. Location: hands and feet. It is accompanied by alterations of the autonomic nervous system, muscular atrophy, loss of strength, atrophy of the distal muscles, orthostatic hypotension, bradycardia, and hypotension ${ }^{11}$.

\section{Neuropathic pain treatment in MM patients}

There are several therapeutic guidelines to treat neuropathic pain, drugs commonly prescribed are: tricyclic antidepressants, serotonin reuptake inhibitors, anticonvulsants, and opioids ${ }^{11}$.

First-line treatment.

- Tricyclic antidepressants.

Amitriptyline: $25-150 \mathrm{mg} / 24 \mathrm{~h}$.

Nortriptyline: $25-150 \mathrm{mg} / 24 \mathrm{~h}$.

- Selective norepinephrine and serotonin reuptake inhibitors.

Duloxetine: $30 \mathrm{mg} / 24 \mathrm{~h}-60 \mathrm{mg} / 12 \mathrm{~h}$.

Venlafaxine: $375-225 \mathrm{mg} / 24 \mathrm{~h}$.

- a2-d calcium channel blockers.

- Pregabalin in low doses, to reduce side effects such as drowsiness, dizziness, and nausea. 
Initial doses of 25-75 mg every $24 \mathrm{~h}$ increasing the dose of $150 \mathrm{mg}, 300 \mathrm{mg}$, up to a maximum dose of $600 \mathrm{mg} /$ day divided into two doses.

- Gabapentin: the initial dose is $300 \mathrm{mg} / \mathrm{d}$, increased by $300 \mathrm{mg}$ every 3-7 days, up to doses of $900-3,600$ $\mathrm{mg} / \mathrm{d}$ at 8 -h intervals. The most frequent, moderate, and normally well-tolerated side effects are drowsiness, dizziness, headache, and diarrhea.

- Lidocaine patch 5\% (700 mg): place the patch on the affected area for $12 \mathrm{~h}$, the maximum dose is three patches.

Second-line: opioids

- Tramadol has two mechanisms of action, binding to opioid receptors and inhibition of reuptake of norepinephrine and serotonin, this second effect is the most potent. Dose of $50-600 \mathrm{mg} / 24 \mathrm{~h}$ divided into three doses.

- Tapentadol: $50 \mathrm{mg}$ twice a day, titrating up to a maximum dose of $250 \mathrm{mg}$ twice a day, with a maximum dose of $700 \mathrm{mg}$ a day. The standard dose is $50 \mathrm{mg}$ every $6-8 \mathrm{~h}$, with a maximum dose of $400 \mathrm{mg} / \mathrm{d}$.

- Potent opioids: use oxycodone has good results in the treatment of neuropathic pain, initial dose 5-10 $\mathrm{mg} / 12 \mathrm{~h}$.

- Morphine sulfate: start with low doses of $15-30 \mathrm{mg}$ in $24 \mathrm{~h}^{12}$.

Supportive measures:

The following support measures are recommended:

In general, these patients have difficulty performing activities of daily living, so they benefit from rehabilitation exercises and physical therapy.

As support for the prevention of opioid-induced constipation: fiber and liquid intake, as well as laxatives, hydration, and drug adjustments ${ }^{1}$.

Due to the great variety of causal and contributing factors in the pathogenesis of neuropathy, there is no satisfactory single treatment for this entity. Relief from this manifestation can be one of the most difficult problems faced by doctors and patients. Genetic differences in pain pathways seem to explain why different types of drugs that selectively inhibit specific pathways may be effective in some patients, but not in others.

\section{Chemotherapy-induced neurotoxicity}

Neurotoxicity is common in cancer patients, whether caused by the disease or the treatment. It frequently involves different structures of the nervous system, such as peripheral sensory nerves, that frequently are the most affected and produce pain. Pain intensity depends on its type and accumulation, besides being dose-dependent. It is more frequent in patients with pre-existing neuropathy. Symptoms will depend on the fibers involved, however, the most common presents with alterations of temperature perception and pain, the condition is usually symmetrical, similar to the distribution of diabetic neuropathy, in glove and sock, and mainly affecting feet ${ }^{13}$.

Besides treatment previously mentioned, management of chemotherapy-induced neuropathy will benefit with the use of Vitamin $E$ at doses of $200-400 \mathrm{mg}$ every $12 h^{14}$.

\section{Management of other MM symptoms}

Unfortunately, there are more symptoms affecting MM patients. Within the early stages of the disease, the symptoms that most affect quality of life are pain and psycho-affective symptoms, such as anxiety and depression. In more advanced stages, extreme fatigue and mucositis have been reported, mainly in the case of management with melphalan and cyclophosphamide ${ }^{14}$.

\section{Mucositis}

Mucositis is defined as a side effect to chemotherapy or radiotherapy and it is characterized by:

- Erythematous areas.

- Ulcerative lesions of the oral mucosa causing pain and feeding limitations.

- This is one of the most common side effects in the cancer treatment, about $40 \%$ of the patients will develop mucositis, depending on the chemotherapy agent used ${ }^{18}$.

According to their classification, the following scale may be used as shown in table 4 .

\section{NON-PHARMACOLOGICAL MEASURES}

Promote oral hygiene using non-abrasive agents: Aloe vera, honey, bicarbonate, and chamomile; these agents promote healing, slow the evolution of the lesion, prevent the progression of advanced stages, due to its properties for the production of saliva, anti-inflammatories, antioxidants, and antibiotics ${ }^{15}$.

\section{Pharmacological therapy}

Some of the drugs used against mucositis are: Mucosal protective drugs, benzydamine, calcium 
phosphate, chlorhexidine, cryotherapy, growth factors, laser therapy, and oral hygiene ${ }^{1}$.

Mouthwashes: cytoprotective drugs combined with local anesthetics and antihistamines; they form a protective plaque on the mucosa, increasing the secretion of prostaglandin E2; and promote tissue repair with anti-inflammatory and analgesic properties ${ }^{16}$.

The following master formula is recommended:

- Lidocaine $1 \% 5 \mathrm{ml}$.

- Aluminum and magnesium hydroxide $30 \mathrm{ml}$.

- Diphenhydramine or chlorpheniramine syrup $30 \mathrm{ml}^{16}$.

Benzydamine: decreases the severity of the injury and painful symptoms.

Calcium phosphate or chlorhexidine rinses: decrease injury and pain, thus improving food intake.

Cryotherapy: causes vasoconstriction reducing the size of the lesion, as well as reducing painful symptoms.

\section{Fatigue}

Similarly, to understand treatment of fatigue it is necessary to know its causes, which in MM turn out to be multifactorial and are usually associated to insomnia. Being fatigued and unable to sleep has a high impact on patients' quality of life and mood indexes ${ }^{16}$.

Fatigue is defined as a symptom that can be derived from the disease or its treatments, negatively impacting the quality of life of patients. The clinical manifestations of fatigue include low energy levels, feeling weak or lethargic, reduced concentration and memory impairment, abrupt mood changes, irritability and emotional liability, dizziness, disorientation, dyspnea, insomnia, altered libido, and loss of appetite ${ }^{16}$.

The origin of fatigue in the case of MM is multifactorial and among its causes there is anemia, renal failure disturbances, pain, associated infections, little food intake, metabolic alterations (due to the release of cytokines caused by to disease), mood disturbances, and hematological treatments. It is important to treat each of the causes to control this symptom to promote a better quality of life in this group of patients ${ }^{17}$.

Within the treatment for fatigue, we have pharmacological and non-pharmacological measures. Among the non-pharmacological measure, we can have the patient to rest during the day, with a limited schedule to avoid interference with the circadian cycle; blood transfusions to correct anemia, a topic that will be addressed in the section of prophylaxis and management of cytopenias, and maintaining adequate hydration and nutrition, sometimes requiring food supplements. Among the pharmacological measures, we have the use of opioids and adjuvant drugs for pain control (previously described in the pain section) and antibiotics in case of infections (the schemes should be used according to the sensitivity and causing microorganism) ${ }^{18}$.

\section{Insomnia}

Insomnia is a symptom present in up to a third of hemato-oncology patients at some point in the disease. It is closely related to the presence of depression, anxiety, or uncontrolled physical symptoms. It can also appear on its own without being an expression of a psychiatric disorder, as a side effect of other treatments. Its treatment is based on correcting the cause when possible, on adequate sleep hygiene (placing clocks, calendars, keeping the room illuminated with natural light during the day and completely dark at night, establishing sleeping schedules, and routines) and in the use of benzodiazepine, non-benzodiazepine, or neuroleptic hypnotics, if a situation of dementia or delirium occurs. Sleep inducers such as melatonin may also be used occasionally ${ }^{18}$.

Valoración multidimensional en cuidados paliativos. In: Benitez del Rosario MA, Salinas Martín A, editores. Cuidados paliativos y atención primaria. Barcelona: Springer-Verlag Ibérica, 2000; p. 207-35.

\section{Psychoaffective symptoms}

Two important aspects must be considered in the appropriate management of psycho-affective symptoms: the pharmacological one, which will be addressed in this section; and the non-pharmacological, which will be addressed in the section on psycho-emotional approaches for patients and informal primary caregivers.

\section{DePRESSION}

According to the WHO, it is a mood disorder characterized by the presence of sadness, loss of interest or pleasure, feelings of guilt, or lack of self-esteem, sleep or appetite disorders, feeling tired, and lack of concentration ${ }^{18}$.

There are clinical conditions usually associated with the presence of depressive symptoms in patients with $\mathrm{MM}$, such as changes in calcium, sodium and 
potassium levels, anemia, Vitamin B12 deficiency, pre-existing diseases, and the use of drugs: steroids, interferon, some antibiotics, chemotherapeutic agents (vincristine, vinblastine, asparaginase, intrathecal methotrexate, IL, amphotericin B, and tamoxifen) or appetite disturbances, feeling tired, and poor concentration.

Antidepressants are the indicated drugs to manage depressive episodes and their clinical manifestations. Antidepressant groups with more scientific evidence are selective serotonin reuptake inhibitors (SSRIs) and tricyclic antidepressants (TADs) ${ }^{19}$.

\section{Prophylaxis and management of cytopenias}

\section{Neutropenia}

Neutropenia is a common adverse effect of many drugs used in hemato-oncology, as well as an initial manifestation of various diseases. The development of guidelines for the management of this complication is aimed at its prophylaxis and management in solid tumors and diseases that require intensive chemotherapy, such as acute leukemia; there are no specific guidelines for neutropenia in $\mathrm{MM}$; therefore, we will adapt what is useful to us from the existing guidelines.

The initial step is to determine whether or not a patient requires prophylaxis with G-CSF in determining the risk of neutropenia. This determination is made based on the type of management and the characteristics of the patient. We will consider high-risk factors for neutropenia to aplasia causing chemotherapies (anthracyclines, antimetabolites, and the only scheme used in MM considered as high risk is DT-PACE), use of monoclonal antibodies, age over 60 years, poor physical status, active infections at the time of chemotherapy administration and those with liver or renal failure. This group of patients is considered to have a $20 \%$ risk of developing febrile neutropenia and requires prophylaxis with stimulating factors. Patients who do not fall into this category will be considered intermediate risk, with a $10 \%$ risk of developing febrile neutropenia, and the use of prophylaxis with stimulating factors will remain, at the decision of the treating physician.

The choice of the factor to be used (G-FEC vs. pegylated G-FEC) will fall on the availability of the treatment. FEC-G is one of the most widely used, the recommended dose is $5 \mathrm{mcgr} / \mathrm{kg}$ of body weight, $3-4$ days after aplasiant chemotherapy or until neutropenia is resolved. The recommended dose of pegylated factors is $6 \mathrm{mg}$, a single dose 1 day after chemotherapy has ended. In the event of febrile neutropenia, the same stimulating factor used for prophylaxis should be used, considering that there is no accurate evidence that this intervention has any impact on mortality, especially if the dose was reduced during neutropenia, and the dose to be used will be the same as for prophylaxis, but accompanied by the appropriate antibiotic scheme for each case ${ }^{16}$.

\section{Anemia}

Anemia is, per se, a manifestation of MM and of some of the gammopathies studied, its surveillance is one of the key points for the follow-up of these patients, therefore, before deciding on the use of any stimulating factor, we must rule out that such cytopenia is not a manifestation of disease progression.

It is known that erythropoietin and its analogs increase the risk of thrombosis, a risk already elevated by the biology and treatment of the disease, so its use should be discussed and weighed against this risk in cases where it has been fully demonstrated that anemia is secondary to any of the therapeutic schemes used.

In this case, transfusion of RBC concentrates should be considered for the management of anemic syndrome, according to the guideline for clinical use of blood. In this way, all patients with $\mathrm{Hb}<10 \mathrm{~g}$ and those with clinical data of tissue hypoxia (integumentary pallor, dizziness, and dyspnea of medium to small efforts) should be transfused RBC, the recommended dose will depend on each patient and presence of comorbidities, and special attention should be paid to those patients undergoing HSCT or post-transplant, in whom the indication is transfusion of irradiated $\mathrm{RBCs}^{18}$.

In case, the patient is highly dependent on RBC transfusions, the use of erythropoietin analogues as a treatment measure may be assessed, which has been shown to decrease transfusion dependence, but not positively impact the disease prognosis ${ }^{17}$.

\section{Thrombocytopenia}

Thrombocytopenia may also be an initial finding of the disease, less frequently than anemia. Administration of platelet concentrates or prophylactic platelet apheresis is indicated in the following cases: clinically stable patients with platelet counts $<10,000$ platelets 
secondary to chemotherapy, HSCT, or disease activity; patients with < 20,000 platelets with active infections, coagulation disorders, either secondary to treatment or disease, and with a history of massive bleeding. The dose of platelet concentrates to administer will be 5-8 PC every $24 \mathrm{~h}$ or one platelet apheresis every $24 \mathrm{~h}$ until the resolution of the risk factor for bleeding or the normalization of the platelet number. In the case of patients undergoing HSCT, leukoreduced platelet products should be administered ${ }^{19}$.

\section{Psycho-emotional approaches in patients and primary and informal caregivers}

From the biopsychosocial model, it is assumed that a disease comprises not only alterations at an organic level but also that there is a process of change and adaptation at the psychological, family, social, work, and spiritual level that considers the history of the patient's development, as well as its social, historical, political, and cultural context. Thus, the approach to MM implies the integration of disciplines complementary to medicine, such as psychology, which in the health field has been implementing interventions in the three levels of health care for several decades, ranging from prevention and health promotion to palliative care and well-dying care, with special emphasis on behavior, since this plays a fundamental role in the health-disease process ${ }^{20}$.

First, it is necessary to consider that informing the diagnosis of MM to a patient implies giving bad news that cause an alteration of the meaning and expectations of the present and the future of the patient's life $^{21}$. This diagnosis supposes that the disease acquires the quality of stressor, since it is perceived as a threat to the organism by the patient; therefore, response patterns are automatically generated based on the individual differences of each patient, such as coping styles and perception of resources available to deal with this threat ${ }^{22,23}$.

These responses to stress can be observed through changes at the cognitive, emotional, physiological, and behavioral levels, and in the context of a diagnosis such as MM, there are a series of responses that can be expected due to the relevance of this situation in life, such as crying, anger, sadness, anxiety, fear, negative thoughts, social isolation, irritability, exacerbation of pain, increased dyspnea, and among others.

As such, the constant monitoring of the patient and his family by the health team is an extremely important task, since MM acquires the character of chronic stressor, this can generate maladaptive responses and evolve to pathological states. Thus, the support the patient receives, whether from his family, friends, and medical team, acquires a fundamental role in the course of the disease, since it allows the patient to develop adaptive response patterns and to have the necessary resources to face effectively the demands of the disease, and thus, a better adjustment to the situation ${ }^{24}$.

Despite the fact that therapeutic advances in the treatment of MM have achieved an increase in PFS and OS rates, the effects of the disease and the toxicity produced by treatment, plus a greater intensity of symptoms and negative effects typical of the natural history of the disease still translate into a lower quality of life for the patient. Therefore, one of the greatest challenges at present is to achieve a balance between the burden of the symptoms of the disease and those derived from treatments while maintaining the functionality and quality of life of the patient ${ }^{25}$.

In view of the foregoing, there is currently recognition of the need for psychological care in patients with hematological cancers such as MM, because it is itself a risk factor for the development of mental health problems ${ }^{26}$. Psychological needs do not have a specific course of behavior, on the contrary, they can appear at the time of diagnosis, during the treatment and in the last days of life, so the evaluation performed by the health personnel represents a key factor in the recognition and care of these needs ${ }^{27}$.

From the scope of palliative medicine, these psychosocial needs acquire special relevance in the care of patients and their relatives, for these reason psychological interventions are aimed at ${ }^{28}$.

- Symptoms management such as pain, nausea, vomit, insomnia, and dyspnea;

- Psychoeducation about the disease, symptoms, treatments, and adverse effects;

- Management of emotional state in problems such as depression or anxiety;

- Development of protective and self-care behaviors such as adherence to treatment and physical activity;

- Attention to sexual problems;

- Strengthening of self-esteem, spirituality and sense of life;

- Management of grief and early grief;

- Improvement in interpersonal relationships and optimization of family resources;

- Maintenance of life values, hope, and dignity.

In this way, one of the present challenges for psychology as a discipline has been the adaptation of 
interventions to adjust them to frailty conditions in which palliative medicine works ${ }^{29}$.

Multifactors get special relevance in MM care, since it must be addressed from different aspects, from the physical to the psycho-emotional to provide quality care to the patient throughout the disease.

It is important to consider the psychologic structure and personality of the patient; as well as the presence of previous psychopathologies, and the direct experience with the disease may influence on the patient's emotional response.

Hence, it becomes necessary to count on a psychological attention protocol to allow the intervention with the patients from the initial phase and to be able to accompany them during their disease.

\section{Associated factors to emotional disturbances in MM patients}

- MM multifactors gain special relevance during treatment, since it must be approached from different angles, starting with physical to psychoemotional aspects to provide the patient with quality care during their disease;

- Persistent anxiety from the onset and during the disease, with limited resources to face it;

- Limited support networks, increasing the threat perception and physiological responses before stress;

- Low adherence to medical treatments, which results in the lack of control of the physical and psychological symptoms;

- Poor communication with the medical team, making difficult a therapeutical alliance with the medical team.

\section{Diagnostic phase}

In the diagnostic phase, the intervention of the psychologist is aimed at detecting the needs and deficits of the patient and his family, as well as providing communication skills to the patient and his family to establish common goals and treatment objectives with the medical team, in addition to maintain a level of information appropriate to the patient's personal needs ${ }^{30}$.

In addition, the psychologist intervenes by providing functional tools to the patient to provide the perception of control over the disease, such as promoting the integration of the patient's coping styles that allow them to maintain their daily functionality and start training with stress management, anxiety, and other psychological symptoms that may occur due to notification of the diagnosis of the disease. Likewise, it is important to support informal primary caregivers and family members in solving problems related to the new health situation of their patient.

\section{Treatment phase}

At this stage, it is important to support the patient in the knowledge of the disease, as well as in the symptoms associated with it and the treatments proposed by the medical team through psychoeducation sessions, where relevant, clear, and effective information are provided. Likewise, an open space should be provided for the resolution of doubts with the medical team, achieving a therapeutic alliance with the health team that will lead to adherence to treatments ${ }^{31}$.

In addition to the above, to approach to physical symptoms associated with the disease (anticipatory nausea, pain, etc.) and the expected emotional reactions (anxiety, depression, loss of sense of life, etc.) from psychology, through interventions based on evidence such as cognitive behavioral therapy, relaxation techniques, cognitive restructuring techniques, mindfulness, or meaning-focused therapy facilitate adaptation to disease during the treatment process ${ }^{32}$.

It is equally relevant to promote the creation of effective social support networks in this phase, since they will be of utmost importance to directly affect treatment adherence and the prevention of primary caregiver syndrome ${ }^{33}$.

\section{Disease-free interval phase}

The intervention of the psychologist at this stage becomes relevant, since the patient may present emotional alterations related to the previous experiences with the disease and the fear that they will appear again. This can also be reflected in constant attention to the bodies' reactions, which can create hypochondriacal attitudes, drift, and problems such as anxiety and depression.

\section{Transplantation phase}

Literature reports that before admission for a transplantation, $40 \%$ of patients present anxiety, which may disappear during follow-up, however, depression persists as the predominant symptom associated with 
prolonged hospital stays, as well as physical symptoms that can be presented. Similarly, isolation is an important part of the factors that promote depressive symptoms.

It is important to note that entering a transplantation unit can lead to various emotions such as anguish, fear, confusion, hope, and uncertainty, and there will be an important psychological adjustment. One of the moments reported as most distressing for patients and families who undergo a transplant is the signing of the informed consent, which describes all the details of the procedure and the possible consequences for the patient ${ }^{34}$.

Here, the role of the psychologist is to explore the conflicts that arise in each phase of the transplantation to carry out a detailed intervention aimed at the patient and his family, such as hospitalization in isolation, which can last up to several months. The psychological intervention will be aimed at adapting the patient to these treatment conditions, in addition to developing and enhancing resources and strategies that favor adherence to it and carrying out interventions from the cognitive behavioral approach.

\section{Recurrence phase}

The emotional impact can be much stronger than the diagnosis, and various symptoms that are difficult to control for the psychology team can appear. This stage is aimed at providing containment and emotional validation, helping to prevent and detect mental health problems, providing support strategies for adaptation to this disease state, supporting the doctor/ patient relationship to create strengthened alliances, as well as opening channels for communication for the expression and resolution of doubts regarding this new stage.

\section{Palliative phase}

This phase is particularly relevant to accompany the patient and the family before the irreparable loss of health, and the limitations that come along. To be with the family and support these new needs, as well as the mobilization of resources to manage adverse emotions such as rage, sadness, complaints, repercussions in self-sufficiency, and among others; hence, it is important to be able to detect the patients specific needs and prioritize those more relevant.
In this final stage of the disease, physical and emotional symptoms, cognition, spiritual, and psychological needs become more relevant; therefore, attention must be paid to emotions management, communication between doctor/family and patient, decision-making, and attention of the primary caregiver.

In this sense, it is important to prevent caregiver overload, promoting self-care and healthy habits, as well as promoting family planning and organization in patient care.

Likewise, one of the psychologist's interventions is focused on accompanying the family in the preparation of grief, through various clinical interventions (family reunions, psychoeducation, and therapy tailored to the needs of the relative) that can promote active communication and conflict resolution with the patient.

\section{Spirituality}

Spirituality is generally recognized as encompassing experiential aspects, either related to participation in religious practices or to the recognition of a general feeling of peace and connectivity. Spirituality is a resource to transcend the suffering that accompanies loss and to promote acceptance in the process of dying.

Spiritual care is based on the bio-psycho-social-spiritual care model, and on an integral perspective of the person, recognizing, and enhancing the resources of patients and facilitating healing by transcending suffering. Patients accept that professionals care about their spiritual needs and want to be supported in the dying process.

It is important to validate the spiritual needs of the patient which may be oral or written. There are several instruments to evaluate spiritual belief systems, the integration of a spiritual community, medical attention implications, end of life events planning, and among others. The approach of the spiritual aspects has implications in improving the quality of life, and a higher probability to receive attention at the end of the life $^{35}$

\section{Module 9}

\section{Thromboprophylaxis and hemostasia in MM}

It is well known that cancer is a risk factor for thrombosis, with an increased risk of 4-7 times in comparison with the general population. MM increases 9 
Table 1. DVT risk factors in multiple myeloma patients

\begin{tabular}{|l|l|l|}
\hline Patient related & Disease related & Treatment related \\
\hline AGE & Monoclonal component related & IMID \\
\hline BMI $>30$ & Hiperviscosity & High dose dexamethasone \\
\hline Family history of DVT & Fibrin mesh disorders & Polychemotherapy \\
\hline Immobilization & Lupus anticoagulant & Doxorubicin \\
\hline Comorbidities & Antithrombin inhibition, PC and S & Central catheter \\
\hline Recent surgery & Related to the hypercoagulability component & \\
\hline Central catheter & Increase of FT, f fibrinogen, VWF, and FVIII & \\
\hline Acute infection & Decrease of PC, S, and APT & \\
Hospitalization & Increase of PAI 1
\end{tabular}

Table 2. Risk factors for thrombosis

Risk factor
Individual factors
- Obesity (BMI > 30)
- Pacemaker
- Prior thrombosis
- Related diseases
- DM
- SBP
- Renal disease
- Infection
- Bedridden patient
- Surgery
- EPO use
- Coagulopathies
Myeloma related factors
- Myeloma in itself
- Hiperviscosity
Therapy related factors
I. IMiD in combination with dexamethasone high dose,
doxorubicin, or combined CT.
Modified from NCCN 2019.

times the risk of thrombosis because this a malignancy, and therefore phenomena of the pathophysiology of the disease, treatment and patient's own factors, with an estimated thrombosis incidence in myeloma of 8-22/1000 persons/year'.

The risk of deep venous thrombosis is higher in the first 3-6 chemotherapy cycles in newly diagnosed patients, in comparison with arterial thrombosis which increases in the year after the diagnosis ${ }^{2}$.

The pathophysiology of thrombosis in MM depends on factors inherent to the disease, the patient, and the treatment used.

The factors related to the disease are divided into:
A. Monoclonal component: includes the production of paraprotein factors which cause excessive blood viscosity, resulting in an alteration of the fibrin structure, and the delay of fibrinolysis, as well as the production of pro-coagulant antibodies of the lupus anticoagulant type.

B. Hypercoagulability: increased Factor VIII, VWF and fibrinogen, decreased Protein $\mathrm{C}$ and $\mathrm{S}$, increased PAI-1.

The most significant characteristics of the patient considered to be at risk are: age, older than 60 years; overweight; cardiac, renal, pulmonary, and metabolic comorbidities; a history of surgery $<6$ weeks before diagnosis; infection; central venous accesses; and coagulopathies (Table 1$)^{1}$.

Treatment is the third element that comes into play when defining the risk of thrombosis in myeloma patients. It is well known that the use of chemotherapy and high-dose steroids, such as dexamethasone at doses higher than $480 \mathrm{mg} / \mathrm{cycle}$, should be taken into account when deciding whether to give treatment or not.

IMiD deserve special attention, this group of drugs has been shown to increase thrombotic events in varying degrees, this is due to increased expression of tissue factor, VEGF, resistance to activated protein C, and among others (reference TO). Clear examples are thalidomide, which is frequently reported with thrombotic events of $2-4 \%$ used as monotherapy, and up to $17 \%$ in combination with chemotherapy and steroids 1 .

In other studies, the combined use of thalidomide and dexamethasone reported up to $26 \%$ of thrombosis, while the combination with anthracycline confers 


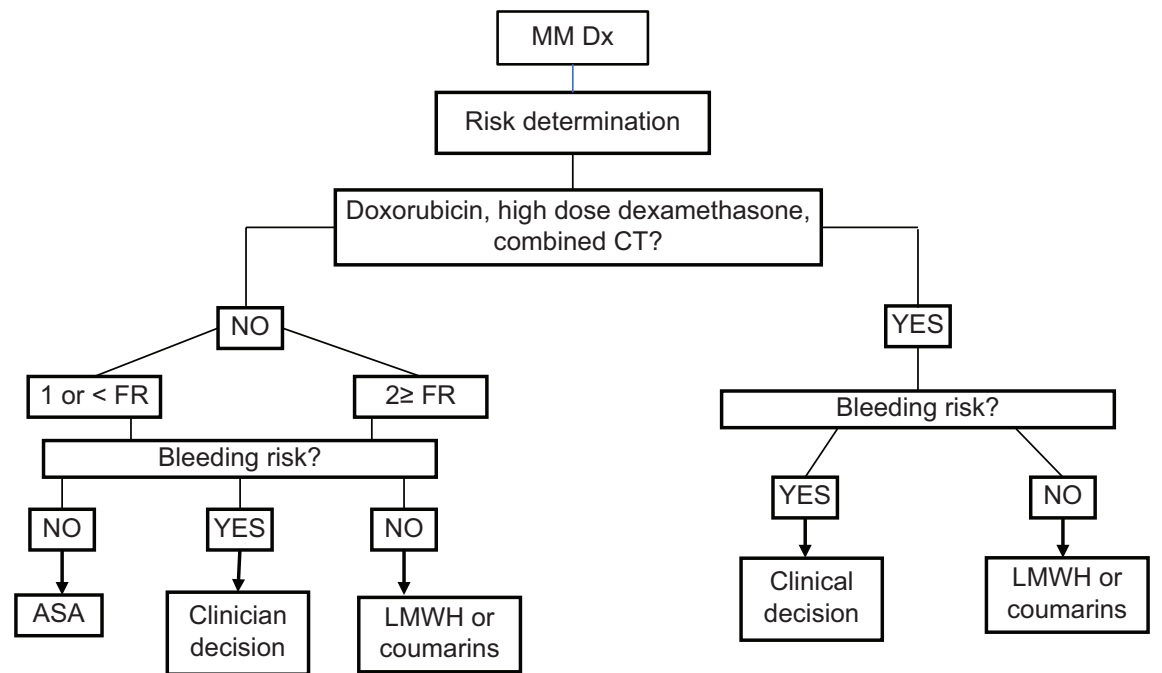

Figure 1. Thrombotic Risk.

MM: multiple myeloma; DX: diagnostic; FR: risk factor; ASA: acetylsalicylic acid: LMWH: low molecular weight heparin.

Table 3. Anticoagulant treatment in multiple myeloma

\begin{tabular}{l|l|l|}
\hline $\begin{array}{l}\text { Treatment } \\
\text { LMWH 1 mg/kg }\end{array}$ & $\begin{array}{l}\text { Days } \\
\text { every 12 h days initially, followed by a } \\
\text { change to VKA, DAC, or LMWH } \\
\text { (prophylactic dose) }\end{array}$ & 4-6 months* \\
\hline VKK & INR 2-3 & 4-6 months* \\
\hline DAC & No evidence & $4-6$ months $^{*}$ \\
\hline
\end{tabular}

*Individualized by each patient's risk.

a risk of $35 \%$. In the case of lenalidomide, the reports are similar.

There are several international guidelines for the use of thromboprophylaxis in malignant diseases, but in most of these, there is a special consideration for MM due to the high frequency of thrombosis and the risk implied by its characteristics. There are no specific risk predictor models for these patients, but efforts have been made taking into account the number of risk factors available at the time of diagnosis, to guide the clinician regarding which medicine to the use for prophylaxis (Table 2).

The decision to use aspirin versus heparins or coumarins will be made based on the number of factors present at the time of assessment and the absence of contraindications to their use. Aspirin is the most frequently used prophylactic medication. Acetylsalicylic acid has been shown to be effective in preventing thrombotic events in sub-analyses of several treatment studies; however, the information obtained from these studies is not robust enough to be considered high-quality sources for this recommendation, since in most of them patients with a high risk of thrombosis have been eliminated ${ }^{3}$.

IMWG and NCCN guidelines accept that the use of ASA as monotherapy may be useful for low-risk patients (one individual factor or related to myelo$\mathrm{ma}$ ), but not for those initiating an IMiD plus chemotherapy ${ }^{3}$.

Low-molecular-weight heparin and coumarins have shown similar efficacy in the prevention of thrombosis in a comparative study between these drugs and $\mathrm{ASA}^{4}$. In case of coumarins, the INR to follow is between 2 and 3 , the advantage of an oral administration and the existence of an antidote, as well as studies specifically aimed at demonstrating its efficacy in patients with MM make them an excellent option; however, its monitoring and management are complex and may have repercussions on patient adherence. Low-molecular-weight heparins decrease the frequency of thrombus in the same way as coumarins, their great disadvantage is the route of administration, and their advantage is their relative safety and little interaction with other medications or foods; however, the fact of being injected also impacts negatively on the adherence to it.

For several years now, there has been an extensive discussion regarding the role of direct anticoagulants in myeloma and cancer in general. While less recent guidelines, such as the IMWG, did not recommend these drugs due to the lack of 
appropriate studies to demonstrate their safety, more recent guidelines open up the possibility of their use, especially in those patients who have contraindications to traditional ACs, those who do not wish to receive the latter or those who are resistant to them. In the area in which we can find more information about it is in the treatment of proven thrombosis.

Direct anticoagulants have shown superiority over aspirin in the management after the acute phase of thrombosis, the phase in which the indication is still LMW heparin. Although, the oral administration and not requiring monitoring are attractive conditions for its use, there are some objections that we must consider. Patients with myeloma and cancer in general have alterations in the gastrointestinal absorption of medications due to chemotherapy, secondary nausea, the use of multiple drugs and other alterations. In addition to the lack of knowledge of the interactions that may exist between ACDs and the medications used for myeloma management, their routine use may be questionable ${ }^{5}$.

There is a special group in which DAC may be the first-choice treatment (frail patients or long distances to sample collection).

NCCN, IMWG, and ESMO have established management algorithms according to the patient risk, considering those with an individual factor or one of those related to myeloma previously described as low risk and high risk for those with two or more, or those with prior history of VTE (NCCN). Having categorized the thrombotic risk and ruled out the risk of bleeding (presence of thrombocytopenia, renal failure, liver failure, hemophilia, or HAS) in our patients, measures to be taken include the following:

In case patients with renal failure with GFR $<30 \mathrm{ml}$, dose adjustments, or switching to another type of heparin should be considered (Figure 1).

Surgical procedures tend to be common events in cancer patients, as well as prolonged hospitalizations due to drug toxicity or other complications. During hospitalization periods the use of prophylactic full dose low-molecular-weight heparin (LMWH) is recommended. In case a surgical procedure is needed, LMWHs are also the choice over other agents ${ }^{6}$.

With respect to management of established thrombosis in these patients, it will depend on the site, grade and severity of the thrombosis; besides, international guidelines should be followed and tailored for each thrombosis type, and if possible, involve a thrombosis and coagulation expert.
In Table 3 are summarized some of the interventions recommenden by local and international guidelines.

\section{References}

\section{Module 1}

\section{Classification of monoclonal gammopathies}

1. Kumar SK, San Miguel J. Plasma cell disorders. En: Steensma DP Cuker A, Kempton CL, Nowakowski GS, editores. ASH-SAP Textbook. Sixth ed. The American Society of Hematology; 2016.

2. Maciocia N, Wechalekar A, Yong K. Monoclonal gammopathy of undetermined significance (MGUS) and smoldering myeloma (SMM): a practical guide to management. Hematol Oncol. 2017;35:432-9.

3. Merlini G. Determining the significance of MGUS. Blood. 2014; 123:305-7.

4. Kyle A, Therneau T, Rajkumar SV, Offord JR, Larson DR, Plevak MF, et al. A longtterm study of prognosis in monoclonal gammopathy of undetermined significance. N Engl J Med. 2002:346:564-9.

5. Van Nieuwenhuijzen N, Spaan I, Peperzak VR. From MGUS to multiple myeloma, a paradigm for clonal evolution of premalignant cells. Cancer Res. 2018;78:10.

6. Ravindran A. Prevalence, incidence and survival of smoldering multiple myeloma in the United States. Blood Cancer J. 2016;6:e486.

7. Rajkumar SV, Larson D, Kyle RA. Diagnosis of smoldering multiple myeloma. N Engl J Med. 2011;365:474-5.

8. Kastritis E, Terpose E, Moulopoulos L, Spyropoulou-Vlachou M, Kanellias N, Eleftherakis-Papaiakovou E, et al. Extensive bone marrow infiltration and abnormal free light chain ratio identifies patients with asymptomatic myeloma at high risk for progression to symptomatic disease. Leukemia. 2013;27:947-53.

9. de Waal EG, Leene M, Veeger N, Vos HJ, Ong F, Smit WG, et al. Progression of a solitary plasmacytoma to multiple myeloma. A population-based registry of the northern Netherlands. $\mathrm{Br} J$ Haematol. 2016; 175:661-7.

10. Wilder RB, Ha CS, Cox JD, Weber D, Delasalle K, Alexanian R. Persistence of myeloma protein for more than one year after radiotherapy is an adverse prognostic factor in solitary plasmacytoma of bone. Cancer. 2002:94:1532-7.

11. Dores GM, Landgren O, McGlynn KA, Curtis RE, Linet MS, Devesa SS Plasmacytoma of bone, extramedullary plasmacytoma, and multiple myeloma: incidence and survival in the United States, 1992-2004. Br J Haematol. 2009;144:86-94

\section{Module 2}

POEMS (polyneuropathy, organomegaly, endocrinopathy, monoclonal gammopathy) syndrome, Castleman disease and Waldeström Macroglobulinemia (WM)

1. Dispenzieri A. POEMS syndrome: 2017 Update on diagnosis, risk stratification, and management. Am J Hematol. 2017;92:814-29.

2. Dispenzieri A, Kyle RA, Lacy MQ, Rajkumar SV, Therneau TM Larson DR, et al. POEMS syndrome: definitions and long-term outcome. Blood. 2003;101:2496-506.

3. Nasu S, Misawa S, Sekiguchi Y, Shibuya K, Kanai K, Fujimaki Y, et al. Different neurological and physiological profiles in POEMS syndrome and chronic inflammatory demyelinating polyneuropathy. J Neurol Neurosurg Psychiatr. 2012;83:476-9.

4. Kourelis TV, Buadi FK, Kumar SK, Gertz MA, Lacy MQ, Dingli D, et al. Long-term outcome of patients with POEMS syndrome: an update of the Mayo Clinicexperience. Am J Hematol. 2016;91:585-9.

5. Kuwabara S, Misawa S, Kanai K, Sawai S, Hattori T, Nishimura M, et al. Thalidomide reduces serum VEGF levels and improves peripheral neuropathy in POEMS syndrome. J Neurol Neurosurg Psychiatr. 2008;79:1255-7.

6. Castleman B, Towne V. CASE records of the Massachusetts General Hospital weekly clinicopathological exercises: case 40011. N Engl J Med. 1954;250:26-30.

7. Liu A, Nabel CS, Finkelman B, Ruth JA, Kurzrock R, van Rhee F, et al. Idiopathic multicentric Castleman's disease: a systematic literature review. Lancet Haematol. 2016:3:e163-75.

8. Kyle RA, Treon SP, Alexanian R, Barlogie B, Bjorkholm M, Dhodapkar M, et al. Prognostic markers and criteria to initiate therapy in Waldenstrom's 
macroglobulinemia: consensus panel recommendations from the second international workshop on Waldenstrom's Macroglobulinemia. Semin Oncol. 2003;30:116e20.

9. Bélec L, Authier FJ, Mohamed AS, Soubrier M, Gherardi RK. Antibodies to human herpesvirus 8 in POEMS (polyneuropathy, organomegaly, endocrinopathy, M protein, skin changes) syndrome with multicentric Castleman's disease. Clin Infect Dis. 1999;28:678-9.

10. Owen RG, Treon SP, Al-Katib A, Fonseca R, Greipp PR, McMaster ML, et al. Clinicopathological definition of Waldenstrom's macroglobulinemia: consensus panel recommendations from the second international workshop on Waldenstrom's macroglobulinemia. Semin Oncol. 2003;30:110-5

11. Herrinton LJ, Weiss NS. Incidence of Waldenström's macroglobulinemia. Blood. 1993;82:3148-50

12. Phekoo KJ, Jack RH, Davies E, Møller H, Schey SA, South Thames Haematology Specialist. The incidence and survival of Waldenstrom's macroglobulinaemia in South East England. Leuk Res. 2008;32:55-9.

13. Teras LR, DeSantis CE, Cerhan JR, Morton LM, Jemal A, Flowers CR. 2016 US Iymphoid malignancy statistics by World Health Organization subtypes. CA Cancer J Clin. 2016;66:443-59.

14. McMaster ML. Familial Waldenstrom's macroglobulinemia. Semin Oncol. 2003;30:146-52.

15. Ruiz-Argüelles GJ, Ramírez-Cisneros FJ, Flores-Martínez J, CernudaGraham MC. Waldenströjm's macroglobulinemia is infrequent in Mexican mestizos: experience of a hematological diseases referral center. Rev Invest Clin Mex. 2000:52:497-9.

16. Kristinsson SY, Eloranta S, Dickman PW, Andersson TM, Turesson I, Landgren $\mathrm{O}$, et al. Patterns of survival in lymphoplasmacytic lymphoma/waldenström macroglobulinemia: a populationロbased study of 1,555 patients diagnosed in Sweden from 1980 to 2005. Am J Hematol. 2013;88:60-5.

17. Kastritis E, Leblond V, Dimopoulos MA, Kimby E, Staber P, Kersten MJ, et al. Waldenström's macroglobulinaemia. ESMO clinical practice guidelines for diagnosis, treatment and follow-up. Ann Oncol. 2018:29 Suppl 4:iv41-50.

18. Yun S, Johnson AC, Okolo ON, Arnold SJ, McBride A, Zhang L, et al. Waldenström's macroglobulinaemia: review of pathogenesis and management. Clin Lymphoma Myeloma Leuk. 2017;17:252-62.

19. Ngo VN, Young RM, Schmitz R, Jhavar S, Xiao W, Lim KH, et al. Oncogenically active MYD88 mutations in human lymphoma. Nature. 2011;470:115-9.

20. Treon SP, Xu L, Yang G, Zhou y, Liu X, Cao Y, et al. MYD88 L265P somatic mutation in Waldenström's macroglobulinemia. N Engl J Med. 2012;367:826-33.

21. Kristinsson SY, Landgren $\mathrm{O}$. What causes Waldenström's macroglobulinemia: genetic or immunerelated factors, or a combination? Clin Lymphoma Myeloma Leuk. 2011:11:85-7.

22. Cao Y, Hunter ZR, Liu X, Xu L, Yang G, Chen J, et al. The WHIM-like CXCR4S338X somatic mutation activates AKT and ERK, and promotes resistance to ibrutinib and other agents used in the treatment of Waldenstrom's Macroglobulinemia. Leukemia. 2015;29:169-76

23. Paiva B, Montes MC, Garcia-Sanz R, Ocio EM, Alonso J, de Las Heras N, et al. Multiparameter flow cytometry for the identification of the Waldenstrom's clone in IgM-MGUS and Waldenstrom's macroglobulinemia: new criteria for differential diagnosis and risk stratification. Leukemia. 2014;28:166-73.

24. Dimopoulos MA, Panayiotidis P, Moulopoulos LA, Sfikakis P, Dalakas M. Waldenström's macroglobulinemia: clinical features, complications, and management. J Clin Oncol. 2000;18:214.

25. Dhodapkar MV, Hoering A, Gertz MA, Rivkin S, Szymonifka J, Crowley J, et al. Long-term survival in Waldenstrom macroglobulinemia: 10-year follow-up of Southwest oncology group-directed intergroup trial S9003. Blood. 2009;113(4):793e6.

26. Gertz MA. Waldenström macroglobulinemia treatment algorithm 2018. Blood Cancer J. 2018;8:40.

27. Treon SP, Emmanouilides C, Kimby E, Kelliher A, Preffer F, Branagan AR et al. Extended rituximab therapy in Waldenström'smacroglobulinemia. Ann Oncol. 2005;16:132-8.

28. Dimopoulos MA, Anagnostopoulos A, Kyrtsonis MC, Zervas K, Tsatalas C Kokkinis $\mathrm{G}$, et al. Primary treatment of Waldenströmmacroglobulinemia with dexamethasone, rituximab, and cyclophosphamide. J Clin Oncol. 2007;25:3344-9.

29. Kastritis E, Gavriatopoulou M, Kyrtsonis MC, Roussou M, Hadjiharissi E, Symeonidis A, et al. Dexamethasone, rituximab, and cyclophosphamide as primary treatment of Waldenström macroglobulinemia: final analysis of a phase 2 study. Blood. 2015;126(11):1392-4.

30. Buske C, Hoster E, Dreyling M, Eimermacher H, Wandt H, Metzner B, et al. The addition of rituximab to front-line therapy with $\mathrm{CHOP}(\mathrm{R}-\mathrm{CHOP})$ results in a higher response rate and longer time to treatment failure in patients with lymphoplasmacytic lymphoma: results of a randomized trial of the German Low-Grade Lymphoma Study Group (GLSG). Leukemia. 2009; 23(1):153-161.

31. Treon SP, Branagan AR, loakimidis L, Soumerai JD, Patterson CJ, Turnbull B, et al. Long-term outcomes to fludarabine and rituximab in Waldenström macroglobulinemia. Blood. 2009;113:3673-8.

32. Rummel MJ, Niederle N, Maschmeyer G, Banat GA, von Grünhagen U, Losem C, et al. Bendamustine plus rituximab versus CHOP plus rituximab as first-line treatment for patients with indolent and mantle-cell lymphomas: an openlabel, multicentre, randomised, phase 3 non-inferiority trial. Lancet. 2013;381:1203-10.

33. Ghobrial IM, Xie W, Padmanabhan S, Badros A, Rourke M, Leduc R, et al. Phase II trial of weekly bortezomib in combination with rituximab in untreated patients with Waldenström macroglobulinemia. Am J Hematol. 2010;85(9):670-674.

34. Facon T, Brouillard M, Duhamel A, Morel P, Simon M, Jouet JP, et al. Prognostic factors in Waldenstrom's macroglobulinemia: a report of 167 cases. J Clin Oncol 1993:11:1553e8.

35. Dimopoulos MA, Zervas C, Zomas A, Hamilos G, Gika D, Efstathiou E, et al. Extended rituximab therapy for previously untreated patients with Waldenström's macroglobulinemia. Clin Lymphoma. 2002:3:163-6.

36. Treon SP, loakimidis L, Soumerai JD, Patterson CJ, Sheehy P, Nelson M, et al. Primary therapy of Waldenström macroglobulinemiawith bortezomib, dexamethasone, and rituximab: WMCTG clinical trial 05-180. J Clin Oncol. 2009;27:3830-5.

37. Dimopoulos MA, GarcGarcía-Sanz R, Gavriatopoulou M, Morel P, Kyrtsonis MC, Michalis $\mathrm{E}$, et al. Primary therapy of Waldenstrommacroglobulinemia (WM) with weekly bortezomib, low-dose dexamethasone, and rituximab (BDR): long-term results of a phase 2 study of the European Myeloma Network (EMN). Blood. 2013;122:3276-82.

38. Treon SP, Hanzis C, Tripsas C, loakimidis L, Patterson CJ, Manning RJ, et al. Bendamustine therapy in patients with relapsed or refractoryWaldenström's macroglobulinemia. Clin Lymphoma Myeloma Leuk. 2011:11:133-5.

\section{Module 3}

\section{Myeloma overview}

1. Kyle A, Gertz MA, Witzig T, Lust JA, Lacy M, Dispenzieri A, et al. Review of 1027 patients with newly diagnosed multiple myeloma. Mayo Clin Proc. 2003;78:21-33.

2. Chng WJ, Dispenzieri A, Chim CS, Fonseca R, Goldschmidt $H$, Lentzsch S, et al. IMWG consensus on risk stratification in multiple myeloma. Leukemia. 2014;28:269-77.

3. Ziogas DC, Dimopoulos MA, Kastritis E. Prognostic factors for multiple myeloma in the era of novel therapies. Expert Rev Hematol. 2018;11(11): 863-79.

4. Moreau P, San Miguel J, Sonneveld P, Mateos MV, Zamagni E, Avet-Loiseau $\mathrm{H}$, et al. Multiple myeloma: ESMO clinical practice guidelines for diagnosis, treatment and follow-up. Ann Oncol. 2017;28 Suppl 4:iv52-61.

5. Rajkumar SV. Multiple myeloma: 2016 update on diagnosis, risk-stratification and management. Am J Hematol. 2016;91:719-34.

\section{Module 4}

\section{Treatment}

1. Sekine L, Ziegelmann PZ, Manica D, Pithan C, Sosnoski M, Morais VD, et al. Frontline treatment for transplant-eligible multiple myeloma: a 6474 patients networks meta-analysis. Hematol Oncol. 2019;37:62-74.

2. Kumar S, Flinn I, Richardson PG, Hari P, Callander N, Noga SJ, et al. Randomized, multicenter, phase 2 study (EVOLUTION) of combinations of bortezomib, dexamethasone, cyclophosphamide, and lenalidomide in previously untreated multiple myeloma. Blood. 2012:119:4375-82.

3. Barlogie B, Anaissie E, van Rhee F, Haessler J, Hollmig K, Pineda-Roman M, et al. Incorporating bortezomib into upfront treatment for multiple myeloma: early results of total therapy 3. Br J Haematol. 2007:138:176-85.

4. Dingli D, et al. Therapy for Relapsed Multiple Myeloma: Guidelines From the Mayo Stratification for Myeloma and Risk-Adapted Therapy. Mayo Clin Proc. 2017 ; 92(4): 578-598

5. Sonneveld $P$. Management of multiple myeloma in the relapsed/refratory patient. Hematology Am Soc Hematol Educ Program. 2017; Dec8;2017(1):508-517

6. Laubach, $J$ et al. Management of relapsed multiple myeloma: recommendationsof the International Myeloma Working Group. Leukemia. 2016. 30, 1005-1017.

7. Stewart AK, Rajkumar SV, Dimopoulos MA, Masszi T, Špička I, Oriol A et al. Carfilzomib, lenalidomide, and dexamethasone for relapsed multiple myeloma. N Engl J Med. 2015;372(2):142-52.

8. Dimopoulos MA, Oriol A, Nahi H, San-Miguel J, Bahlis NJ, Usmani SZ, et al. Daratumumab, lenalidomide, and dexamethasone for multiple myeloma. N Engl J Med. 2016;375(14):1319

9. Palumbo A, Chanan-Khan A, Weisel K, Nooka AK, Masszi T, Beksac M, et al. Daratumumab, bortezomib, and dexamethasone for multiple myeloma. N Engl J Med. 2016;375(8):754-66

10. Richardson PG, Siegel DS, Vij R, Hofmeister CC, Baz R, Jagannath S, et al. Pomalidomide alone or in combination with low-dose dexametha- 
sone in relapsed and refractory multiple myeloma: a randomized phase 2 study. Blood. 2014;123(12):1826-32.

11. Richardson PG, Oriol A. Pomalidomide, bortezomib, and dexamethasone for patients with relapsed or refractory multiple myeloma previously treated with lenalidomide (OPTIMISMM): a randomised, open-label, phase 3 trial. Lancet Oncol. Lancet Oncol 2019;20:781-94.

12. Shah JJ, Stadtmauer EA, Abonour R, Cohen AD, Bensinger WI, Gasparetto $\mathrm{C}$, et al. Carfilzomib, pomalidomide, and dexamethasone for relapsed or refractory myeloma. Blood. 2015;126:2284-90.

13. Chari A, Suvannasankha A, Fay JW, Arnulf B, Kaufman JL, Ifthikharuddin JJ, et al. Daratumumab plus pomalidomide and dexamethasone in relapsed and/or refractory multiple myeloma. Blood. 2017:130:974-81.

14. Krishnan A, Kapoor P, Palmer J, Tsai NC, Kumar S, Lonial S, et al, Phase I/II trial of the oral regimen ixazomib, pomalidomide, and dexamethasone in relapsed/refractory multiple myeloma. Leukemia. 2018;32:1567-74.

\section{Module 5}

\section{Response criteria in multiple myeloma}

1. Rajkumar SV, Dimopoulos MA, Palumbo A, Blade J, Merlini G, Mateos $M V$, et al. International myeloma working group updated criteria for the diagnosis of multiple myeloma. Lancet Oncol. 2014:15:e538-48.

2. Munshi N, Avet-Loiseau L. Minimal residual disease predicts superior survival in patients with multiple myeloma: a meta-analysis. JAMA Oncol. 2017:3:28-35

3. Chng WJ, Ddispenzieri A. International myelola working group consensus on risk stratification in multiple myeloma review. Leukemia. 2014;28: 269-77.

4. Resumen Oncoguía Mieloma Múltiple 2017 - versión 3.1 [Internet]. Sociedad Española de Hematología y Hemoterapia, Grupo cooperativo para el estudio de gamapatías monoclonales de Castilla y León; 2017 [fecha de última actrualización: 12 de junio de 2017]. Disponible en: https://www.sehh.es/publicaciones/guias-y-documentos/122223-resumen-oncoguia-mieloma-multiple-2017-version-3-1

\section{Module 6}

\section{Usefulness of the flow cytometry in the multiple myeloma diagnosis}

1. Paiva B, San Miguel JF. Multiparameter flow cytometry quantification of bone marrow plasma cells at diagnosis provides more prognostic information than morphological assessment in myeloma patients. Haematologica. 2009;94:1599-602.

2. Kalina T, Flores-Montero J, van der Velden VH, Martin-Ayuso M, Böttcher S, Ritgen M, et al. EuroFlow standardization of flow cytometer instrument settings and immunophenotyping protocols. Leukemia. 2012;26:1986-2010

3. Montero JF, Sanoja-Flores L, Paiva B, Puig N, García-Sánchez O, Böttcher S, et al. Next generation flow for highly sensitive and standardized detection minimal disease in multiple myeloma. Leukemia. 2017; 31:2094-103.

4. Kumar S, Piava B, Anderson KC, Durie B, Landgren O, Moreau P, et al. International myeloma working group consensus criteria for response and minimal residual disease assessment in multiple myeloma. Lancet Oncol. 2016;17:e328-46.

5. Landgren $\mathrm{O}$, Rustad $\mathrm{EH}$. Meeting report: advances in minimal residual disease testing in myeloma multiple 2018. Adv Cell Gene Ther. 2019;2:e26.

\section{Module 7}

\section{Hematopoietic stem cell transplantation in multiple myeloma}

1. Jain $\mathrm{T}$, Kunze $\mathrm{KL}$, Temkit $\mathrm{M}$, et al. Comparison of reduced intensity conditioning regimens used in patients undergoing hematopoietic stem cell transplantation for myelofibrosis. Bone Marrow Transplant 54, $204-$ 211 (2019).

2. Kapoor P, Kumar SK, Dispenzieri A, Lacy MQ, Buadi F, Dingli D, et al. Importance of achieving stringent complete response after autologous stem-ceII transplantation in multiple myeloma. J Clin Oncol. 2013:31:4529-35.

3. Attal, M, Lauwers-Cances V, Hulin, C, Leleu X, Caillot D, Escoffre, M, et al. Lenalidomide, bortezomib, and dexamethasone with transplantation for myeloma. N Engl J Med. 2017;376:1311-20.
4. Straka C, Liebisch P, Salwender H, Hennemann B, Metzner B, Knop S, et al. Autotransplant with and without induction chemotherapy in older multiple myeloma patients: long-term outcome of a randomized trial. Haematologica. 2016;101:1398-406.

5. Ferm JP, Ravaud P, Chevret S, Divine M, Leblond V, Belanger C, et al. High-dose therapy and autologous peripheral blood stem cell transplantation in multiple myeloma: up-front or rescue treatment? Results of a multicenter sequential randomized clinical trial. Blood. 1998:92:3131-6.

6. Kim MG, Han N, Lee EK, Kim T. Pegfilgrastim vs filgrastim in PBSC mobilization for autologous hematopoietic SCT: a systematic review and meta-analysis. Bone Marrow Transplant. 2015;50:523-30.

7. Mikhael J, Ismaila N, Cheung MC, Costello C, Dhodapkar MV, Kumar S, et al. Treatment of multiple myeloma: ASCO and CCO joint clinical practice guideline. J Clin Oncol. 2019;37:1228-63.

8. Giralt S, Costa L, Schriber J, Dipersio J, Maziarz R, McCarty J, et al. Optimizing autologous stem cell mobilization strategies to improve patient outcomes: consensus guidelines and recommendations. Biol Blood Marrow Transplant. 2014;20:295-308.

9. Gonsalves W, Buadi F, Ailawadhi S, Bergsagel P, Khan AA, Dingli D, et al. Utilization of hematopoietic stem cell transplantation for the treatment of multiple myeloma: a mayo stratification of myeloma and risk-adapted therapy (mSMART) consensus statement. Bone Marrow Transplant. 2019;54:353-67.

10. Park SS, Kim K, Kim SJ. A phase I/II, open-label, prospective, multicenter study to evaluate the efficacy and safety of lower doses of bortezomib plus busulfan and melphalan as a conditioning regimen in patients with multiple myeloma undergoing autologous peripheral blood stem cell transplantation: the KMM103 study. Biol Blood Marrow Transplant. 2019:25:1312-9.

11. Czerw T, Sadus-Wojciechowska M, Michalak K, Najda J, Mendrek W, Sobczyk-Kruszelnicka M, et al. Increased efficacy of stem cell chemomobilization with intermediate-dose cytarabine plus granulocyte colony-stimulating factor (G-CSF) compared with G-CSF alone in patients with multiple myeloma: results of a randomized trial. Biol Blood Marrow Transplant. 2019;25:248-55.

12. Andritsos LA, Huang $Y$, Abraham I, Huff K, Scrape SR, Fan $T$, et al. Clinical and cost outcomes of pre-emptive plerixafor administration in patients with multiple myeloma undergoing stem cell mobilization. Leuk Res. 2019;85:106215.

13. Wallis W, Qazilbash M. Peripheral blood stem cell mobilization in multiple myeloma: Growth factors or chemotherapy?. World J Transplant 2017.

14. Muzaffar $\mathrm{H}$. quzilbash. A randomized phase III trial of busulfan + melfalan vs melphalan alone for multiple myeloma. Blood. 2017:130:399.

15. Park SS, Kim K, Kim SJ, Lee JH, Yoon SS, Mun YC, et al. A phase I/II, open-label, prospective, multicenter study to evaluate the efficacy and safety of lower doses of bortezomib plus busulfan and melphalan as a conditioning regimen in patients with multiple myeloma undergoing autologous peripheral blood stem cell transplantation: the KMM103 study. Biol Blood Marrow Transplant. 2019;25:1312-9.

16. Farag S, Jeker B, Bacher U, Taleghani BM, Mueller BU, Novak U, et al. Dose-intensified bendamustine and melphalan (BenMel) conditioning before second autologous transplantation in myeloma patients. Hematol Oncol. 2018:36:671-8.

17. Badros A, Barlogie B, Siegel E, Morris C, Desikan R, Zangari M, et al. Autologous stem cell transplantation in elderly multiple myeloma patients over the age of 70 years. Br J Haematol. 2011;114:600-7.

18. Dimopoulos MA, Gay F, Schjesvold F, Beksac M, Hajek R, Weisel KC et al. Oral ixazomib maintenance following autologous stemm cell transplantation (TORMALINE- MM3): a double-blind, randomised, placebo-sontrolled phase 3 trial. Lancet. 2019;393:253-64.

19. Gay F, Engelhardt M, Terpos E, Wäsch R, Giaccone L, Auner HW, et al. From transplant to novel celular therapies in multiple myeloma: European yeloma network guidelines and future perspectives. Haematologica. 2018; 103:197-211.

20. McCarthy MD, Owzar K, Hofmeister CC, Hurd DD, Hassoun H, Richardson PG, et al. Lenalidomide after stem-cell transplantation for multiple myeloma. N Engl J Med. 2012;366:1770-81.

\section{Module 8}

\section{Pain and supportive treatments}

1. Cömert M, Güneş $A E$, Sahin F, Saydam G. Quality of life and supportive care in multiple myeloma. Turk J Haematol. 2013;30:234-46.

2. Yeh A, Raje E. Denosumab for the treatment of bonedisease in solid tumors and multiple mieloma. Future Oncol. 2018:14:195-203.

3. Edelstyn GA, Gillespie PJ, Grebbell FS. The radiological demonstration of osseous metastases. Experimental observations. Clin Radiol. 1967:18:158-62.

4. Regelink JC, Minnema MC, Terpos E, Kamphuis MH, Raijmakers PG, den Bos IC, et al. Comparison of modern and conventional imaging te- 
chniques in establishing multiple myeloma-related bone disease: a systematic review. Br J Haematol. 2013;162:50-61.

5. Terpos E, Morgan G, Dimopoulos MA, Drake MT, Lentzsch S, Raje N et al. International myeloma working group recommendations for the treatment of multiple myeloma-related bone disease. J Clin Oncol. 2013;31:2347-57.

6. Dimopoulos MA, Kastritis E, Anagnostopoulos A, Melakopoulos I, Gika D, Moulopoulos LA, et al. Osteonecrosis of the jaw in patients with multiple myeloma treated with bisphosphonates: evidence of increased risk after treatment with zoledronic acid. Haematologica. 2006;91:968-71.

7. Dahan A, Niesters M, Olofsen E, Smith T y Overdyk F. Opioids. En: Barash P, Cullen BF, Stoelting RK, Cahalan MK, Stock MC, Ortega R. Clinical Anesthesia. 7th ed. Wolters Kluwer, Lippincott Williams; 2013.

8. Buitrago R. Fisiología y Farmacología de Opioide. Uso de opioides en el tratamiento del dolor. Manual para Latinoamérica. Association for Hospice and Palliative Care; 2009.

9. Nalbuphine [Internet]. (Última consulta septiembre 07 2019) Disponible en: https:/reference.medscape.com/drug/nalbuphine-343329.

10. Tapentadol dosage [Internet]. Drugs.com [fecha de actualización: 18 de octubre de 2019]. Disponible en: https://www.drugs.com/dosage/tapentadol.html

11. Kaye AD, Beakley BD, Kaye AM, Kaye AD. Tramadol, pharmacology, side effects, and serotonin syndrome: a review. Pain Physician 2015; $18: 395-400$

12. Revisión Bibliográfica: Dolor en el paciente con insuficiencia renal crónica[Internet]. México: Instituto Nacional de Ciencias Médicas y Nutrición Salvador Zubirán, Departamento de Medicina del Dolor y Paliativa [Últimaconsulta septiembre 07 2019]. Disponible en: http://www.dolorypaliativos.org/art142.asp

13. Bueno-Arias G, Jiménez MV, German Cl, Lazarini RJ, Galindo SJ. Tapentadol, un nuevo horizonte en el tratamiento de la neuropatía periférica dolorosa. Acta Méd Grupo Ángel. 2018;16:41-6.

14. Samper B, Tabasco M, Riera H, Pedrola S. Etiologia y manejo de la neuropatía diabética dolorosa. Rev Soc Española Dolor. 2010;17:286-96.

15. Cuevas González MV, Echevarría-y-Pérez E, Minerva Díaz-Aguirre C Cuevas-González JC. Tratamiento de la mucositis oral en pacientes oncológicos. Revisión de la literatura y experiencia en el Hospital General de México. Int J Odontostomat. 2015;9(2):289-4.

16. Coleman EA, Goodwin J, Coon K, Richards K, Enderlin C, Kennedy R, et al. Fatigue, sleep, pain, mood and performance status in patients with multiple myeloma. Cancer Nurs. 2011;34:219-27.

17. Fatigue Infoguide [Internet]. Myeloma UK [fecha de actualización: julio de 2019]. Disponible en: https://www.myeloma.org.uk/documents/fatigue-infoguide/

18. Benítez del Rosario MA, Salinas Martín A Valoración multidimensional en cuidados paliativos. Cuidados paliativos y atención primaria. 2000;29(4): pp. 237-40.

19. NCCN: Clinical Practice Guidelines in Oncology. Hematopoietic Growthfactors.V.019

20. Morales-Catalayud F. Introducción al Estudio de la Psicología de la Salud. Hermosillo: Editorial Unison; 1997.

21. Ptacek JT, Eberhardt TL. Breaking Bad News. JAMA. 1966:276:496.

22. Lazarus R, Folkman S. Stress, Appraisal, and Coping. New York: Springer Publishing Company; 1984.

23. Szmuilowicz E, El-Jawahri A, Chiappetta L, Kamdar M, Block S. Improving residents' end-of-life communication skills with a short retreat: a randomized controlled trial. J Palliat Med. 2010;13:439-52.

24. Cohen S, Wills TA. Stress, social support, and the buffering hypothesis. Psychol Bull. 1985;98:310-57.
25. Kiely F, Cran A, Finnerty D, O'Brien T. Self-reported quality of life and symptom burden in ambulatory patients with multiple myeloma on disease-modifying treatment. Am J Hosp Palliat Med. 2017;34:671-6.

26. Beard C, Weisberg RB, Keller MB. Health-related quality of life across the anxiety disorders: findings from a sample of primary care patients. $J$ Anxiety Disord. 2010;24:559-64.

27. Swash B, Hulbert-Williams N, Bramwell, R. Unmet psychosocial needs in haematological cancer: a systematic review. Support Care Cancer. 2014;22:1131-41

28. De Lima L, Pastrana T. Opportunities for palliative care in public health. Ann Rev Public Health. 2016;37:357-74

29. De Paolis G, Naccarato A, Cibelli F, D'Alete A, Mastroianni C, Surdo L, et al. The effectiveness of progressive muscle relaxation and interactive guided imagery as a pain-reducing intervention in advanced cancer patients: a multicentre randomised controlled non-pharmacological trial. Complement Ther Clin Pract. 2019;34:280-7.

30. Biglu MH, Nateq F, Ghojazadeh M, Asgharzadeh A. Communication skills of physicians and patients' satisfaction. Mater Soc Med. 2017;29: 192-5.

31. Brighton LJ, Bristowe K. Communication in palliative care: talking about the end of life, before the end of life. Postgrad Med J. 2016;92: 466-70.

32. Breitbart W, Rosenfeld B, Pessin H, Applebaum A, Kulikowski J, Lichtenthal WG. Meaning-centered group psychotherapy: an effective intervention for improving psychological well-being in patients with advanced cancer. J Clin Oncol. 2015;33:749-54.

33. Reblin M, Uchino BN. Social and emotional support and its implication for health. Curr Opin Psychiatry. 2008:21:201-5.

34. Arranz P, Coca C, Bayés R, Rincón C, Navarro FH. Intervención psicológica en pacientes que deben someterse a un trasplante de médula ósea. Psicooncología. 2003:1:93-105.

35. https://www.secpal.com/grupo-espiritualidad. Ultima actualización 2014

\section{Module 9}

\section{Thromboprophylaxis and hemostasia in multiple myeloma}

1. Fotiou D, Gerotziafas G, Kastritis E, Meletios, A. Dimopoulos y Terpos E. A review of the venous thrombotic issues associated with multiple myeloma. Expert Rev Hematol. 2016;7:695-706.

2. Leebeek FW. Update of thrombosis in multiple myeloma. Thomb Res. 2016;140:S76-80.

3. Dede RJ, Pruemer JM. Comparing venous tromboemolism prophy lactic strategies for ambulatory multiple muyeloma patienetes on inmmunomudulatory drug therapy. J Oncol Pharm Pract. 2016;22:248-55.

4. Plesner T, Arkenau HT, Lokhorst HM, Gimsing P, Krejcik J, Lemech C et al. Safety and efficacy of daratumumab with lenalidomide and dexamethasone in relapsed or relapsed, refractory multiple myeloma. Blood. 2014;124:21.

5. Swan D, Rocci A, Bradbury C, Thachil J. Venous thromboembolism in multiple myeloma choice of prophylaxis, role of direct oral anticoagulants and special considerations. Br J Haematol. 2018;183:538-56.

6. Lyman $\mathrm{H}$, Khorana $\mathrm{H}$, Kuderer N, Lee A, Arcelus Jl, Balaban E, et al. Venous thromboembolism prophylaxis and treatment in patients with cancer: American society of clinical oncology clinical practice guideline update. J Clin Oncol 2013;31:17. 